Universidade de São Paulo

Faculdade de Medicina de Ribeirão Preto

\title{
2015
}

\section{Dor cervical crônica e postura em trabalhadores de}

escritório usuários de computador
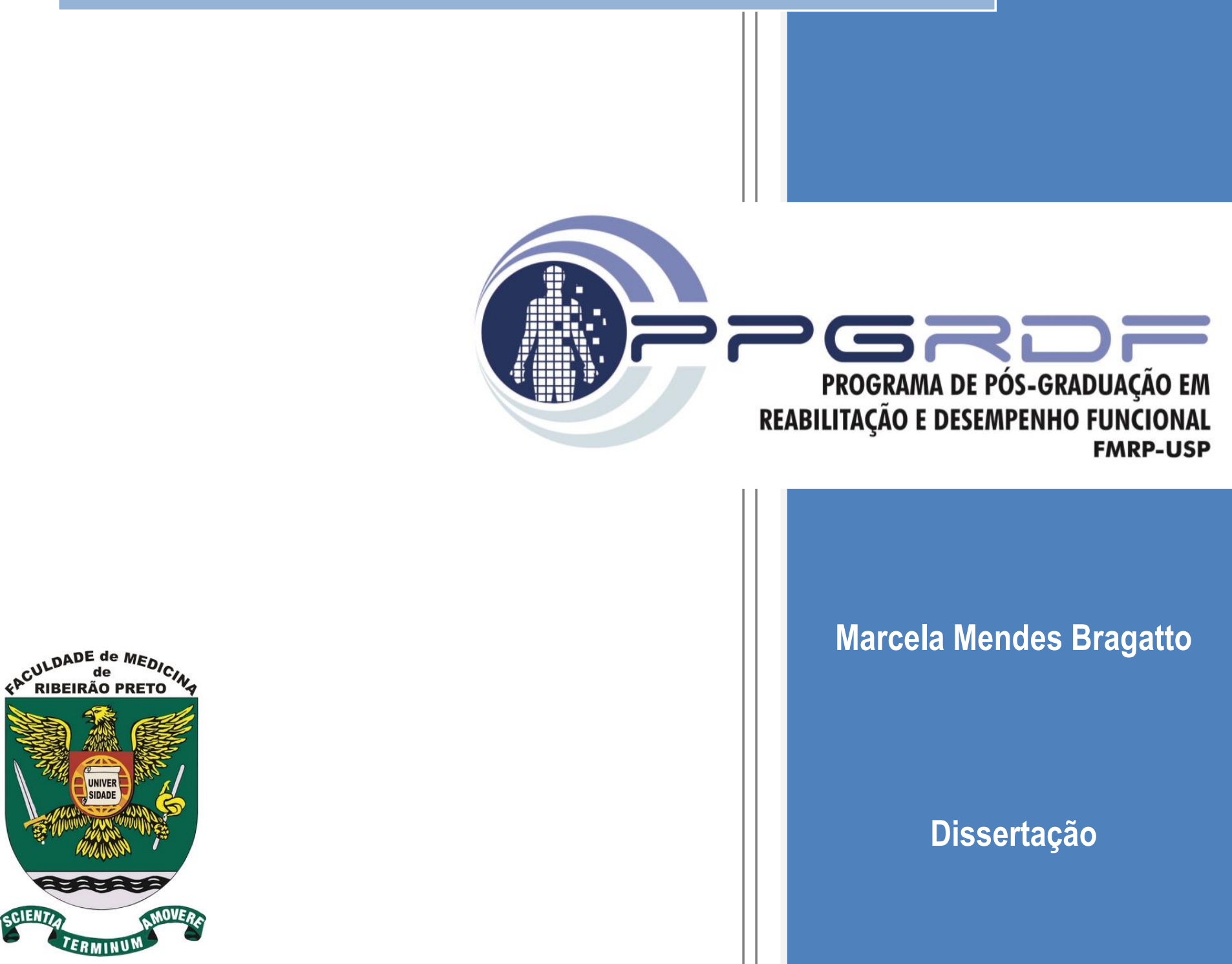

Marcela Mendes Bragatto 
UNIVERSIDADE DE SÃO PAULO

FACULDADE DE MEDICINA DE RIBEIRÃO PRETO

MARCELA MENDES BRAGATTO

\section{Dor cervical crônica e postura em trabalhadores de escritório usuários de computador}

Dissertação de mestrado apresentada ao Programa de Pós-Graduação em Reabilitação e Desempenho Funcional da Faculdade de Medicina de Ribeirão Preto da Universidade de São Paulo

Área de concentração: Fisioterapia Orientadora: Profa. Dra. Thaís Cristina Chaves

Versão corrigida

Ribeirão Preto 
Autorizo a reprodução e divulgação total ou parcial deste trabalho, por qualquer meio convencional ou eletrônico, para fins de estudo e pesquisa, desde que citada a fonte.

\section{Catalogação da Publicação}

Faculdade de Medicina de Ribeirão Preto da Universidade de São Paulo

Bragatto, Marcela Mendes

Dor cervical crônica e postura em trabalhadores de escritório usuários de computador. Ribeirão Preto, 2015.

$$
\text { p.130 : il.; } 30 \mathrm{~cm}
$$

Dissertação de Mestrado, apresentada à Faculdade de Medicina de Ribeirão Preto/USP - Programa de Pós Graduação Reabilitação e Desempenho Funcional. Área de concentração: Fisioterapia.

Orientador: Chaves, Thaís Cristina.

1.Trabalhadores usuários de computador 2.Dor cervical crônica 3.Disfunção temporomandibular 4.Postura corporal 5. Dor crônica 
UNIVERSIDADE DE SÃO PAULO

FACULDADE DE MEDICINA DE RIBEIRÃO PRETO

MARCELA MENDES BRAGATTO

Dor cervical crônica e postura em trabalhadores de escritório usuários de computador

Ribeirão Preto 


\section{FOLHA DE APROVAÇÃo}

Marcela Mendes Bragatto

Dor cervical crônica e postura em trabalhadores de escritório usuários de computador.

Dissertação apresentada ao Programa de PósGraduação em Reabilitação e Desempenho Funcional da Faculdade de Medicina de Ribeirão Preto da Universidade de São Paulo

Área de concentração: Fisioterapia

Aprovado em:

\section{Banca Examinadora}

Profa Dra Tatiana de Oliveira Sato

Instituição: Curso de Fisioterapia - Universidade Federal de São Carlos - UFSCar

Assinatura:

Prof. Dra. Simone Cecilio Hallak Regalo

Instituição: Curso de Odontologia - Faculdade de Odontologia de Ribeirão Preto - USP

Assinatura:

Profa. Dra. Thaís Cristina Chaves

Instituição: Curso de Terapia Ocupacional - Faculdade de Medicina de Ribeirão Preto - USP Assinatura: 
Dedico às mulheres fortes, sonhadoras e determinadas da minha vida, minhas avós Rosa e Aparecida, minhas queridas primas Giana e Priscila e aquela que sonha os meus sonhos, minha mãe. 


\section{Agradecimentos}

Em primeiro lugar, quero agradecer a Deus por sempre estar à frente do meu caminho, me guiando, me iluminando e colocando anjos disfarçados de pessoas na minha vida.

Agradeço à minha mãe por estar sempre ao meu lado, me apoiando e me ensinando os princípios e valores da vida. À minha querida família, em especial alguns que foram essênciais nessa minha caminhada, meu tio Gilberto Chierice, as conversas tão sabias; minhas amadas primas Giana Chierice e Priscila Silvestre, a todo amor e dedicação em todos os momentos; à minha vó Zinha (Aparecida), de quem, mesmo tendo partido no meio da minha jornada, guardo os ensinamentos de sempre enfrentar tudo com força e alegria.

Agradeço à minha "família” de Ribeirão Preto, às minhas queridas "sisters" (Karina, Mirela e Aline), cada uma com suas qualidades e defeitos admiráveis. Uma delas, em especial, foi fundamental nessa jornada: Mirela, que esteve comigo sempre com pensamentos positivos, criticas construtivas, companheirismo, parceria e carinho. Às minhas queridas vizinhas Cida, Lucila e Renata, o carinho e amizade. Também quero agradecer a todos aqueles que, mesmo sem saberem ou sem intenção, abrilhantaram os meus dias.

Agradeço a todos os meus amigos a compreensão da minha ausência nessa etapa de tamanha dedicação, estando sempre de braços abertos para o meu retorno, com a mesma alegria, carinho e cumplicidade.

Agradeço também ao Centro Universitário Claretiano de Batatais e a todo seu corpo docente o alicerce que me foi proporcionado, tão necessário para alcançar esta etapa.

Agradeço imensamente à minha orientadora professora, Dra. Thaís Cristina Chaves, a oportunidade, aprendizado, apoio, crecimento profissional e pessoal e pela orientação.

Agradeço a toda equipe do Laboratório Lapidim (Ana Barbara, Aroldo, Jaqueline, Mariana, Marina) o apoio e carinho. Em especial, agradeço às minhas queridas alunas de Iniciação Cientifica (Suzana, Izabela, Jennifer e Luisa) o acompanhamento e a permissão para 
acompanhá-las e aprender com seus acertos e erros. Agradeço as mais que parceiras de laboratório, minhas parceiras de vida, Carina Ferreira Pinheiro, Raquel Descie e Mirela Sant'Ana Rodrigues, todo apoio, compreensão, dedicação, paciência, alegria e amizade.

Agradeço a todos os professores e alunos do programa de Pós-graduação em Reabilitação e Desempenho Funcional a disponibilidade, atenção e apredizado. Agradeço também a todos os funcionários da USP - Ribeirão Preto, em especial à secretária do curso de Terapia Ocupacional carinhosamente chamada de "Soninha", por toda atenção e ajuda prestada.

Agradeço ao financiamento dado pela FAPESP pela bolsa de treinamento técnico (processo: 2012/18686-3), bolsa de mestrado (processo: 2012/24315-8) e auxílio à pesquisa (processo: 2011/21537-7) que possibilitaram a realização e divulgação desta pesquisa. Também agradeço a FAEPA aos auxílios que me possibilitaram a divulgação desta pesquisa.

Finalizo meus agradecimentos com a seguinte mensagem: "Sonho que se sonha só, é só um sonho que se sonha só, mas sonho que se sonha junto é realidade”. 
“Ensinar é um exercício de imortalidade. De alguma forma continuamos a viver naqueles cujos olhos aprenderam a ver o mundo pela magia da nossa palavra. O professor, assim, não morre jamais”.

Rubem Alves 


\section{Resumo}

Introdução: A prevalência de disfunção musculoesquelética entre trabalhadores usuários de computador (TUC) pode variar entre 10 a $62 \%$ e os lugares mais acometidos são os membros superiores, pescoço, cabeça e a coluna vertebral. As queixas musculoesqueléticas nesses trabalhadores apresentam etiologia multifatorial e dentre as principais causas é possível citar aspectos posturais e fatores psicossociais. O Maastricht Upper Extremity Questionnaire (MUEQ-Br) é uma das poucas ferramentas existentes na literatura para avaliar aspectos ergonômicos e psicossociais relacionados ao trabalho com uso do computador. A dor cervical é a queixa musculoesquelética mais comum em trabalhadores de escritório usuários de computador. A coexistência entre dor cervical e disfunção temporomandibular (DTM) é comumente citada na literatura. A adoção da postura em anteriorização da cabeça para uso do computador pode estar associada ao aparecimento de sintomas orofaciais e cervicais. A posição sentada é a mais adotada nos ambientes de trabalho especialmente quando este envolve o uso de computador, entretanto, a manutenção dessa posição por tempo prolongado pode acarretar a adoção de posturas inadequadas e intensificar a sobrecarga nas estruturas do sistema musculoesquelético. Desta forma, a manutenção da postura sentada pode estar relacionada ao desenvolvimento de alterações de postura corporal, DTM e disfunção cervical. Objetivo: O objetivo deste estudo foi verificar associações entre dor cervical, DTM e alterações na postura estática em trabalhadores de escritório usuários de computador com e sem relato de dor cervical crônica. Material e Métodos: A amostra desse estudo foi selecionada a partir da aplicação do Maastricht Upper Extremity Questionnaire que contempla 7 domínios (posto de trabalho, postura corporal, controle do trabalho, demanda de trabalho, pausas, ambiente de trabalho e suporte social), preenchidos por trabalhadores usuários de computador. Participaram deste estudo 52 mulheres trabalhadoras de escritório usuárias de computador em dois grupos: Grupo com dor cervical crônica e incapacidade (GD, n=26 36.50 anos - IC95\%: 33.40-36.60; $66.37 \mathrm{~kg}$ - IC 95\%: 62.48-70.26 e $1.62 \mathrm{~m}$ - IC95\%: $1.60-$ 1.65) e Grupo sem relato de dor cervical (GS, $n=26$ - 33.81 anos - IC 95\%: 33.66-36.95, 71.75 kg - IC95\%: 65.90-77.60 e 1.64 m - IC95\%: 1.62-1.67). Como critérios de inclusão as funcionárias deveriam exercer a mesma função há pelo menos 12 meses (GD, 110 meses IC95\%: 73-147 /GS, 91 meses - IC95\%:63-119) e utilizar o computador ao menos 4 horas por dia durante a jornada de trabalho (GD, 7.46 horas/dia - IC95\%: 7.10-7.83 /GS, 7.58 horas/dia - IC95\%: 7.23-7.92). No grupo com dor cervical crônica as trabalhadoras deveriam apresentar relato positivo de dor crônica cervical e se enquadrarem nos seguintes critérios: a) dor cervical há pelo menos 3 meses; b) dor de intensidade 3 na maioria dos dias em uma escala numérica de dor (END) ( 0 a 10, sendo $0=$ sem dor e $10=$ pior dor possível $)$ e c) limitação funcional, pelo menos leve, no Índice de incapacidade relacionada ao pescoço (NDI): $10-28 \%$ (5-14 pontos) - incapacidade leve; 30-48\% (15- 24 pontos) - incapacidade moderada; $50-68 \%$ ( 25 - 35 pontos) - incapacidade severa; $72 \%$ ou mais (36 pontos ou mais) - incapacidade completa. Foram realizadas avaliações clínicas para diagnóstico da DTM por meio do Research Diagnostic Criteria for Temporomandibular Disorders (RDC/TMD), avaliação da dor cervical e mastigatória através da palpação manual e algometria por pressão para obtenção do limiar de dor por pressão (LDP) de estruturas crânio-cervicais, bem como avaliação da postura corporal estática dessas trabalhadoras usando a fotogrametria. Os dados demonstraram distribuição normal de acordo com o teste Shapiro Wilks. O teste-t de student para amostras independentes $(\mathrm{p}<0.05)$ foi utilizado para comparar a pontuação máxima de cada domínio do MUEQ-Br entre os grupos sem e com dor cervical crônica. Para verificar diferenças entre os valores médios de LDP e palpação muscular entre os grupos de trabalhadores sem dor e com dor cervical crônica e para verificar diferenças entre os ângulos posturais foi utilizado também o teste-t de Student. Para análise das associações entre as 
variáveis disfunção temporomandibular, incapacidade relacionada à disfunção cervical, cervicalgia e "aspectos do trabalho" (domínios do MUEQ) foi utilizada a análise de regressão linear múltipla. Para verificação de diferenças entre valores de porcentagem foi utilizado o teste de Qui-quadrado $(\mathrm{p}<0.05)$. O pacote estatístico utilizado foi o SPSS versão 22. Resultados: Os resultados deste estudo demonstraram que ao compararmos os domínios do MUEQ-Br, o grupo com dor cervical crônica obteve maior pontuação no domínio postura corporal (GD, 12.58 - IC95\%: 11.21-13.94/ GS, 9.42 - IC95\%: 8-10.84) e no item queixas (GD, 17.46- IC95\%: 14.17-20.75/ GS, 8.58 - IC95\%: 6.14-11.02), bem como na pontuação total do questionário (GD, 40.08 - IC95\%: 35.01-45.15/ GS, 33.31 - IC95\%: 28.99-37.63). Os voluntários com dor cervical apresentaram maior porcentagem de diagnósticos de DTM quando comparados com o grupo sem dor $(42.30 \%$ vs. $23.07 \%, \mathrm{p}<0.05)$. O grupo com dor apresentou maior intensidade de dor na palpação manual dos músculos cervicais, trapézio (ponto médio) lado direito (GD, 4.03 - IC95\%: 3.02-5.06/ GS, 1.46 - IC95\%: 0.69-2.23) e suboccipitais direito (GD, 2.58 - IC95\%: 1.64-3.51/ GS, 1.0 - IC95\%: 0.42-1.58) e esquerdo (GD, 2.15 - IC95\%: 1.21-3.09/ GS, 1.0 - IC95\%: 0.46-1.54), porém os valores do LDP não foram significativos para nenhum dos músculos avaliados entre os grupos com e sem dor cervical crônica. Também não foram encontradas diferenças significativas na avaliação postural entre os grupos para os ângulos analisados no plano frontal face e vista anterior e para os ângulos analisados no plano sagital. Na análise de associação entre as variáveis, foi observado que quando a incapacidade foi considerada variável dependente em relação à cervicalgia, total da pontuação do MUEQ-Br (aspectos de trabalho) e DTM, foi observado um $\mathrm{R}^{2}=0.93$ e todos os preditores mostraram-se significativos no modelo. Nossos resultados demonstram que a incapacidade cervical é influenciada pela DTM, dor no pescoço e aspectos físicos e psicossociais relacionados ao trabalho com uso do computador. Os trabalhadores com dor cervical apresentaram maior porcentagem de diagnósticos de DTM quando comparados com o grupo de trabalhadores sem dor, bem como a intensidade da dor à palpação dos músculos cervicais mostrou-se significativamente maior nos trabalhadores usuários de computador com dor cervical. Assim, é possível sugerir uma associação entre relato de dor cervical, incapacidade cervical e DTM no contexto de trabalho envolvendo o computador em mulheres com dor relato de dor cervical crônica.

Palavras-Chave: Trabalhadores usuários de computador, dor cervical crônica, disfunção temporomandibular, postura corporal, dor crônica 


\section{Abstract}

Introduction: The prevalence of musculoskeletal disorders among computer office workers (COW) can vary between 10-62\% and the most affected regions affected are the upper extremities, neck, head and spine. Musculoskeletal complaints in these workers have a multifactorial etiology and the main causes are postural aspects and psychosocial factors. The Maastricht Upper Extremity Questionnaire (MUEQ-Br) is one of the few tools available in the literature to evaluate ergonomic and psychosocial aspects of work related to computer use. Neck pain is the most common musculoskeletal complaints in COW. Coexistence between neck pain and Temporomandibular Disorders (TMD) are commonly cited in the literature. The adoption of forward head posture for computer use may be linked to the onset of orofacial symptoms. The sitting position is the most widely adopted in the workplace especially when it involves the use of computer, however, to maintain this position for long periods, the adoption of awkward postures could be necessary, increasing the strain on the musculoskeletal system structures. Thus, maintenance of sitting posture may be related to the development of changes in body posture, TMD and neck disorders. Aim: The aim of this study was to examine associations between neck pain, TMD and changes in static body posture on COW with and without chronic neck pain. Material and Methods: The sample of this study was selected from the application of the Maastricht Upper Extremity Questionnaire which includes seven domains (work station, body posture, job control, job demands, break time, work environment and social support). The study included 52 women which work using computer into two groups: Group with chronic neck pain and disability (NPG, $\mathrm{n}=26-36.50$ years - confidence interval 95\% (CI): 33.40-36.60; 66.37 kg -CI: 62.48-70.26 and 1.62m 95\% CI: 1.60-1.65) and group without neck pain (WONPG, $\mathrm{n}=26$ - 33.81 years - CI: 33.66$36.95,71.75 \mathrm{~kg}-\mathrm{CI}: 65.90-77.60 \mathrm{~m}$ and 1.64 - CI: 1.62-1.67). As criteria inclusion, the employees should exercise the same function for at least 12 months (NPG, 110 months - CI: 73-147 / WONPG, 91 months - CI: 63-119) and use the computer for at least 4 hours day during the work day (NPG, 7:46 hours / day - CI: 7.10-7.83 / WONPG, 7:58 hours/day - CI: 7.23-7.92). In the group with chronic neck pain workers should present a positive report of chronic neck pain and falling within the criteria: a) neck pain for at least 3 months; b) pain intensity 3 on most days on a numerical pain scale (NPS) $(0-10$, where $0=$ no pain and $10=$ worst possible pain) and c) Neck pain related disability at least mild in the Neck Disability Index (NDI): 10-28\% (5-14 points) - mild disability; 30-48\% (15- 24 points) - moderate disability; 50-68\% (25 - 35 points) - severe disability, $72 \%$ or more (36 or more points) Complete. Clinical assessments for diagnosis of TMD was conducted using the Research Diagnostic Criteria for Temporomandibular Disorders (RDC/TMD), evaluation of masticatory and neck pain through manual palpation and algometry pressure to obtain the pressure pain threshold (PPT) of craniocervical structures as well as evaluation of the static body posture by the use of photogrammetry. The data showed normal distribution according to the Shapiro Wilks test. The Student's t-test for independent samples $(\mathrm{p}<0.05)$ was used to compare the maximum score for each domain MUEQ-Br between the groups with and without chronic neck pain. Differences between the mean values of LDP and muscle tenderness between groups of workers without pain and chronic neck pain and to check for differences between the postural angles were verified by student t-test. For analysis of associations between TMD, disability related to neck pain, neck pain and "aspects of the job" (domains of MUEQ) a multivariate regression analysis was used. Differences between the percentage values were verified using chi-square test $(\mathrm{p}<0.05)$. The statistical package used was SPSS version 22. Results: The results showed that when comparing the domains of MUEQ-Br, the group with chronic neck pain scored highest in the area posture (NPG, 12.58 points - CI: 11.21-13.94 / WONPG, 9.42 - CI: 8-10.84) and complaints item (NPG, 17.46 - 
CI: 14.17-20.75 / WONPG, 8.58 - CI: 6.14 -11.02), and the total score of the questionnaire (NPG, 40.08 - CI: 35.01-45.15 / WONPG, 33.31 points - CI: 28.99-37.63). The volunteers with neck pain showed a higher percentage of diagnoses of TMD when compared with the group without pain $(42.30 \%$ vs. $23: 07 \%$, p <0.05). The group with pain had higher pain intensity on manual palpation of the neck muscles, trapezius (midpoint) right (NPG, 4.03 - CI: 3.02-5.06 / WONPG, 1.46 - CI: 0.69-2.23) and right suboccipital (WONPG, 2.58 NPS - CI: 1.64-3.51 / WONP, 1.0 - CI: 0.42-1.58) and left (NPG, 2.15 - CI: 1.21-3.09 / WONP, 1.0 - CI: $0.46-1.54$ ) but the values of the LDP were not significant for any of the muscles tested between the groups with and without chronic neck pain. Also no significant differences were found in postural assessment between groups for the analyzed angles in the frontal plane face and anterior views and angles analyzed in the sagittal plane. The analysis of association between the variables, it was observed that when disability was considered the dependent variable in relation to the neck pain, total score MUEQ-Br (aspects of work) and TMD, we observed a strong association $\left(\mathrm{R}^{2}=0.93\right)$ and all predictors showed significant in the model. Our results demonstrate that cervical disability is influenced by the TMD, neck pain and physical and psychosocial aspects of the computer work. Workers with neck pain showed a higher percentage of diagnoses of TMD when compared with the group of workers without neck pain, and the pain intensity on palpation of the neck muscles was significantly higher in computer workers with neck pain. Thus, it is possible to suggest an association between reporting of neck pain, neck related disability and TMD in the context of work involving the computer in women reporting chronic neck pain.

Key-words: Computer office worker, chronic neck pain, temporomandibular disorders, body posture, chronic pain 


\section{LISTA DE TABELAS}

Tabela 1 - Caracterização da amostra.

Tabela 2 - Caracterização da dor cervical. 45

Tabela 3 - Identificação dos pontos anatômicos para demarcação. .59

Tabela 4 - Descrição dos ângulos, métodos de obtenção e valores de referências dos ângulos considerados. 68

Tabela 5 - Pontuação do MUEQ-Br na amostra total e comparação quanto aos grupos sem e com dor cervical crônica

Tabela 6 - Classificação diagnóstica dos trabalhadores usuários de computador do grupo sem dor e com dor cervical crônica.

Tabela 7 - Valores Médios e intervalo de confiança 95\% (IC 95\%) de intensidade dolorosa à palpação muscular de estruturas orofaciais mensurados através de faces nos grupos sem e com dor cervical crônica. .74

Tabela 8 - Valores médios e intervalo de confiança 95\% da duas medidas dos valores de $\mathrm{LDP}\left(\mathrm{KG} / \mathrm{cm}^{2}\right)$ da musculatura orofacial e região tênar dos grupos sem dor e com dor cervical crônica. . .75

Tabela 9 - Valores médios e intervalo de confiança 95\% da amplitude de movimento mandibular (mm) de ambos os grupos sem dor e com dor cervical crônica. .76

Tabela 10 - Valores médios e intervalo de confiança 95\% da intensidade de dor obtida através da palpação manual e limiar de dor por pressão na avaliação de músculos cervicais nos grupos sem dor e com dor cervical crônica. 
Tabela 11 - Valores médios e desvio-padrão dos ângulos (em graus) de avaliação postural obtidos nas fotografias dos planos frontal e sagital dos grupos sem dor e com dor cervical

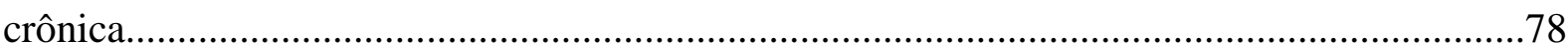

Tabela 12 - Descrição dos dados obtidos na Análise de regressão linear múltipla entre incapacidade cervical, a disfunção temporomandibular (DTM), o relato de cervicalgia e os aspectos relacionados ao trabalho (pontuação dos domínios e item do MUEQ-Br) $(\mathrm{n}=52)$.. 


\section{LISTA DE FIGURAS}

Figura 1 - Avaliação da amplitude de abertura da boca através do uso do paquímetro .50

Figura 2 - Avaliação da amplitude de desvio mandibular lateral esquerdo através do uso do paquímetro .50

Figura 3 - Avaliação da amplitude de protrusão através do uso do paquímetro. .50

Figura 4 - Escala Numérica de Dor (END). 51

Figura 5 - Dinamômetro digital (Kratos®, São Paulo, Brasil, modelo DDK-20) com disparador acoplado. .53

Figura 6 - Palpação manual do fascículo anterior do músculo temporal .55

Figura 7 - Palpação manual do fascículo anterior do músculo temporal em uma vista anterior demonstrando a estabilização contra-lateral da cabeça do voluntário. 55

Figura 8 - Palpação manual do fascículo médio do músculo temporal. .56

Figura 9 - Palpação manual do fascículo posterior do músculo temporal 56

Figura 10 - Palpação manual da origem do músculo masseter. .56

Figura 11 - Palpação manual do ventre do músculo masseter. .56

Figura 12 - Palpação manual da inserção do músculo masseter .56

Figura 13 - Palpação manual da região posterior da mandíbula (m. pterigoideo medial).......56

Figura 14 - Palpação manual do pólo lateral da ATM. 
Figura 15 - Palpação manual do pólo posterior da ATM

Figura 16 - Palpação manual intra-oral do tendão do temporal

Figura 17 - Palpação manual da inserção do músculo esternocleidomastoideo

Figura 18 - Palpação manual dos músculos suboccipitais

Figura 19 - Palpação manual do ponto médio do músculo trapézio .57

Figura 20 - Identificação dos pontos anatômicos: tragus da orelha; articulação acrômioclavicular; articulação esternoclavicular; espinha ilíaca ântero-superior.....

Figura 21 - Identificação dos pontos anatômicos: processos espinhosos de C4 e C7 .60

Figura 22 - Identificação dos pontos anatômicos: ângulo inferior da escápula; espinhas ilíacas póstero-superior e póstero-inferior; processos espinhosos de $\quad$ T7 $\mathrm{e}$ L3. .60

Figura 23 - Identificação dos pontos anatômicos: Olécrano da ulna; processos espinhosos de T12 e L5. .60

Figura 24 - Ângulo da comissura labial - CL.............................................................62

Figura 25 - Ângulo da articulação esternoclavicular - EC.

Figura 26 - Ângulo da articulação acromioclavicular - OE.

Figura 27 - Ângulo do tragus da orelha - TO

Figura 28 - Ângulo das espinhas ilíacas ântero-superiores AS. 63 
Figura 29 - Ângulo inferior da escápula - IE. .64

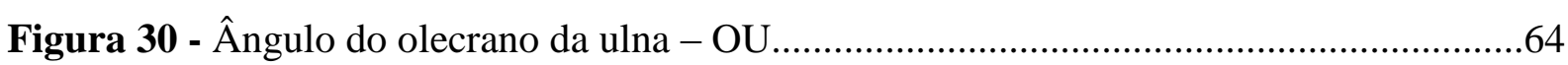

Figura 31 - Ângulo das espinhas ilíacas póstero-superiores - PS...

Figura 32 - Ângulo das espinhas ilíacas póstero-inferiores - IE. .65

Figura 33 - Ângulo de protrusão da cabeça - PC .66

Figura 34 - Ângulo da báscula pélvica - BP. .66

Figura 35 - Ângulo da lordose cervical - LC .66

Figura 36 - Ângulo da lordose lombar - LL .66

Figura 37 - Ângulo da cifose torácica - CT ..67 


\section{LISTA DE SIGLAS}

AC

ATM

BP

CL

CT

DCC

DTM

EC

EIAS

EIPI

EIPS

END

FHP

IE

IIRP

LAPIDIM

LC

LDP

$\mathbf{L} \mathbf{L}$

MUEQ-Br

NDI

OE
Ângulo da articulação acrômioclavicular

Articulação temporomandibular

Ângulo da báscula pelvica

Ângulo da comissura labial

Ângulo da cifose torácica

Disfunção da coluna cervical

Disfunção temporomandibular

Âgulo da comissura labial

Espinaha ilíaca ântero- superior

Espinha ilíaca póstero-inferior

Espinha ilíaca póstero-superior

Escala numérica de dor

Forward Head Posture

Ângulo inferior da escápula

Neck Disability Index

Laboratório de Pesquisa Interdisciplinar na Disfunção

Musculoesquelética

Ângula da lordose cervical

Limiar de dor por pressão

Ângulo da lordose lombar

Maastrich Upper Extremity Questionnaire

Índice de Incapacidade Relacionada ao pescoço

Ângulo orbicular externo 
OU

PC

PM

RDC/DTM

TUC
Ângulo olecrano da ulna

Ângulo de protrusão da cabeça

Palpação manual

Research Diagnostic Criteria for Temporomandibular Disorders

Trabalhadores usuários de computador 


\section{SUMÁRIO}

1. INTRODUÇÃO .......................................................................................................................... 23

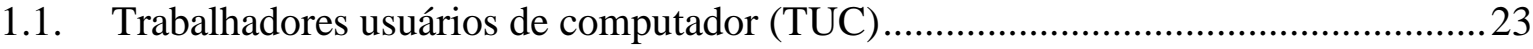

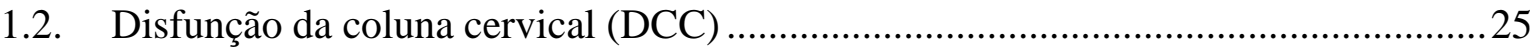

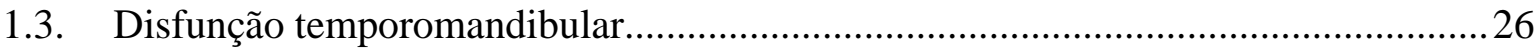

1.4. Disfunção temporomandibular (DTM) e disfunção da coluna cervical (DCC).........29

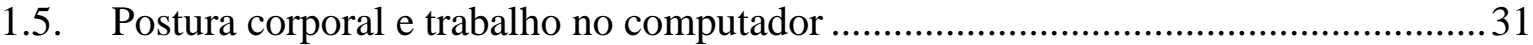

1.6. Trabalhadores usuários de computador (TUC) e disfunção musculoesquelética .......34

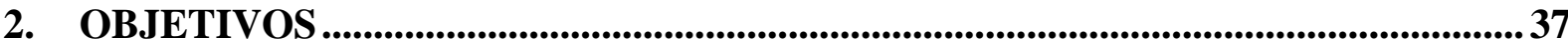

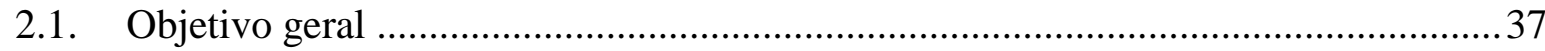

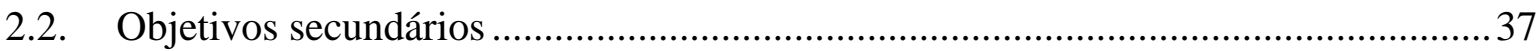

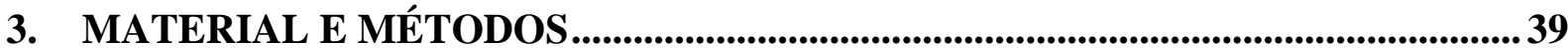

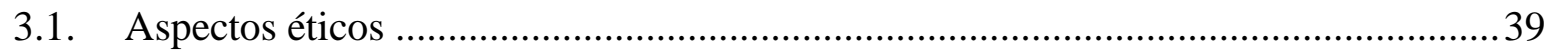

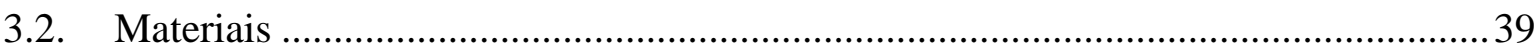

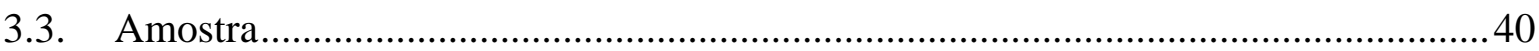

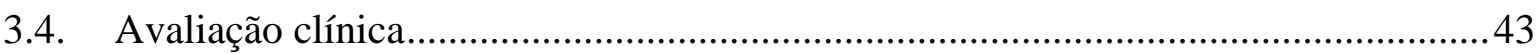

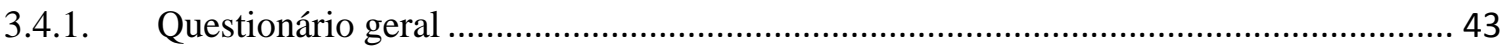

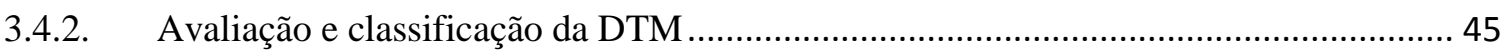

3.4.3. Procedimentos de palpação manual e algometria para obtenção dos valores de limiar de

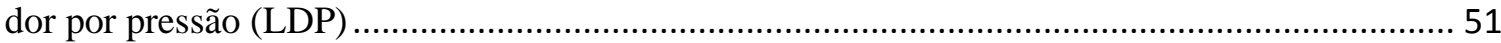

3.5. Avaliação da postura corporal estática de tronco, cabeça e extremidade superior ....58

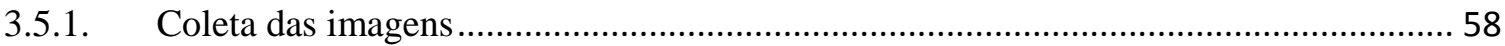

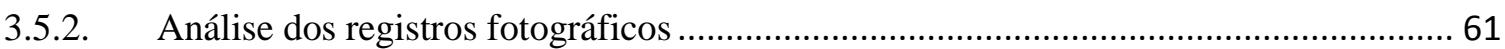


3.6. Índice de Incapacidade Relacionada à Dor no Pescoço - IIRP (Neck Disability Index - ANEXO 3)

3.7. Análise estatística 69

4. RESULTADOS 72

4.1. Avaliação dos aspectos ergonômicos e psicossociais relacionados ao trabalho -

MUEQ-Br 72

4.2. Classificação quanto aos sinais, sintomas e diagnóstico de DTM. 73

4.3. Resultados da avaliação dos sintomas de disfunção cervical 76

4.4. Avaliação da postura corporal 77

5. DISCUSSÃO 82

5.1. Avaliação de aspectos físicos e psicossocias relacionados ao trabalho 82

5.2. Disfunção temporomandibular e dor cervical em trabalhadores usuários de computador

5.3. Limiar de dor por pressão (LDP) e palpação manual para avaliação de estruturas crânio-cervicais em trabalhadores de escritório usuários de computador

5.4. Avaliação da Postura Corporal

5.5. Associações entre aspectos do trabalho, disfunção temporomandibular e dor no pescoço nos trabalhadores usuários de computador

5.6 Limitações do estudo

6. CONCLUSÃO 93

7. REFERÊNCIAS 95

ANEXO 1 - Documento de aprovação do projeto pelo Comitê de Ética em Pesquisa. .114 
ANEXO 2 - Questionário Maastrich Upper Extremity Questionnaire - Br (MUEQ-Br)115

ANEXO 3 - Índice de Incapacidade Relacionada à Dor no Pescoço - IIRP (Neck Disability Index).

APÊNDICE 1 - Termo de Consentimento Livre e Esclarecido

APÊNDICE 2 - Ficha Avaliação 123 


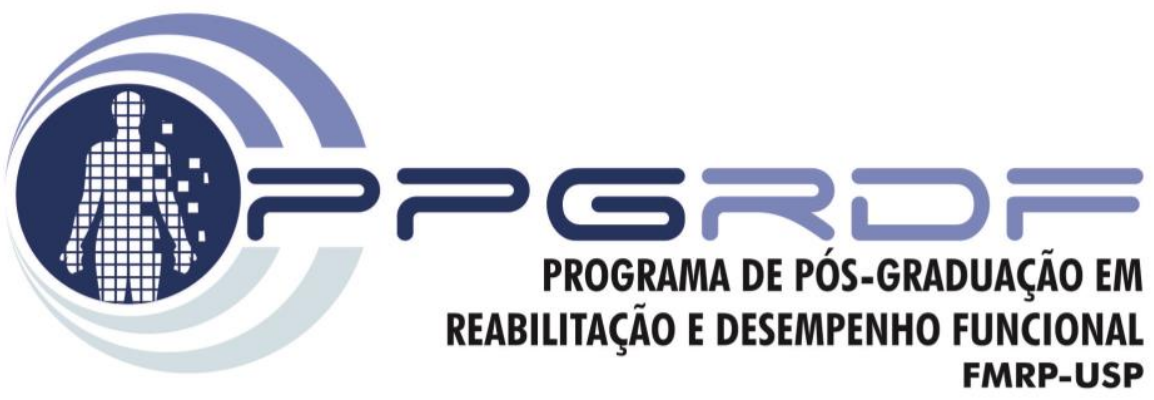

INTRODUÇÃO

"Não há ensino sem pesquisa e pesquisa sem ensino"

Paulo Freire 


\section{INTRODUÇÃO}

\subsection{Trabalhadores usuários de computador (TUC)}

Durante as duas últimas décadas houve um grande aumento no número de trabalhadores usuários de computador (TUC), tanto em países desenvolvidos como também em desenvolvimento (WAHLSTRÖM, 2005; RANASINGHE et al., 2011b; OHA et al., 2014). Em 1997, estimava-se que 50\% da população adulta empregada dos Estados Unidos trabalhavam utilizando um computador (AMICK et al., 2003). Em 2000, 60\% desses trabalhadores eram obrigados a usar o computador como parte de suas funções de trabalho, sendo que $80 \%$ desses relatavam utilizar o computador em uma base diária (SONNE et al., 2012).

O trabalho no computador é amplamente percebido como um fator de risco para doenças musculoesqueléticas, que coletivamente se tornaram as doenças profissionais mais frequentemente diagnosticadas em países europeus (OHA et al., 2014).O Brasil mostrou um aumento na demanda por serviços de saúde entre os trabalhadores, sendo gasto muito dinheiro com o absenteísmo e aposentadorias antecipadas (precoces), em 2005 o custo total desses benefícios atingiu 170 milhões de dólares (CUNHA et al.,2009) .

Trabalhadores de escritório frequentemente relatam desconforto e dor relacionada ao trabalho, porém, até o momento, uma relação clara entre o uso do computador e distúrbios musculoesqueléticos não foi encontrada (MADELINE et al., 2013). A prevalência de desconforto musculoesquelético relatado por TUC varia entre 15 a 70\%, dependendo do tipo de trabalho realizado (CHO et al., 2012). A incapacidade no trabalho é uma condição complexa que resulta de interações entre trabalhadores, profissionais de saúde, local de trabalho e o sistema de compensação, e apesar de a incapacidade para o trabalho ser desencadeada por um problema de saúde (por exemplo, dor cervical), o seu prognóstico é influenciado por determinantes contextuais, 
tais como o ambiente psicossocial do trabalho, estruturas jurídicas e normativas, convicções dos trabalhadores e expectativas (VARATHARAJAN et al., 2014).

As principais desordens musculoesqueléticas nos TUC acometem os membros superiores (GERR et al., 2002), pescoço, cabeça (KORHONEN et al., 2003) e a coluna vertebral (JENSEN et al., 2002). A prevalência de dor musculoesquelética no pescoço em trabalhadores usuários de computador pode variar entre de 55-69\%; coluna lombar, entre 31-54\%; e extremidades superiores, entre 5-15\% (OHA et al., 2014). Portanto, dentre as queixas comumente citadas por estes trabalhadores, a dor cervical é a mais prevalente (ELTAYEB et al., 2007), com característica quase sempre crônica intermitente e de baixa intensidade (JOHNSTON et al., 2008).

Estudos demonstram que funcionários de escritório usuários de computador apresentam alto risco para o desenvolvimento de dor cervical, com prevalência anual maior que a observada na população geral (ARIËNS et al., 2001). O aumento do uso do mouse e computador foi associado a um aumento da prevalência de doenças no pescoço e extremidades superiores (SILLANPÄ̈̈ et al., 2003). Janwantanakul et al. (2008) relatam que durante o trabalho no escritório ocorre a manutenção de posturas estáticas continuamente, o que pode ser um fator de risco para a dor cervical. Muitas vezes a postura inadequada adotada no trabalho é decorrente de postos ergonomicamente inadequados. A intervenção ergonômica é utilizada para readequar os postos de trabalho, sendo o método mais eficaz de intervenção quando o objetivo é eliminar fatores de risco provindos da estrutura física do ambiente de trabalho (SONNE et al., 2012).

Existe uma gama de ferramentas disponíveis na literatura para avaliação das condições de trabalho. Algumas dessas ferramentas estão mais relacionadas aos aspectos físicos, como o Questionário Nórdico de Sintomas Osteomusculares - QNSO (KUORINKA et al., 1987; BARROS; ALEXANDRE, 2003) que avalia os sintomas osteomusculares relacionados ao trabalho, ou com os aspectos ergonômicos como o "Rapid entire body assessment" - REBA (HIGNETT; MCATAMNEY, 2000; TAKALA et al., 2010), o "Rapid Upper Limb Assessment" - 
RULA (MCATAMNEY; CORLETT, 1993; TAKALA et al., 2010), o “Ovako Working posture Assessment System" - OWAS (De BRUIJN et al., 1998; TAKALA et al., 2010) e o "Rapid Office Strain Assessment" - ROSA (SONNE et al., 2012). Porém, existe uma outra ferramenta que avalia aspectos ergonômicos e psicossociais, com caráter específico para trabalhadores usuários de computador que é o questionário Maastricht Upper Extremity Questionnaire (MUEQ-Br) (TURCI et al., 2015), o qual, foi desenvolvido para analisar de maneira mais detalhada as queixas de dor cervical, ombro e braço (CANS) (ELTAYEB et al., 2007).

\subsection{Disfunção da coluna cervical (DCC)}

A dor cervical afeta $67 \%$ da população em alguma fase da vida (FALLA, 2004), sendo que cerca de um terço dos adultos em idade ativa são regularmente afetados (BRANDT et al., 2014). Korpinen et al (2013) relatam que a incidência pode variar de 0.055 por 1000 pessoas-ano (hérnia de disco com radiculopatia) para 213 por 1000 pessoas (dor no pescoço auto-referida) (KORPINEN, et al., 2013). Nos Estados Unidos as queixas de dor cervical representam um custo de 45 a 54 bilhões por ano (BONGERS et al., 2006).

A dor cervical pode ser provocada por quaisquer estruturas inervadas relacionadas com o pescoço e coluna cervical tais como discos intervertebrais, músculos, ligamentos, articulações zigoapofisárias, raízes nervosas e dura-máter (BOGDUK, 1998). Ela pode ocorrer por vários motivos, que variam de tumores, traumas (por exemplo, fratura, síndrome de whiplash), infecções, doenças inflamatórias (por exemplo, artrite reumatóide), doenças congênitas e dor cervical não específica (BOGDUK, 1998). A dor cervical não específica ocorre na maioria dos casos, quando nenhuma doença sistêmica pode ser detectada como causa subjacente às queixas, como por exemplo, pacientes com transtornos principalmente mecânicos, incluindo alterações degenerativas (BOGDUK, 1998). 
A dor cervical é um importante problema na saúde dos trabalhadores de escritório (COTÉ et al., 2009). Paksaichol et al. (2012) relataram que entre 49-69\% desses trabalhadores experimentaram dor no pescoço nos últimos 12 meses e cerca de 34-49\% relatam um novo início de dor durante um 1 ano de acompanhamento, visto que a dor no pescoço possui uma ocorrência episódica ao longo da vida, com recuperação variável entre os episódios. A dor no pescoço pode levar ao sofrimento pessoal, devido à dor, incapacidade e prejuízo na qualidade do trabalho e da vida em geral, podendo ser um grande peso socioeconômico para pacientes e sociedade (PAKSAICHOL, 2014).

Uma recente revisão sistemática de estudos de coorte prospectivos identificou vários fatores de risco para a dor no pescoço em trabalhadores usuários de computador, incluindo gênero feminino, história de queixas cervicais, início da dor após acidente, má postura cervical, tempo de trabalho, inferior a um ano, na mesma função (apenas para homens), conhecimentos de informática pobres (apenas para homens), distância do teclado ao bordo da mesa inferior $15 \mathrm{~cm}$, intensa dificuldade na tarefa, pouca autonomia no trabalho (apenas para indivíduos do gênero feminino), e percepção de alta tensão muscular (PAKSAICHOL et al., 2012).

A incapacidade relacionada à disfunção cervical pode ser avaliada por meio de questionários que permitem quantificar o nível de funcionalidade dos indivíduos acometidos. Uma das ferramentas mais utilizadas na literatura é o Neck Disability Index ou Índice de incapacidade relacionada ao pescoço (VERNON; MIOR, 1991).

\subsection{Disfunção temporomandibular}

A articulação temporomandibular (ATM) conecta a mandíbula ao crânio e regula o movimento da mandibula. É uma articulação bi-condilar em que os côndilos, localizados nas duas extremidades da mandíbula, funcionam ao mesmo tempo (INGAWALE et al., 2009). Suas 
superfícies articulares são cobertas por fibrocartilagem avascular e não inervada, com uma elevada capacidade de regeneração. Os músculos temporais e masseteres controlam os movimentos da articulação (KITSOULIS et al., 2011). A ATM é uma das mais complexas e utilizadas articulação do corpo humano, sendo que suas principais funções estão relacionadas a mastigação e a fala (INGAWALE et al., 2009).

A disfunção temporomandibular (DTM) é um conjunto de desordens caracterizadas por sinais (ruídos articulares e limitações na amplitude de movimento ou desvios durante a função mandibuar) e sintomas (dor pré-articular, dor na ATM ou nos músculos mastigatórios) envolvendo a ATM e os músculos mastigatórios, bem como estruturas relacionadas (DWORKIN e LERESCHE, 1992). Há indícios de que sua etiologia seja multifatorial e que fatores psicológicos, biomecânicos e neurofisiológicos atuem correlacionados (SUVINEN et al., 2005).

A disfunfunção temporomandibular é a mais prevalente de todos os tipos de dor orofacial (DWORKIN, 2011). Estudos epidemiológicos estimam que 40-75\% da população apresetam ao menos um sinal de disfunção temporomandibular, sendo que 33-39,2\% apresentam ao menos um sintoma álgico na face ou na ATM (DE LEEUW, 2010; GONÇALVES et al.,2009). A maior incidência da DTM ocorre entre os 20 e 45 anos de idade, sendo as mulheres mais acometidas que os homens em uma proporção de 5:1 (BIASOTTO-GONZALEZ, 2005).

No Japão, a prevalência dos sinais e sintomas da DTM relatados são maiores na população trabalhadora (aproximadamente 17-18\%) do que na população geral (5-12\%) (NISHIYAMA et al., 2012), porém não há estimativa para diagnóstico de DTM em TUC. Autores acreditam que essa diferença pode ser atribuída aos agravos psicológicos resultados das obrigações no trabalho, mudanças no ambiente de trabalho, relações interpessoais e um ambiente orientado por metas (ambiente sem um contrato de trabalho ou com insuficientes produções e resultados) (NISHIYAMA et al., 2012). Além disso, autores observaram também que indivíduos que utilizavam o computador por 4 horas por dia possuíam o dobro de queixas quando comparados 
com aqueles que utilizavam apenas 2 horas por dia, sendo que as mulheres apresentavam maior queixa temporomandibular que os homens. (NISHIYAMA et al., 2012).

Apesar de existirem vários instrumentos para avaliação de DTM disponíveis na literatura (CHAVES et al., 2008), a ferramenta internacionalmente reconhecida e utilizada é o Research Diagnostic Criteria for Temporomandibular Disorders (RDC/TMD). O RDC/TMD é uma avaliação clínica, não invasiva, utilizada para diagnosticar a DTM (AHMAD et al., 2009; BEVILAQUA-GROSSI et al., 2009). Ela possui dois componentes de avaliação: o eixo I, que se refere ao diagnóstico clínico, e o eixo II, que avalia o diagnóstico do status psicológico e incapacidade relacionada à dor.

Para avaliação da dor na DTM e na disfunção cervical é possível o emprego da algometria para determinação do limiar de dor por pressão (LDP). O LDP é o ponto a partir do qual um paciente sente que a pressão crescente exercida sobre uma área torna-se desagradável ou dolorosa (CUNHA, 2011). Para avaliar o LDP do paciente durante o exame físico da DTM é necessário o uso de instrumento conhecido como algômetro (FRICTON; SCHIFFMAN, 1986; HALEY et al., 2001; CATHCART; PRITCHARD, 2006; GOMES et al., 2008). O algômetro é um aparelho que registra o valor da exata pressão exercida sobre uma área (CHUNG; KIM; KIM, 1993; VISSCHER et al., 2000;VISSCHER; LOBBEZOO; NAEIJE, 2004; SIMA,2007; GOMES et al., 2008).

Alguns estudos têm demonstrado diferenças no LDP de estruturas orofaciais entre pacientes com DTM em relação a controles assintomáticos (ETÖZ e ATAOĞLU, 2007; MICHELOTTI et al., 2008; FERNÁNDEZ-DE-LAS-PEÑAS et al., 2009; SILVEIRA et al., 2014). Além disso, estudo longitudinal recente (SLADE et al., 2014) demonstrou que os valores de LDP acompanharam em sincronicidade as flutuações clínicas da DTM e a incidência da disfunção em casos novos. Também foram observadas associações moderadas a fortes entre a presença de DTM e os valores de LDP obtidos (SLADE et al., 2014). Em pacientes com disfunção 
cervical/dor cervical também foram observadas diferenças no LDP em relação a controles saudáveis (HÄGG; ASTRÖM, 1997; SCHOMACHER et al., 2013)

\subsection{Disfunção temporomandibular (DTM) e disfunção da coluna cervical (DCC)}

$\mathrm{Na}$ literatura existe um grande número de trabalhos que demonstraram a associação entre dor cervical e DTM (STIESCH-SCHOLZ et al., 2003, BEVILAQUA-GROSSI et al., 2007, KRAUS 2007, OLIVO et al., 2010, ARMIJO-OLIVO et al., 2011).

A coexistência entre dor cervical e DTM é muito comum (DEWIJER et al., 1996; VISSCHER et al., 2001; FINK et al., 2002, ARMIJO-OLIVO et al., 2006). Existem mecanismos neurofisiológicos e biomecânicos que explicam tal associação. Um dos mecanismos neurofisiológicos que explicam essa associação está relacionado à convergência de aferências dos neurônios do núcleo caudal do trigêmeo e das raízes nervosas de C2 e C3 na cervical. Essa região de convergência é denominada de "complexo trigemino-cervical". Assim, informação nociceptiva resultante da região cervical pode ser transmitida por neurônios trigeminais, devido à convergência nociceptiva no complexo trigêmino-cervical entre fibras nervosas cervicais e trigeminais, resultando em dor difusa na região orofacial (BENDTSEN, 2000) e vice e versa. Dessa forma, sugere-se uma associação entre dor cervical e DTM (BEVILAQUA-GROSSI et al., 2007).

Como mecanismos biomecânicos podemos citar os desalinhamentos posturais da cabeça e cervical que podem causar ou predispor a disfunções da coluna cervical e da região orofacial contribuindo para alterações na biomecânica e desequilíbrio muscular. Há vários estudos demonstrando que as posturas do pescoço podem levar alterações na postura da mandíbula e alterações na atividade da musculatura mastigatória (GONZALEZ e MANNS, 1996; VISSCHER et al., 2000; ARMIJO-OLIVO, 2006). Rocabado (1983) considera que há um equilíbrio de forças 
entre a musculatura extensora cervical, a musculatura mastigatória (especificamente os músculos supra-hióideos) e a musculatura flexora anterior para manutenção da postura da cabeça.

Ainda considerando as justificativas biomecânicas, a teoria do deslizamento do crânio descrita por Makofsky (1989) demonstra que o deslizamento nas articulações atlanto-occipitais, com consequente movimento de flexão/extensão da cabeça provoca alterações do posicionamento da mandíbula. Assim posições em extensão da cabeça (deslizamento anterior dos côndilos occipitais nas facetas articulares superiores da vértebra atlas) levariam a inferiorização e posteriorização da mandíbula e posições em flexão da cabeça, ao contrário, levariam a anteriorização e elevação da mandíbula. Associada a mudança de postura da mandíbula, podem ocorrer alterações do posicionamento do côndilo da mandíbula na fossa mandibular. Dessa maneira, na inferiorização e posteriorização da mandíbula, o côndilo da mandíbula tenderia a se posicionar mais posteriorizado na fossa mandibular do osso temporal e na anteriorização e elevação da mandíbula, o côndilo da mandíbula tenderia a um posicionamento mais anterior na fossa mandibular. Além disso, estudos recentes têm demonstrado uma associação entre redução de endurance dos músculos cervicais flexores e extensores e DTM (ARMIJO-OLIVO et al., 2011, ARMIJO-OLIVO et al., 2010), sugerindo possíveis associações entre fadigabilidade da musculatura cervical, que pode estar relacionada à sobrecarga dessa musculatura imposta pela manutenção de posturas inadequadas prolongadas nos usuários de computador, e o desenvolvimento de dor na região craniocervical.

Apesar da vasta literatura sobre o tema, uma recente revisão sistemática mostrou que a relação entre a DTM e a postura da cabeça e pescoço ainda é controversa, pois é insuficiente o número de artigos considerados de excelente qualidade metodológica (ROCHA et al., 2013). Porém, não foram encontrados na literatura consultada estudos que tenham verificado a associação entre diagnósticos de DTM em trabalhadores usuários de computador e dor cervical. 


\subsection{Postura corporal e trabalho no computador}

A postura refere-se à posição do corpo humano e a sua orientação no espaço (CUCCIA e CARADOMA, 2009). A complexidade biomecânica da postura corporal deriva da integração funcional de diversos segmentos corporais: quando há uma alteração de qualquer subunidade biomecânica, um aprimoramento do sistema de controle postural ocorrerá necessariamente (SAITO et al., 2009).

A posição sentada é a mais adotada nos ambientes de trabalho, na escola e nas atividades de lazer (MARQUES et al., 2010). Entretanto, a manutenção dessa posição por tempo prolongado acarreta a adoção de posturas inadequadas e intensifica a sobrecarga nas estruturas do sistema musculoesquelético (PYNT et al., 2001,MARQUES et al., 2010). O local de trabalho dos usuários de computador é caracterizado por uma postura sentada bastante rígida que perdura ao longo de períodos prolongados (ZIEFLE, 2003). Em geral, as tarefas de computador são baseadas em movimentos repetitivos, realizados quando o trabalhador está sentado (BARBIERI et al., 2012).

A má postura sentada pode ocasionar dano potencial aos discos intervertebrais, articulações e tecidos moles devido à adoção de posturas cifóticas sustentadas, sendo benéfica a realização de movimentos intercalados com a postura sentada sustentada, estimulando a recuperação e manutenção da lordose (PYNT et al., 2001).

Sonne et al. (2012) caracterizam alguns parâmetros para a postura saudável no computador. A postura sentada correta para um indivíduo usuário de computador é manter os joelhos fletidos em cerca de $90^{\circ}$, com os pés apoiados no chão, pois com a cadeira mais elevada o indivíduo senta-se na borda do assento, aumentando a atividade dos músculos posteriores da coxa e abaixo desse valor, aumenta a pressão nas nádegas (SONNE et al., 2012).

A distância entre os joelhos e a borda do assento da cadeira deve ser de aproximadamente 8 centímetros (SONNE et al., 2012). Os braços devem ser posicionados de modo que os cotovelos 
se mantenham em $90^{\circ}$ sobre o apoio de braços da cadeira e os ombros em uma posição relaxada (SONNE et al., 2012). A inclinação do encosto da cadeira deve variar entre 95 e $110^{\circ}$ para promover uma redução da sobrecarga lombar (SONNE et al., 2012). O monitor deve estar posicionado a uma distância entre 40 e $75 \mathrm{~cm}$ do usuário com a parte superior da tela na altura dos olhos e a inferior não deve ficar mais que $30^{\circ}$ abaixo dos olhos (SONNE et al., 2012). Além disso, o monitor deve ser posicionado diretamente na frente do trabalhador (SONNE et al., 2012) .

O mouse deve ser posicionado de modo que esteja alinhado com o ombro e no mesmo nível do teclado, a fim de manter o ombro relaxado (SONNE et al., 2012). A colocação do teclado deve permitir que o trabalhador o utilize com os cotovelos fletidos em cerca de $90^{\circ}$, os ombros em uma posição relaxada e os punhos em linha reta (SONNE et al., 2012).

$\mathrm{Na}$ literatura as diferenças estruturais entre homens e mulheres são bastante conhecidas (COTÉ, 2012). Dados antropométricos demonstram que mulheres em média são mais baixas do que homens, com maiores discrepância no comprimento das pernas e quadris mais largos nas mulheres (COTÉ, 2012). Alguns estudos também relataram que mulheres tem tendões mais sensíveis ao alongamento (BURGESS et al., 2009), articulações mais flexíveis (ROY et al., 2009). Nordander et al. (2008) verificaram maior atividade eletromiográfica em mulheres do que em homens realizando a mesma tarefa repetitiva de membro superior, sugerindo que as mulheres para realizar a mesma tarefa precisam de maior recrutamento muscular. Além disso, parecem existir diferenças no controle motor entre homens e mulheres (homens mais rápidos e ágeis) para realizar atividades relacionadas ao membro superior, relato de fadiga (os homens relatam fadiga mais precocemente) e menores limiares de dor e tolerância à dor (COTÉ, 2012).

Algumas publicações recentes na literatura ressaltam a importância da avaliação da postura estática da cabeça e coluna vertebral em sujeitos com disfunção cervical (LAU et al., 2010, YIP et al., 2008, MCAVINEY et al., 2005). McAviney et al. (2005) relataram que a retificação cervical apresentou alta correlação com a presença de sintomatologia cervical ao avaliar indivíduos com e 
sem queixa na cervical. Já Yip et al. (2008) verificaram redução no ângulo crânio-vertebral (ângulo formado entre o traço horizontal de um lado ao outro do processo espinhoso de C7 com um traço do processo espinhoso de $\mathrm{C} 7$ até o tragus da orelha) em pacientes com dor cervical. Especificamente a manutenção em postura sentada com anteriorização da cabeça ou flexão cervical parecem estar associadas ao desenvolvimento de dor cervical em trabalhadores usuários de computador (CAGNIE et al., 2007; SIM et al., 2006).

Alterações da postura corporal também podem estar associadas a mudanças na atividade elétrica dos músculos mastigatórios influenciando na posição de repouso mandibular. Havendo uma possível associação entre alterações da postura craniocervical e a morfologia craniofacial (TINGEY et al., 2001).

Existem vários métodos de diagnósticos para avaliação do alinhamento postural, podendo fornecer dados qualitativos e quantitativos. A avaliação postural qualitativa é realizada através da inspeção visual e é amplamente utilizada como um recurso clínico na terapia física, porém sua confiabilidade pode ser afetada pela experiência do examinador e pela diferente formação dos avaliadores. A fotogrametria clínica é uma das ferramentas mais utilizadas para avaliação postural quantitativa e têm demonstrado bons níveis de confiabilidade intra e inter-examinadores (BELLI et al., 2009; IUNES et al., 2005).

De acordo com a American Society of Photogrammetry,em 1979, definiu-se Fotogrametria como sendo: "a arte, ciência e tecnologia de obtenção de informação confiável sobre objetos físicos e o meio ambiente através de processos de gravação, medição e interpretação de imagens fotográficas e padrões de energia eletromagnética radiante e outras fonte" (TOMMASELLI et al., 1999) .

Lau et al. (2010) utilizaram a fotogrametria e verificaram valores de confiabilidade intraavaliador e inter-avaliador, respectivamente, ao medir o ângulo torácico alto de 0,80 e 0,86 e para o ângulo craniovertebral de 0,81 e 0,87 . Além disso, essa é uma técnica relativamente simples e 
facilmente realizável, utilizada devido às suas vantagens e efetividade na aplicação clínica, como baixo custo no sistema de obtenção de imagens, facilidade de fotointerpretação, alta precisão e reprodutibilidade dos resultados, bem como ausência de radiação (IUNES et al., 2005).

\subsection{Trabalhadores usuários de computador (TUC) e disfunção musculoesquelética}

O alto índice de lesões agudas e fatais observados na maioria dos países no início do século XX foi substituído por um acentuado aumento na incidência de distúrbios musculoesqueléticos (COTÉ et al., 2009). Como já mencionado, observam-se alguns estudos na literatura que verificaram a associação entre alterações posturais e dor cervical crônica (YIP et al., 2008; LAU et al., 2010) e também relatos sobre alterações posturais em trabalhadores usuários de computador com dor cervical em relação a usuários sem dor cervical (SZETO et al., 2002).

Existem também alguns estudos que relataram a influência de fatores psicossociais, fisiológicos e individuais no desenvolvimento de dor cervical entre usuários de computador, bem como diferenças na contribuição desses fatores para distintos níveis de incapacidade cervical (JOHNSTON et al., 2007 e 2009).

Distúrbios musculoesqueléticos no pescoço e ombro em TUC são provavelmente influenciados pelo trabalho em posição estática prolongada, levando a contínua atividade de baixo limiar para as unidades motoras, redução do fluxo sanguíneo local, o acúmulo de Ca2+, e outras alterações homeostáticas nas fibras musculares ativas (BRANDT et al., 2014). Assim, os sintomas de dor parecem piorar durante a atividade muscular estática prolongada e em tarefas com trabalhos repetitivos (BRANDT et al., 2014).

Entretanto, na literatura consultada apenas um estudo de revisão foi encontrado que considerasse aspectos que explicam a possível relação entre risco ergonômico, cervical e DTM entre trabalhadores usuários de terminais de vídeo (HOROWITZ e SARKIN, 1992). Assim, é 
possível que as posturas adotadas compulsoriamente no ambiente de trabalho possam estar relacionadas a alterações de postura crônicas, levando a sobrecargas para o sistema musculoesquelético, especificamente para região de extremidade superior e craniocervical, e ao aparecimento de disfunção cervical e temporomandibular (Disfunção craniocervical) concomitantemente, uma vez que essas disfunções podem estar intimamente associadas (KRAUS 2007, STIESCH-SCHOLZ et al., 2003). Sendo assim, justifica-se a realização deste estudo.

\section{Hipótese}

A hipótese desse estudo é de que as alterações de postura e a sobrecarga biomecânica relacionadas com a postura estática sentada e na posição para ao uso do computador podem levar a alterações da postura cervical e da cabeça e estejam associadas ao desenvolvimento de dor cervical e DTM. Além disso, há a hipótese de que TUC que referirem dor cervical apresentem alterações mais severas da postura corporal e intensidade de dor do que os TUC sem dor cervical. Sugere-se que a alteração de postura e sobrecarga biomecânica na postura sentada estejam relacionadas ao desenvolvimento de dor cervical e DTM. Também é possível que as alterações da cervical e cabeça estejam relacionadas a alterações da postura corporal como um todo. 


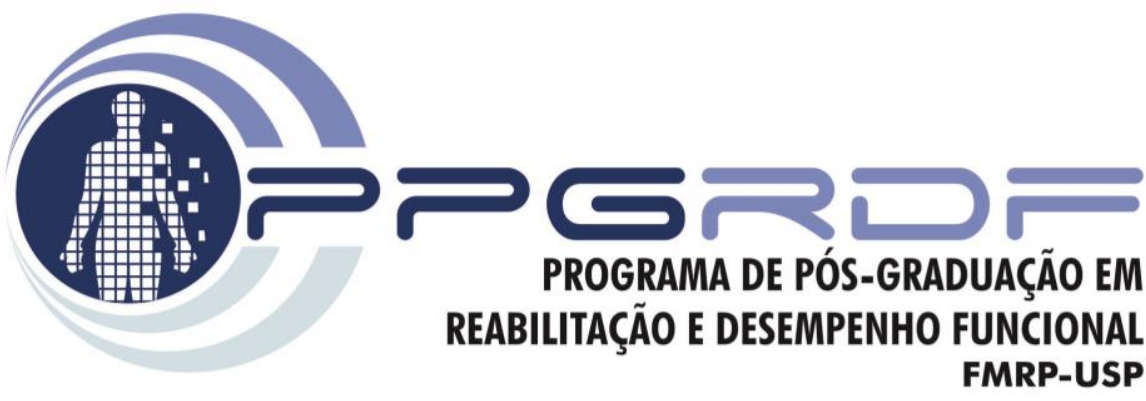

\section{OBJETIVOS}

"O professor é aquele que faz brotar duas idéias onde só havia uma"

Elbert Hubbard 


\section{OBJETIVOS}

\subsection{Objetivo geral}

Verificar associações entre dor cervical, disfunção temporomandibular e alterações na postura estática em trabalhadores de escritório usuários de computador com e sem relato de dor cervical crônica.

\subsection{Objetivos secundários}

- Verificar diferenças nos aspectos físicos e psicossocias relacionados ao trabalho no computador entre trabalhadores com e sem queixa de dor cervical crônica;

- Verificar a presença de disfunção temporomandibular entre trabalhadores de escritório com e sem queixa de dor cervical crônica;

- Avaliar a postura corporal estática dos trabalhadores de escritório com e sem queixa de dor cervical crônica;

- Avaliar o limiar de dor por pressão (LDP) nos músculos mastigatórios e cervicais nos trabalhadores de escritório com e sem queixa de dor cervical crônica;

- Avaliar associações entre aspectos das condições de trabalho, alteração de postura e dor cervical e DTM. 


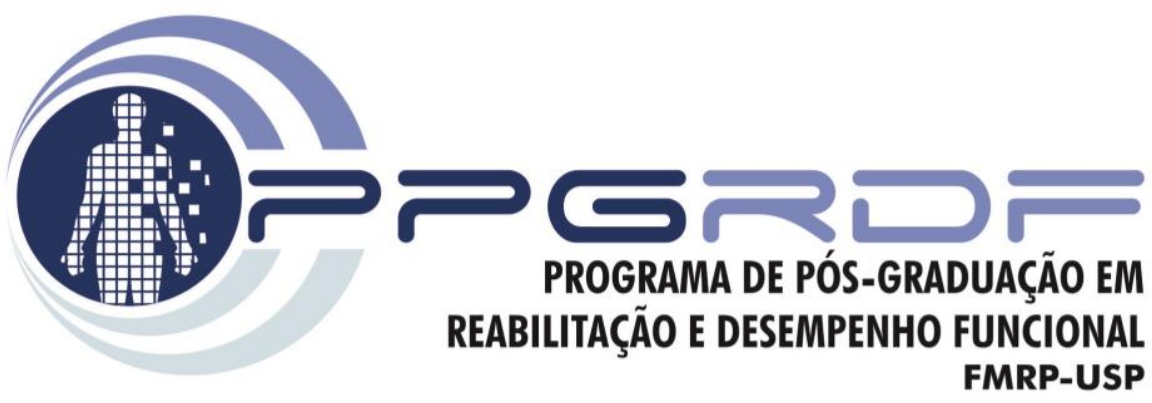

MATERIAL

$\mathbf{E}$

MÉTODOS

"Ensinar não é transferir conhecimento, mas criar as possibilidades para a sua própria produção ou a sua construção".

Paulo Freire 


\section{MATERIAL E MÉTODOS}

\subsection{Aspectos éticos}

O desenvolvimento da pesquisa obteve a aprovação do comitê de ética em pesquisa da Faculdade de Medicina de Ribeirão Preto da Universidade de São Paulo (Processo 10299/2012) (Anexo 1). As trabalhadoras usuárias de computador concordantes com a participação assinaram um Termo de Consentimento Livre e Esclarecido (TCLE) (Apêndice 1) contendo informações sobre o estudo, quanto à liberdade de adesão e desistência, ausência de danos à vida e direito de preservação da identidade.

\subsection{Materiais}

- $\quad$ Paquímetro da marca Mitutoyo® analógico; luva de látex;

- $\quad$ Máquina fotográfica digital Canon EOS Rebel T3i®, lente objetiva de 18-135 mm, tripé fotográfico Benro Universal Video - A2573FS4; fio de prumo; caixote de madeira de $15 \mathrm{~cm}$ de altura, $40 \mathrm{~cm}$ de comprimento e $30 \mathrm{~cm}$ de largura;

- $\quad$ Algômetro de pressão (dolorímetro) para medição da dor por pressão marca Kratos@, São Paulo, Brasil, modelo DDK - 20kgf;

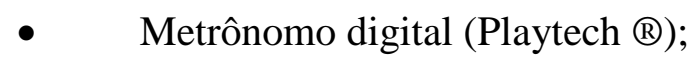

- $\quad$ Balança mecânica WELMY® modelo 110 CH/110 CHG/ 104A. 


\subsection{Amostra}

A amostra deste estudo foi retirada de um banco de dados obtidos através da aplicação do questionário validado para Português o Maastricht Upper Extremity Questionnaire (MUEQ-Br) (TURCI et al., 2015) que é uma ferramenta que avalia aspectos ergonômicos e psicossociais, com caráter específico para trabalhadores usuários de computador (Anexo 2). Esta ferramenta foi desenvolvida para analisar de maneira mais detalhada as queixas de dor cervical, ombro e braço (CANS) (ELTAYEB et al., 2007). O MUEQ-Br contempla 7 domínios (posto de trabalho, postura corporal, controle do trabalho, demanda de trabalho, pausas, ambiente de trabalho, suporte social) e item queixas totalizando 95 questões, com pontuação máxima 219 pontos, sendo que:

- O domínio Posto de Trabalho retrata o mobiliário do ambiente de trabalho, podendo pontuar um máximo de 8 pontos, com 7 opções de respostas sim/não, com pontuação 0/1, respectivamente para todas as questões deste domínio . Além disso, para a questão 13, em caso de resposta positiva $(\operatorname{sim}=0)$, existe ainda a possibilidade de complemento da pontuação, sendo somado mais um ponto $(+1)$ para a resposta "coluna baixa" e pontuação $(+0)$ para as respostas "coluna média" e "coluna alta".

- O domínio Postura Corporal, investiga aspectos sobre a postura física do indivíduo adotada em seu posto de trabalho. Consiste em 11 itens que pontuam no máximo 33 pontos com a possibilidade de 5 respostas (sempre, frequentemente, ás vezes, raramente e nunca), sendo que elas pontuadas de 0 a 3, dependendo do nível de inadequação do item (quanto maior inadequação, pior pontuação).

- $\quad$ O domínio Controle do trabalho, consiste em 9 itens relacionados com a percepção do indivíduo sobre a maneira de conduzir seu trabalhocom pontuação máxima de 27 pontos (regra de pontuação idem domínio postura corporal). 
- $\quad$ O domínio Demanda de trabalho possui 7 itens, com pontuação máxima de 21 pontos, abordam aspectos psicossociais relacionados ao fluxo e desenvolvimento de trabalho (regra de pontuação idem domínio postura corporal).

- $\quad$ O domínio denominado Pausas, com 8 itens e pontuação máxima de 24 pontos, investiga sobre a existência de interrupções no trabalho e a qualidade das pausas segundo a percepção do trabalhador(regra de pontuação idem domínio postura corporal).

- $\quad$ O domínio Ambiente de trabalho, com 9 itens e pontuação máxima de 27 pontos, é caracterizado sobre a percepção do indivíduos em relação a aspectos de caráter técnicos, como iluminação, temperatura, acústica e outros fatores (regra de pontuação idem domínio postura corporal).

- $\quad$ O domínio Suporte Social contempla 8 itens sobre a relação do trabalhador com seus colegas e supervisores e o andamento do trabalho, possui máxima pontuação de 24 pontos (regra de pontuação idem domínio postura corporal).

- $\quad$ O item Queixas, com 29 questões e pontuação máxima de 55 pontos, investiga os pontos de dor nos MMSS no trabalhador. Como opções de respostas temos: para os itens III, 76, 78, 80, 81 e 91 a 93 as respostas são sim/não, com pontuação 0/1, respectivamente. Para a questão 77, as possibilidades de respostas são "nenhum" (0 pontos) e "x" dia(s) ou “x"semana(s) que pontua 1 ponto. Para a questão 79, a resposta "nenhum" pontua zero e "fisioterapia", "medicação", "cirurgia" ou outro apresenta pontuação 1. Na questão 82 as respostas são sim/não, com pontuação $1 / 0$ respectivamente, caso a resposta seja sim, existe ainda as respostas "Em meu trabalho" e "Em meu tempo de lazer", com pontuação zero e mais 1 ponto (+1), respectivamente. A questão 83 não é pontuada. Para as questões de 84 a 87 as respostas são sim/não, com pontuação 1/0, respectivamente, caso a resposta seja sim, existem ainda as respostas sim/não, com pontuação 0/+1, respectivamente. Para as questões de 88 a 90 as respostas são sim/não, com pontuação 1/0, respectivamente, caso a 
resposta seja sim, existe ainda as respostas $\operatorname{sim} /$ não, com pontuação $+1 / 0$, respectivamente. A questão 94 apresenta as respostas "nenhum" (pontua zero) e "Munhequeira", "Cinta", "Colar Cervical" e "Outro" que pontuam estas mais um ponto $(+1)$ cada. A questão 95 apresenta as respostas "nenhum" (pontua 3 pontos) e "Suporte para mouse", "Apoio para pés", "Suporte para textos" e "Outro" pontuam menos um ponto (-1) cada, no máximo de pontos desta questão (3)

Após a análise de 461 questionários (MUEQ-Br) preenchidos por trabalhadores usuários de computador de mesa (desktop) do campus da Universidade de São Paulo da cidade de Ribeirão Preto, foram selecionados apenas os questionários preenchidos por trabalhadores do gênero feminino na faixa etária entre 20 e 50 anos, que exercessem a mesma função há pelo menos 12 meses e utilizassem o computador ao menos 4 horas por dia durante a jornada de trabalho (BLATTER e BONGERS, 2002; SONNE et al., 2012), totalizando 228 questionários. Foram excluídos 32 trabalhadoras devido à idade superior a 50 anos.

Foram excluídos dos grupos desse estudo trabalhadoras que apresentaram outras desordens de dor aguda e crônica, indivíduos com doenças degenerativas sistêmicas com acometimento de várias articulações, indivíduos com síndrome de whiplash cervical e outras condições traumáticas, indivíduos com deformidades congênitas dos membros superiores e coluna vertebral, histórico de cirurgias de coluna, discrepâncias de membros inferiores verdadeiras, deficiência visual (não corrigida pelo uso de óculos ou lentes de contato), deficiência auditiva (não corrigida pelo uso de aparelhos), indivíduos com aparelho fixo ortodôntico, indivíduos com déficits cognitivos, gestantes, lactantes e pós-parto (até um ano).

Os questionários que preencheram os critérios de inclusão da pesquisa foram separados em dois grupos, sendo grupo com dor cervical crônica e grupo sem queixa de dor cervical.

No grupo com dor cervical crônica, as trabalhadoras deveriam apresentar relato positivo de dor crônica cervical e se enquadrarem nos seguintes critérios: a) dor cervical há pelo menos 3 
meses (HOY et al., 2010); b) limitação funcional, pelo menos leve, no Índice de incapacidade relacionada ao pescoço (NDI) e c) dor de intensidade 3 na maioria dos dias em uma escala numérica de dor (0 a 10) (LAU et al., 2010).

Os questionários que não preencheram estes critérios também foram excluídos. Com os questionários restantes, convidamos por telefone de forma aleatória todas as trabalhadoras para participarem da pesquisa.

O cálculo da amostra demonstrou que um "n” mínimo de 26 sujeitos seriam necessários para verificar uma diferença entre os grupos de $3^{\circ}$ para o ângulo de protusão de cabeça (PC) (1 - $\beta$ $=0.95, \alpha=0.05$, effect size de 0.94) (GPower 3.0.10, Universitat of Kiel, Germany).

A avaliação clinica foi realizada no Laboratório de Pesquisa Interdisciplinar na Disfunção Musculoesquelética (LAPIDIM), localizado no primeiro andar do prédio da Fisioterapia e Terapia Ocupacional da Faculdade de Medicina de Ribeirão Preto- USP.

A avaliação clínica do estudo foi realizada por um único avaliador cego para a composição dos grupos, treinado previamente e composta por: avaliação da postura estática, avaliação da DTM, avaliação da dor cervical e mastigatória através da algometria por pressão e aplicação do Índice de incapacidade relacionada ao pescoço (NDI), nas voluntárias que relataram dor cervical crônica.

\subsection{Avaliação clínica}

\subsubsection{Questionário geral}

Esse questiorário foi elaborado com a finalidade de coletar os dados gerais e antropométricos das voluntárias. Foram inclusas perguntas como: ingestão de medicamentos para dor, frenquência e tipo de droga; uso de anticoncepcionais e período ciclo menstrual. Todas as 
voluntárias foram coletadas no seguinte período do ciclo mesntrual: 7 dias antes da menstruação e após a menstruação. Nessa etapa também foi questionado se a voluntária já havia sofrido algum trauma no pescoço (exclusão), se possuía dor cervical, frequência e intensidade da dor (Apêndice 2). Nas tabelas 1 e 2 é possível observar dados da caracterização da amostra.

Tabela 1- Caracterização dos grupos com e sem dor cervical quanto à idade, peso e altura

\begin{tabular}{lcc}
\hline Caracterização da amostra & \multicolumn{2}{c}{ Média (IC 95\%) } \\
\hline & Sem dor cervical & $\begin{array}{c}\text { Com dor cervical } \\
\text { crônica }\end{array}$ \\
\hline Idade (anos) & $33.81(30.66-36.95)$ & $36.50(33.40-36.60)$ \\
Altura (m) & $1.64(1.62-1.67)$ & $1.62(1.60-1.65)$ \\
Peso (kg) & $71.75(65.90-77.60)$ & $66.37(62.48-70.26)$ \\
IMC & $26.52(24.59-28.46)$ & $25.22(23.88-26.55)$ \\
\hline & & \\
Tempo de trabalho (meses) & $91(63-119)$ & $110(73-147)$ \\
Tempo de trabalho no computador (meses) & $127(91-163)$ & $170(128-212)$ \\
Dias de trabalho na semana & 5 & 5 \\
Horas/dia de trabalho & $8.04(7.84-8.24)$ & $7.96(7.76-8.16)$ \\
Horas/dia utilizando computador & $7.58(7.23-7.92)$ & $7.46(7.10-7.83)$ \\
\end{tabular}

IC - Intervalo de Confiança

IMC - Índice de Massa Corpórea 
Tabela 2- Caracterização da dor cervical nos grupos considerados neste estudo

\begin{tabular}{lcc}
\hline $\begin{array}{l}\text { Característica da dor } \\
\text { cervical }\end{array}$ & $\begin{array}{c}\text { Sem dor cervical } \\
(\mathbf{n = 2 6})\end{array}$ & $\begin{array}{c}\text { Com dor cervical crônica } \\
(\mathbf{n}=\mathbf{2 6})\end{array}$ \\
\hline Tempo de dor cervical & & $15.38 \%(\mathrm{n}=4)$ \\
\hline Menos de 2 anos & NA & $50 \%(\mathrm{n}=13)$ \\
2 a 5 anos & NA & $26.92(\mathrm{n}=7)$ \\
6 a 10 anos & NA & $7.69(\mathrm{n}=2)$ \\
Mais de 10 anos & NA & \\
\hline
\end{tabular}

\begin{tabular}{lcc}
\hline Frequência de dor cervical & & \\
\hline Todos os dias do mês & NA & $19.23 \%(\mathrm{n}=5)$ \\
Mais de 15 dias por mês & NA & $11.23 \%(\mathrm{n}=3)$ \\
Entre 8 e 15 dias por mês & NA & $26.92 \%(\mathrm{n}=7)$ \\
Entre 1 a 7 dias po mês & NA & $34.61(\mathrm{n}=9)$ \\
Entre 4 e 11 crises por ano & NA & $7.69(\mathrm{n}=2)$ \\
\hline $\begin{array}{l}\text { Intensidade de dor } \\
\text { cervical }\end{array}$ & NA & \\
& & \\
\hline $\begin{array}{l}\text { Índice de Incapacidade } \\
\text { Relacionada ao Pescoço }\end{array}$ & NA & incapacidade leve \\
& & \\
\hline $\begin{array}{l}\text { NA - Não se Aplica } \\
\text { IC - Intervalo de Confiança }\end{array}$ & &
\end{tabular}

3.4.2. Avaliação e classificação da DTM

3.4.2.1.Aplicação do critério diagnóstico para avaliação da disfunção temporomandibular 
A DTM foi avaliada através do formulário de exame e questionário dos sintomas do RDC/ DTM. Um único examinador, cego para composição dos grupos, treinado aplicou o roteiro de avaliação.

As regras para atribuir um diagnóstico de acordo com o RDC/TMD são as seguintes: Um indivíduo pode receber no máximo um diagnóstico muscular (grupo I) (dor miofascial ou dor miofascial com abertura limitada, mas não ambos). Além disso, cada articulação pode conter no máximo um diagnóstico do grupo II e um diagnóstico do grupo III. Isto é, os diagnósticos dentro de qualquer grupo são mutuamente exclusivos. Isto significa que, a princípio, um indivíduo pode receber desde um prognóstico zero (sem condições musculares ou musculares diagnosticáveis) até cinco diagnósticos (um diagnóstico muscular + um diagnóstico do grupo II para cada ATM + um diagnóstico do grupo III, para cada ATM). Na prática, os casos com mais de três diagnósticos são muito raros. Segue as três principais categorias de classificação.

\section{Diagnósticos musculares:}

a. Dor miofascial: Dor de origem muscular com relato de dor, assim como dor à palpação muscular.

1. Relato de dor na região da mandíbula, têmporas, face, área pré- auricular ou dentro da orelha em repouso ou durante a função; associado a;

2. Dor relatada por um indivíduo em resposta a palpação de três ou mais dos 20 sitios musculares seguidos (lado direito e esquerdo contam como sítios separados para cada músculo): temporal posterior, temporal médio, temporal anterior, origem do masseter, corpo do masseter, inserção do masseter, região posterior da mandíbula, região submandibular, área do pterigoideo lateral e tendão do temporal. Pelo menos um dos sítios deve estar no mesmo lado da reclamação de dor. 
b. Dor miofascial com abertura limitada: Movimento limitado e rigidez do músculo durante o alongamento na presença de dor miofascial.

1. Diagnóstico de dor miofascial; mais

2. Abertura sem auxílio e sem dor $<40 \mathrm{~mm}$; mais

3. Abertura máxima com auxílio (extensão passiva) de $5 \mathrm{~mm}$ ou mais, maior que a abertura sem auxílio e sem dor.

\section{Deslocamento de disco:}

a. Deslocamento de disco com redução: O disco está deslocado de sua posição entre o côndilo e a eminência para uma posição anterior e medial ou lateral, mas há uma redução na abertura, frequentemente resultado em um ruído.

1. Estalido recíproco na ATM (estalido em abertura e fechamento verticais, sendo que o estalido na abertura ocorre em uma distância inter-incisivos pelo menos $5 \mathrm{~mm}$ maior que a distância inter- incisivos na qual ocorre estalido durante o fechamento e considerando-se que o estalido é eliminado durante a abertura protusiva), reproduzível em dois de três experimentos consecutivos; ou

2. Estalido da ATM em um dos movimentos verticais (abertura ou fechamento), reproduzível em dois de três experimentos consecutivos e estalido durante excursão lateral ou protusão, reproduzível em dois de três experimentos consecutivos.

b. Descolamento de disco sem redução, com abertura limitada: Uma condição na qual o disco é deslocado da posição normal entre o côndilo e a fossa para uma posição anterior e medial ou lateral, associado com uma abertura mandibular limitada.

1. História de limitação significante de abertura; mais

2. Abertura máxima sem auxilio menor ou igual a $35 \mathrm{~mm}$; mais 
3. Abertura com auxílio que aumenta a abertura máxima em $4 \mathrm{~mm}$ ou menos; mais

4. Excursão contralateral $<7 \mathrm{~mm}$ e/ou desvio sem correção para o lado ipsilateral durante abertura; mais

5. Ou: (a) ausência de ruídos articulares, ou (b) presença de ruídos articulares não concordando com os critérios para o deslocamento de disco com redução.

c. Deslocamento de disco sem redução, sem abertura limitada: Uma condição na qual o disco é deslocado de sua posição entre côndilo e a eminência para uma posição anterior e medial ou lateral, não associada com a abertura limitada.

1. História de limitação significante de abertura; mais

2. Abertura máxima sem auxílio > 35mm; mais

3. Abertura com auxílio que aumenta a abertura em $5 \mathrm{~mm}$ ou mais; mais

4. Excursão contralateral maior ou igual a $7 \mathrm{~mm}$; mais

5. Presença de ruídos articulares não concordando com os critérios de deslocamento de disco com redução.

\section{Artralgia, artrite, artrose:}

a. Artralgia: Dor e sensibilidade na cápsula articular e/ou no revestimento sinovial da ATM.

1. Dor em um ou ambos sítios articulares (pólo lateral e/ou ligamento posterior ) durante a palpação; mais

2. Um ou mais dos seguintes auto-relatos de dor: dor na região da articulação, dor na articulação durante abertura máxima sem auxílio, dor na articulação durante abertura com auxílio, dor na articulação durante excursão lateral.

3. Para o diagnóstico de artralgia simples, uma crepitação grosseira deve estar ausente. 
b. Osteoartrite da ATM: Uma condição inflamatória dentro da articulação que resulta de uma condição degenerativa das estruturas articulares.

1. Diagnostico de Artralgia; mais

2. $\quad$ a ou b (ou ambos):

a. Crepitação grosseira na articulação

b. Imagem - tomogramas mostram um ou mais dos seguintes: erosão do delineamento cortical normal, esclerose de partes ou de todo o côndilo e eminência articular, achatamento das superfícies articulares, presença de osteófito.

c. Osteoartrose da ATM: Uma desordem degenerativa da articulação na qual a forma e estrutur a articulares estão normais.

1. Ausência de todos os sinais da artralgia, isto é, ausência de dor na região da articulação e ausência de dor a palpação na articulação, durante abertura máxima sem auxílio e nas excursões laterais; mais

2. $\quad$ a ou b (ou ambos):

a. Crepitação grosseira na articulação.

b. Imagem - tomogramas mostram um ou mais dos seguintes: erosão do delineamento cortical normal, esclerose de partes ou de todo o côndilo e eminência articular, achatamento das superfícies articulares, presença de osteófito.

Um único examinador treinado para a aplicação do sistema de diagnóstico RDC/TMD conduziu as avaliações. A amplitude do movimento mandibular foi avaliada através de um paquímetro calibrado da marca Mytutoio ${ }^{\circledR}$. Os movimentos foram registrados em milímetros (mm), em 2 repetições para maior fidedignidade e de acordo com os critérios do RDC/TMD da seguinte maneira: máxima abertura da boca (Figura 1) - distância entre as margens incisais dos 
incisivos centrais superiors e inferiors, solicitando ao voluntário a máxima abertura da boca sem dor; máxima lateralidade ( Figura 2) - distância horizontal entre a linha média interincisivos superior e inferior ao final da excursão lateral da excursão lateral direita e esquerda. Foram realizadas com grafite, as marcações das linhas médias nos dentes superiors e inferiors quando houvesse desvio da mesma; protrusão máxima (Figura 3) com a utilização da extremidade da haste de profundidade do paquímetro.

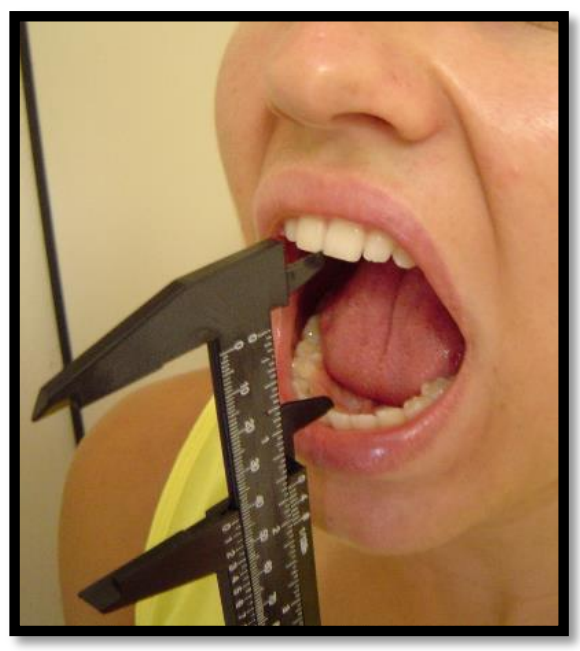

Figura 1 - Avaliação da amplitude de abertura da boca por meio do uso do paquímetro.

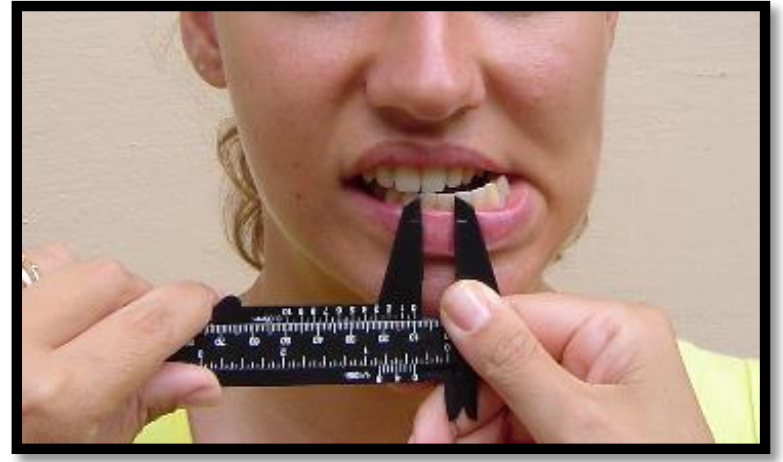

Figura 2 - Avaliação da amplitude de desvio mandibular lateral esquerdo por meio do uso do paquímetro.

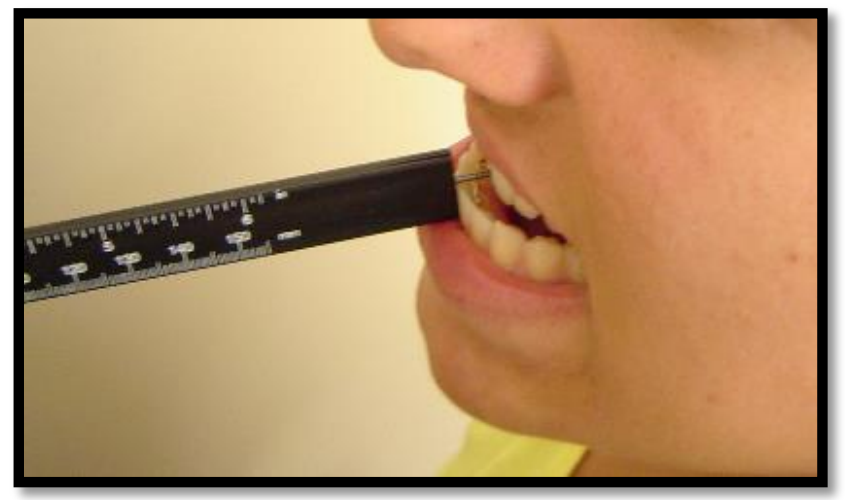

Figura 3 - Avaliação da amplitude de protrusão mandibular por meio do uso do paquímetro. 


\subsubsection{Procedimentos de palpação manual e algometria para obtenção dos valores de}

\section{limiar de dor por pressão (LDP)}

Os procedimentos de algometria e palpação manual foram realizados por um único examinador previamente treinado e cego para composição dos grupos.

\subsubsection{Palpação manual}

A palpação manual foi realizada sempre com o uso do dedo indicador (polpa digital falange distal) (DWORKIN; LERESCHE, 1992) com uma pressão firme e mantida pontualmente, evitando-se alterações no nível de pressão aplicado. As voluntárias deveriam estar relaxadas com a mandíbula em posição de repouso, sem contato entre os dentes e os músculos também relaxados.

O treinamento foi realizado com o uso de um dinamômetro e o examinador foi treinado para aplicar níveis de pressão no intervalo de 0,5 a $1,0 \mathrm{~kg} / \mathrm{cm}^{2}$ para a palpação das estruturas intraorais e ATM e para palpação das demais estruturas foi considerado um intervalo de 1,5 a 2,0 $\mathrm{kg} / \mathrm{cm}^{2}$ (GOULET et al., 1998). Dessa forma, a pressão realizada para a palpação manual das estruturas intra-orais e ATM foi de aproximadamente $0,7 \mathrm{~kg}$, enquanto que para as estruturas extra-orais foi de $1,5 \mathrm{~kg}$, depois de aplicada a pressão, a voluntária graduava a percepção de dor em uma escala numérica de dor (END) (Figura 4) considerando 0 sem dor e 10 a pior dor possível e relatava se a dor era familiar ou não e se a mesma irradiava.

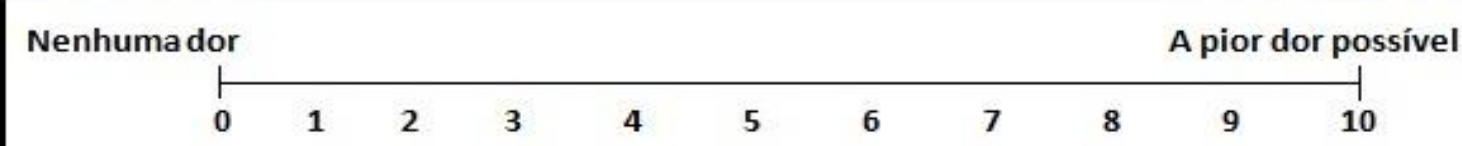

Figura 4 - Escala numérica de dor (END) 
Foi realizada a palpação apenas uma vez para cada um dos locais de palpação, a fim de se evitar possíveis efeitos de sensibilização de nociceptores (ISSELÈE et al., 1997).

\subsubsection{Algometria para obtenção do limiar de dor por pressão (LDP)}

A algometria por pressão foi realizada com a velocidade constante de aplicação de aproximadamente $0.5 \mathrm{~kg} / \mathrm{cm}^{2} / \mathrm{s}$ e correto posicionamento da ponteira metálica do aparelho perpendicularmente às superficies anatômicas avaliadas (DUARTE; GOULART; PENNA, 1999). Um metrônomo digital com frequência determinada de $1 \mathrm{~Hz}$ foi utilizado em todas as avaliações com objetivo de fornecer feedback sonoro e padronização da velocidade de aplicação da força de compressão.

Um dinamômetro digital (Kratos®, São Paulo, Brasil, modelo DDK-20) (Figura 5) para realização de ensaio de compressão foi adaptado para realização da algometria por pressão (CHAVES, 2006; CHAVES et al., 2007). O intervalo de mensuração do aparelho varia de 0 a 10 $\mathrm{kg}$, com precisão de $0,001 \mathrm{~kg}$. um disco de borracha de $1.0 \mathrm{~cm}^{2}$ da área foi adaptado na ponteira metálica do aparelho para evitar danos às superficies avaliadas (JENSEN et al., 1986).

Todo o procedimento foi detalhadamente esclarecido às voluntárias previamente e estas foram instruídas quanto à diferença de percepção de pressão e percepção de início de dor. Assim, para familiarização da voluntária com a técnica o equipamento utilizado foi aplicado previamente na região tênar da mão esquerda do examinador e posteriormente na mesma região anatômica das participantes. As voluntárias foram orientadas a apertarem o disparador acoplado no dinamômetro no exato momento do início da percepção de dor. 
Os valores de LDP foram obtidos em duas mensurações consecutivas bilateralmente com um intervalo de 5 minutos para a reavaliação de cada estrutura. Para análise dos dados de LDP foi considerado a valor médio das duas medidas.

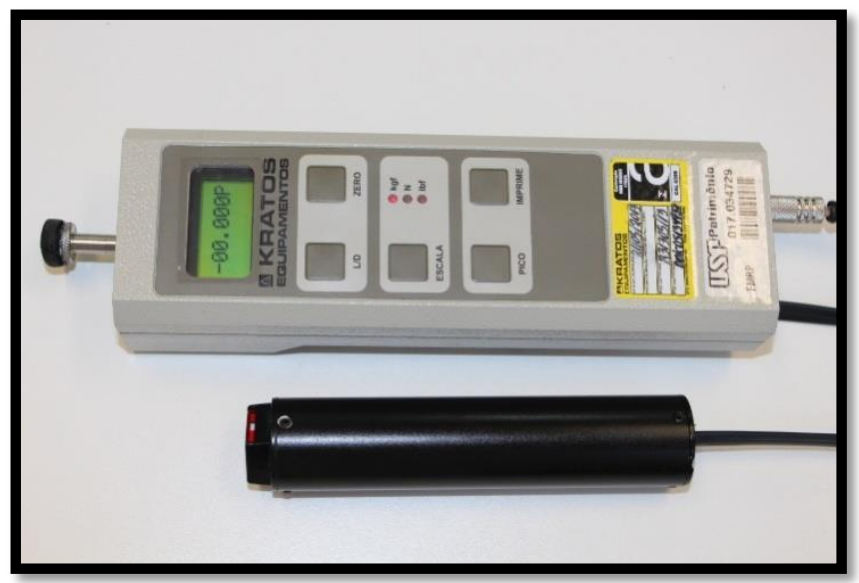

Figura 5 - Dinamômetro digital (Kratos®, São Paulo, Brasil, modelo DDK-20), com disparador acoplado.

3.4.3.3. Localização, palpação e demarcação dos pontos anatômicos do sistema mastigatório para obtenção dos valores de intensidade de dor relativos à palpação manual (PM) e limiar de dor por pressão (LDP)

A sensibilidade dolorosa à palpação muscular foi realizada através da palpação manual como preconizado pelo RDC/TMD. Para graduação da intensidade dolorosa foi utilizada a escala numérica de dor (Figura 4), considerando 0 sem dor e 10 a pior dor possível.

A palpação foi realizada nos seguintes pontos:

- Músculo temporal: (1) (fascículo anterior (Figuras 6 e 7): ponto mais proeminente e

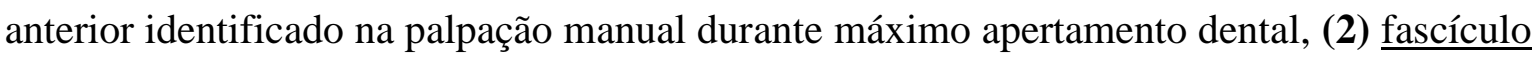
médio (Figura 8): ponto localizado a uma distância de $3 \mathrm{~cm}$ da região determinada para o fascículo anterior do músculo temporal e (3) fascículo posterior ( Figura 9): ponto 
localizado em uma distância de $6 \mathrm{~cm}$ da região determinada para o fascículo anterior do músculo temporal);

- Músculo masseter (4) (origem (Figura 10): região superior mais proeminente identificada na palpação manual durante máximo apertamento dental, (5) ventre (Figura 11): ponto médio entre a origem e inserção) e (6)_inserção (Figura 12): região inferior mais proeminente identificada na palpação manual durante máximo apertamento dental (LIST; HELKIMO; FALK, 1989);

- Região submandibular ou dos músculos supra-hióideos (7) (Figura 13): foi localizada e palpada a região de tecido mole inferior e posterior do corpo da mandíbula;

- $\quad$ Pólo lateral da ATM (8) (Figura 14): o dedo indicador foi posicionado a frente do tragus da orelha e sobre a ATM, pedindo-se para o voluntário abrir levemente a boca, enquanto o examinador tentava encontrar o pólo lateral do côndilo se movimentando para frente;

- Pólo posterior da ATM (9) (Figura 15): palpado através do meato acústico. Diferentemente do recomendado pelo RDC/TMD o dedo indicador também foi utilizado para realização dessa palpação. As pontas dos dedos foram posicionadas na direção do examinador e o voluntário foi solicitado a abrir levemente a boca para que o movimento articular fosse percebido com a ponta do dedo. A pressão foi aplicada quando os dentes de voluntário estavam em oclusão;

- Músculos pterigóideo cabeça lateral (10): ao voluntário foi solicitado que abrisse a boca e movimentasse a mandíbula para o lado que estava sendo examinado ("movimente a sua mandíbula para o lado desta mão"). O dedo indicador foi posicionado na lateral acima do topo alveolar do maxilar posterior aos molares e, movimentado distalmente, para cima, e medialmente (palpação intra-oral);

- Tendão do músculo temporal (11) (Figura 16): logo após a palpação do músculo pterigoideo lateral, o dedo indicador foi rotacionado lateralmente próximo ao processo 
coronóide, e a voluntária foi convidada a abrir a boca levemente e o dedo indicador foi movimentado para cima em direção ao topo do processo coronóide;

- $\quad$ Região posterior da madíbula (12): ângulo da mandíbula até a sua inserção no processo mastóideo;

- Região tênar esquerda (13): utilizada como região controle, não é parte dos pontos determinados pelo RDC/TMD.

- $\quad$ Esternocleidomastóideo (ECOM) (inserção) (14) (Figura 17): palpado no processo mastóide do osso temporal;

- Suboccipitais (15) (Figura 18): após localizar a região posterior do crânio, na linha média, moveu-se os dedos distalmente até atingir um ponto onde eles "afundaram", então realizou-se a palpação;

- Trapézio (ponto médio) (16) (Figura 19): palpação localizada no ponto médio da distância entre C7 e o acrômio da voluntária;

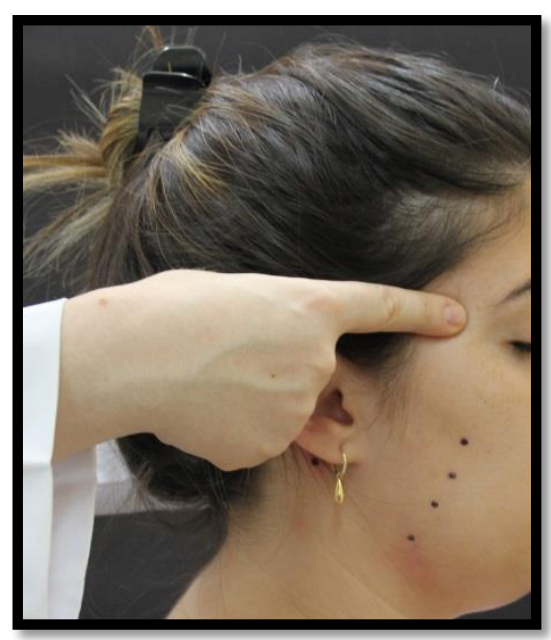

Figura 6 - Palpação manual do fascículo anterior do músculo temporal.

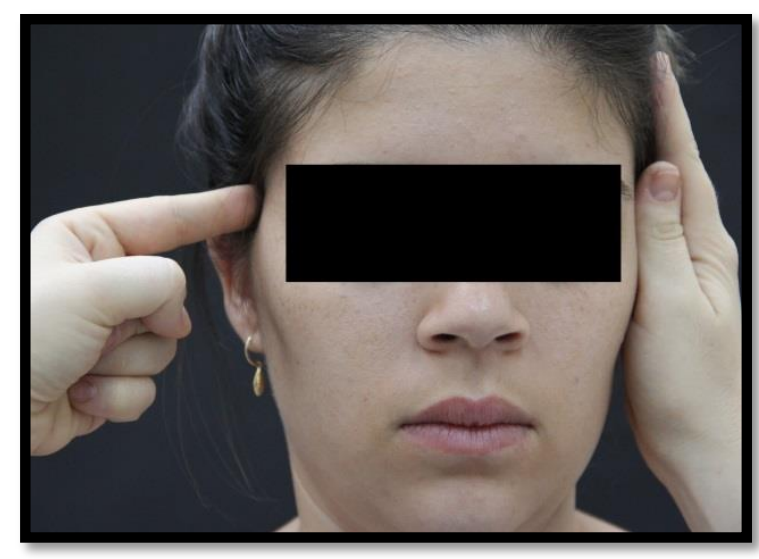

Figura 7 - Palpação manual do fascículo anterior do músculo temporal em uma vista anterior demonstrando a estabilização contralateral da cabeça da voluntária. 


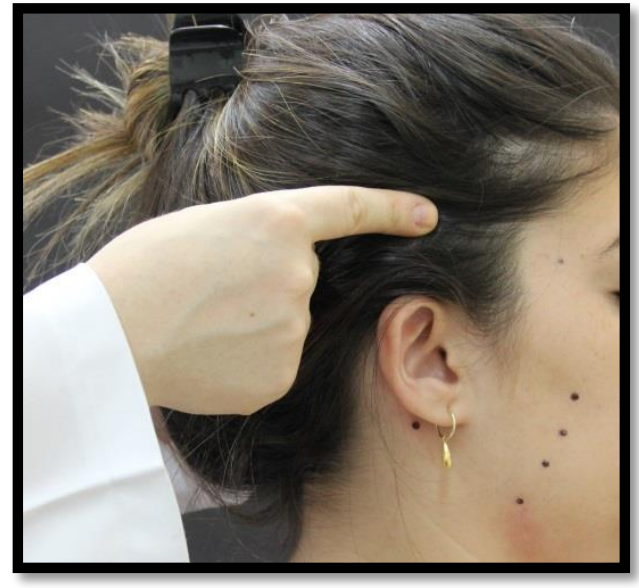

Figura 8 - Palpação manual do fascículo médio do músculo temporal

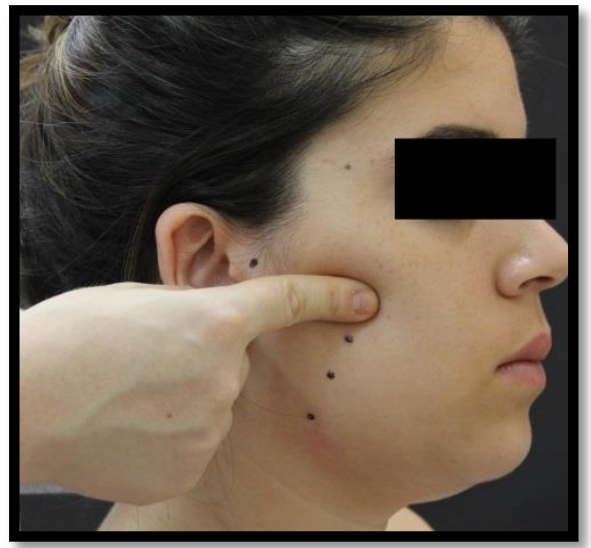

Figura 10 - Palpação manual da origem do músculo masseter.

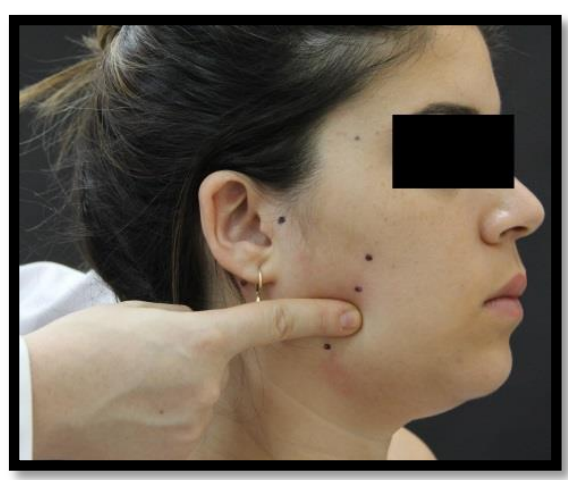

Figura 12 - Palpação manual da inserção do músculo masseter

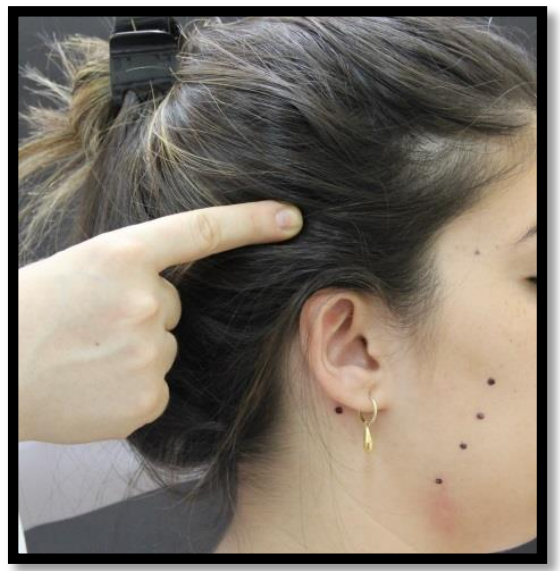

Figura 9 - Palpação manual do fascículo posterior do músculo temporal.

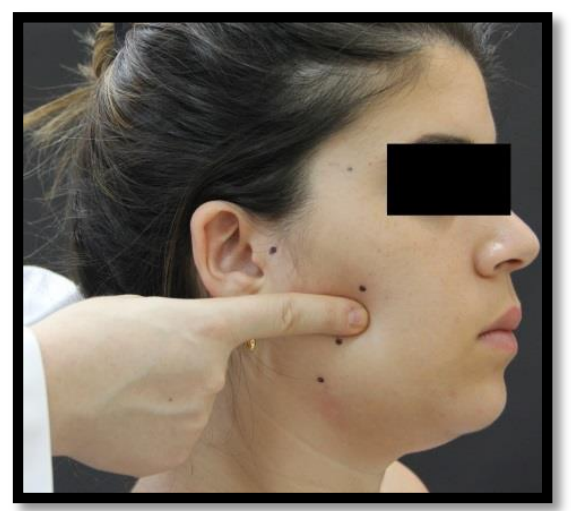

Figura 11 - Palpação manual do ventre do músculo masseter.

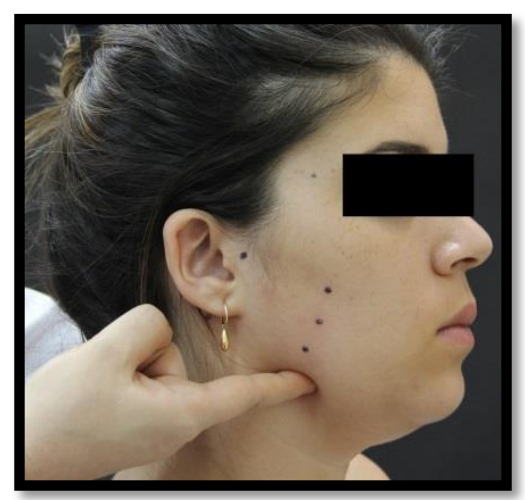

Figura 13 - Palpação manual da região posterior da mandídula (músculo pterigóideo medial) 


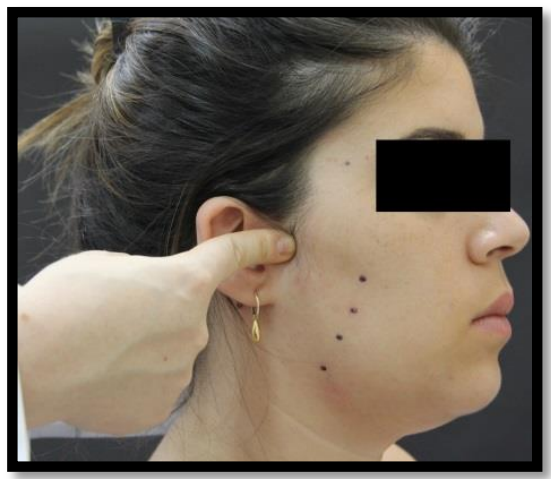

Figura 14 - Palpação manual do pólo lateral da ATM.

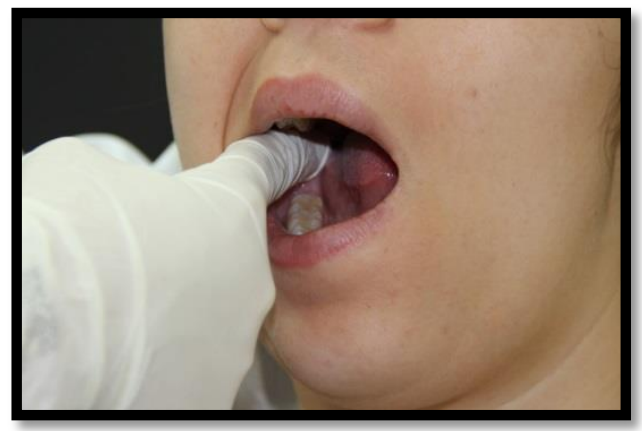

Figura 16 - Palpação manual intra-oral do tendão do temporal.

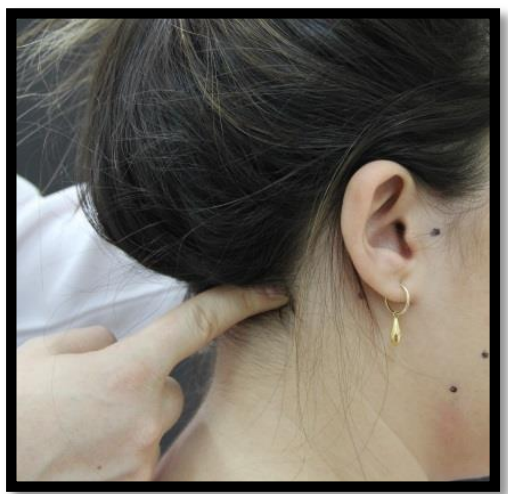

Figura 18 - Palpação manual dos músculos suboccipitais.

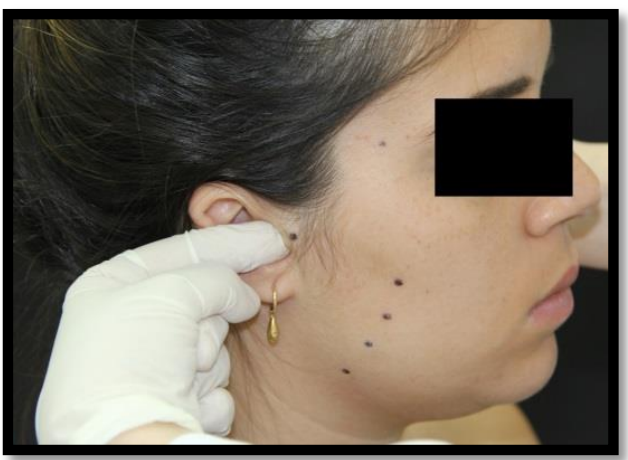

Figura 15 - Palpação manual do pólo posterior da ATM.

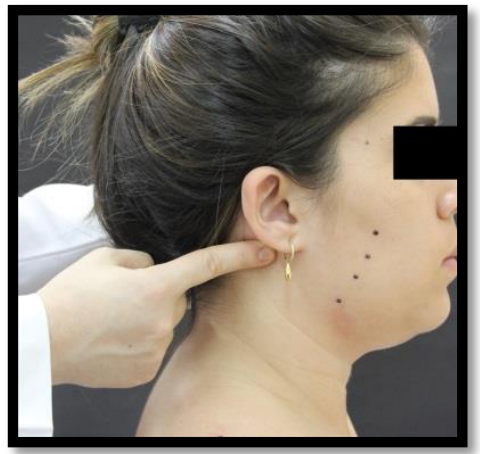

Figura 17 - Palpação manual da inserção do músculo esterneocleidomastóideo.

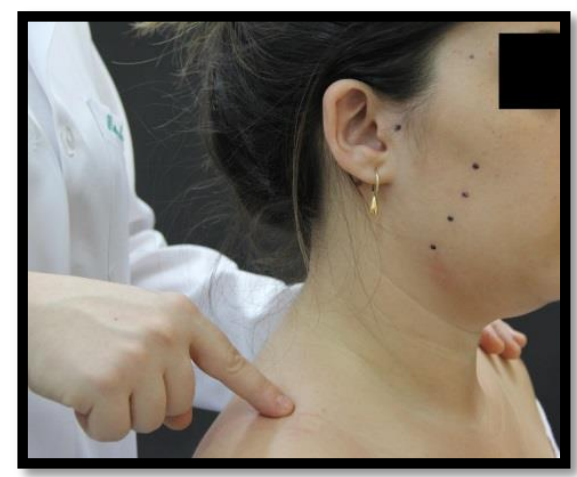

Figura 19 - Palpação manual do ponto médio do músculo trapézio. 
Foram coletados os valores do LDP de dez pontos anatômicos bilateralmente (20 no total) e a região tênar apenas do lado esquerdo, sendo as regiões: 1) Músculo Temporal anterior, 2) Músculo Temporal médio, 3) Músculo Temporal posterior, 4) Músculo Masseter origem, 5) Músculo Masseter ventre, 6) Músculo Masseter inserção, 7) Músculo Esternocleidomastóideo (ECOM) (inserção), 8) Músculo Trapézio médio, 9) Músculo Músculos Suboccipitais e 10) Músculo Frontal

\subsection{Avaliação da postura corporal estática de tronco, cabeça e extremidade superior}

\subsubsection{Coleta das imagens}

Esta etapa foi realizada por apenas um único examinador previamente treinado e cego para obtenção das medidas. As voluntárias foram submetidas aos registros fotográficos no plano frontal anterior e posterior e sagital do tronco superior. Para isso, mulheres em trajes de banho foram posicionadas confortavelmente, relaxadas em posição ortostática com os pés paralelos entre si e os braços ao longo do corpo, no mesmo local e em mesmas condições de iluminação. Os registros fotográficos foram obtidos com uma mesma máquina fotográfica digital (Canon, EOSRebel, Ti3ß), que foi posicionada sobre um tripé fotográfico, cujo centro foi posicionado a uma distância fixa de $4 \mathrm{~m}$ de todas as voluntárias (RAINE e TWOMEY, 1997).

Para as imagens englobarem o corpo todo, o centro da lente da máquina fotográfica foi fixado na altura correspondente ao ponto médio da voluntária, sendo utilizada uma objetiva de 35 mm (NAYLER, 2003; RAINE e TWOMEY, 1997). Já para as fotos do tronco superior, o centro da lente da máquina fotográfica foi posicionado no centro da glabela e foi utilizada uma objetiva de 105 mm (CLAMAN et al., 1990). As imagens foram armazenadas digitalmente para posteriores análises. 
Um fio de prumo foi fixado verticalmente e paralelamente a voluntária, a uma distância fixa de $33 \mathrm{~cm}$ das voluntárias, os quais, foram posicionadas sobre um caixote de madeira de $15 \mathrm{~cm}$ de altura, $40 \mathrm{~cm}$ de comprimento e 30cm de largura (BELLI et al., 2009).

Os pontos anatômicos pré-estabelecidos foram previamente demarcados, por um único avaliador, no corpo das voluntárias da pesquisa, mediante a colocação de demarcadores adesivos de $1 \mathrm{~cm}^{2}$. A identificação dos pontos pode ser observada na tabela 3 e ilustrados pelas figuras 20 , 21,22 e 23.

Tabela 3. Identificação dos pontos anatômicos para demarcação PONTOS ANATÔMICOS

Articulação esternoclavicular

Articulação acrômio clavicular

Espinha ilíaca ântero-superior

Tragus da orelha

Protuberância occipital

Processo espinhoso de C4

Processo espinhoso de C7

Processo espinhoso de T7
Processo espinhoso de T12

Processo espinhoso de L3

Processo espinhoso de L5

Ângulo inferior da escápula

Olécrano da ulna

Espinha ilíaca póstero-superior

Espinha ilíaca póstero-inferior 


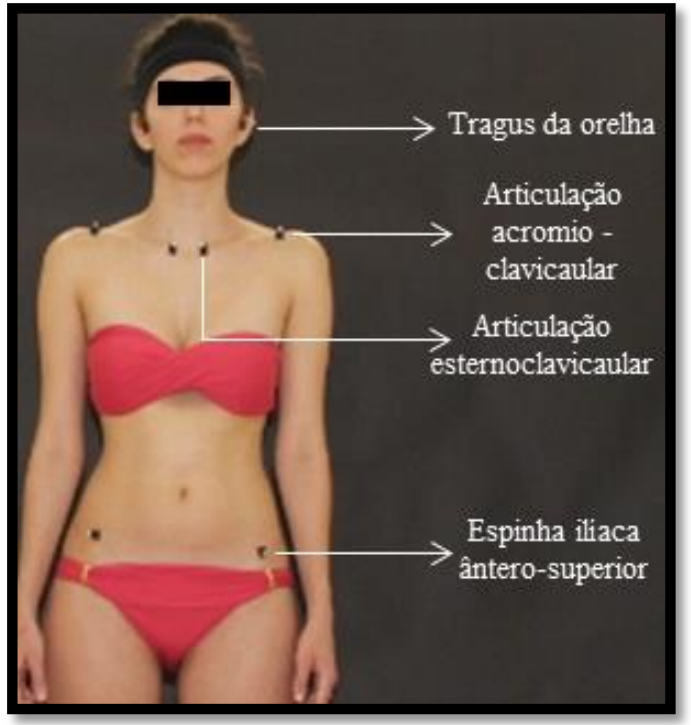

Figura 20 - Identificação dos pontos anatômicos: tragus da orelha; articulação acrômio-clavicular; articulação esternoclavicular; espinha ilíaca ânterosuperior.

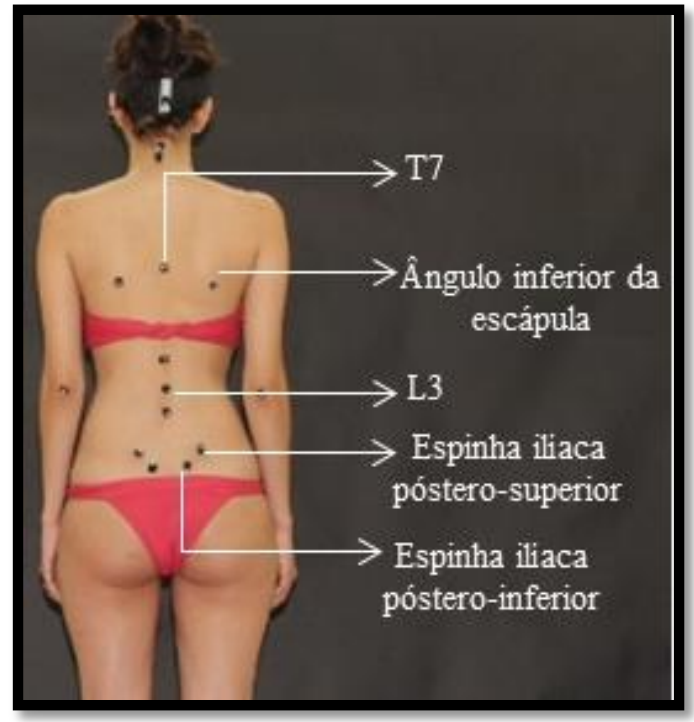

Figura 22 - Identificação dos pontos anatômicos: ângulo inferior da escápula; espinha ilíaca póstero-superior e pósteroinferior; processos espinhosos de T7 e L3.

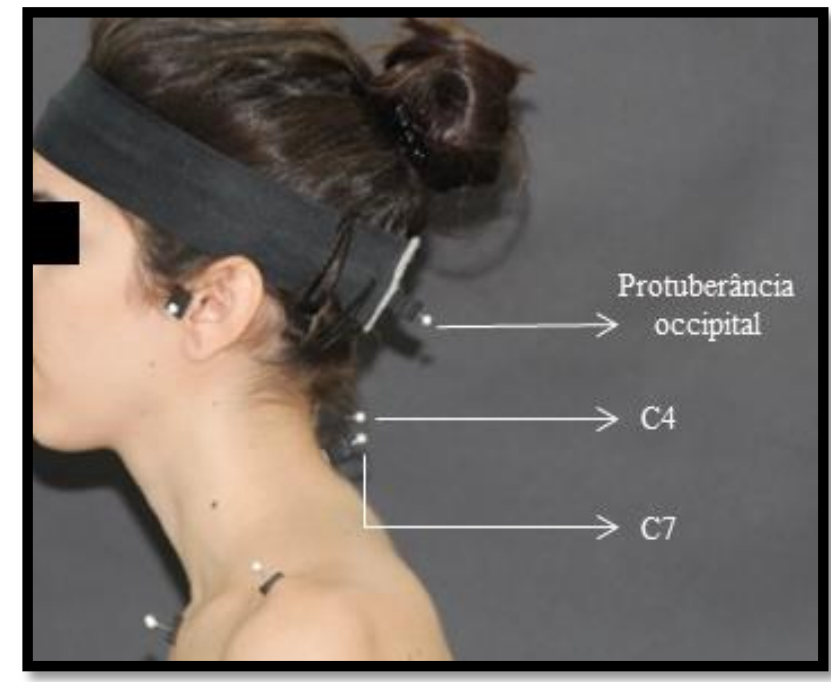

Figura 21 - Identificação dos pontos anatômicos: protuberância occipital; processos espinhosos de C4 e C7.

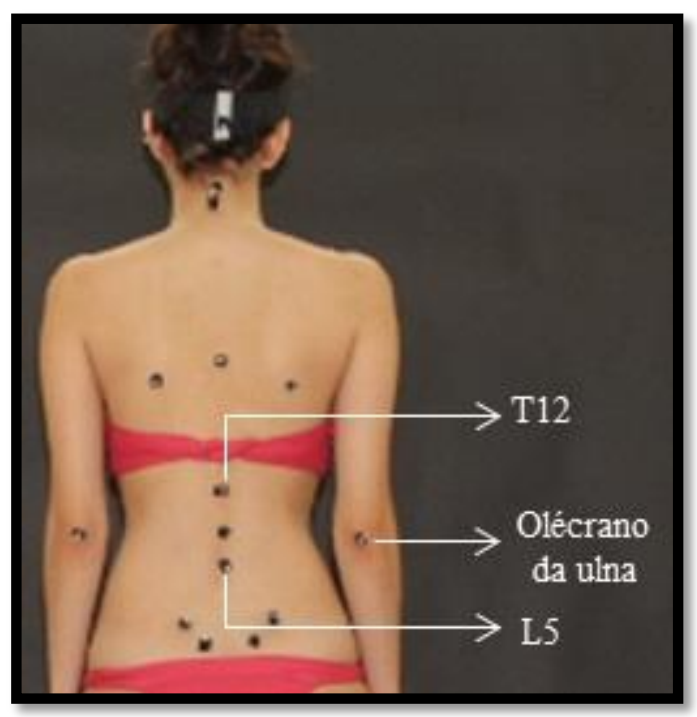

Figura 23 - Identificação dos pontos anatômicos: olecrano da ulna; processos espinhosos de T12 e L5. 


\subsubsection{Análise dos registros fotográficos}

A avaliação quantitativa das imagens foi realizada através do software CorporisPro versão 3.1., com a finalidade de detectar e quantificar simetrias e assimetrias bem como desalinhamentos posturais presentes no corpo de cada voluntário. Esta avaliação foi realizada por um único avaliador, cego para a análise.

As fotos do projeto foram analisadas em um computador Hp Pavilon 23 AiOPCBR, com processador i5 e Windows 8. Foram selecionadas 4 fotos (format JPEG) de cada voluntária, sendo, 1 foto de face anterior, 1 foto no plano frontal vista anterior e 1 na vista posterior, 1 foto no plano sagital. Após o cadastro das fotos no programa, foi realizada a calibração vertical e horizontal de cada foto. Para realizar a calibração foi utilizado zoom de $23 \%$ nas fotos de face anterior e $33 \%$ nas fotos frontais (anterior e posterior) e sagital. Após realizar a calibração vertical a calibração horizontal foi projetada automaticamente. Após esta etapa foram feitas as análises dos ângulos utilizando um zoom de $23 \%$ nas fotos de face e $73 \%$ nas demais. Os ângulos foram formados pelas linhas traçadas a partir dos pontos anatômicos demarcados na paciente. Cada foto foi analisada 3 vezes com um intervalo de um dia entre uma imagem e outra. Foram avaliadas 624 fotos no total.

A análise da confiabilidade intra-examinador dos traçados foi realizada por sorteio de 15 registros dos participantes do estudo. Os traçados foram feitos inicialmente e, em seguida, repetidos após um período de sete dias. As análises foram realizadas sempre pelo mesmo examinador previamente treinado (20 horas de formação) (FERREIRA et al., 2014).

Foram avaliados ao todo 15 ângulos diferentes, assim como descreve o protocolo de Belli et al. (2009). Na imagem da face, os ângulos mensurados estão descritos a seguir e representados através de imagens: 
- $\quad$ Ângulo orbicular externo - OE: formado a partir da linha que liga o ponto orbicular externo da direita com o da esquerda e uma linha traçada na horizontal paralela ao solo;

- $\quad$ Ângulo da comissura labial - CL: formado a partir da linha que liga o ponto da comissura labial da direita com a da esquerda e uma linha traçada na horizontal paralela ao solo (Figura 24);

- $\quad$ Ângulo da articulação esternoclavicular - EC: formado a partir da linha que liga o ponto referente à articulação esternoclavicular direita com a esquerda e uma linha traçada na horizontal paralela ao solo (Figura 25);

- $\quad$ Ângulo da articulação acromioclavicular - AC: formado a partir da linha que liga o ponto referente à articulação acromioclavicular direita com a esquerda e uma linha traçada na horizontal paralela ao solo (Figura 26);

- $\quad$ Ângulo do tragus da orelha - TO: formado a partir da linha que liga o ponto do tragus da orelha da direita com o da esquerda e uma linha traçada na horizontal paralela ao solo (Figura 27)

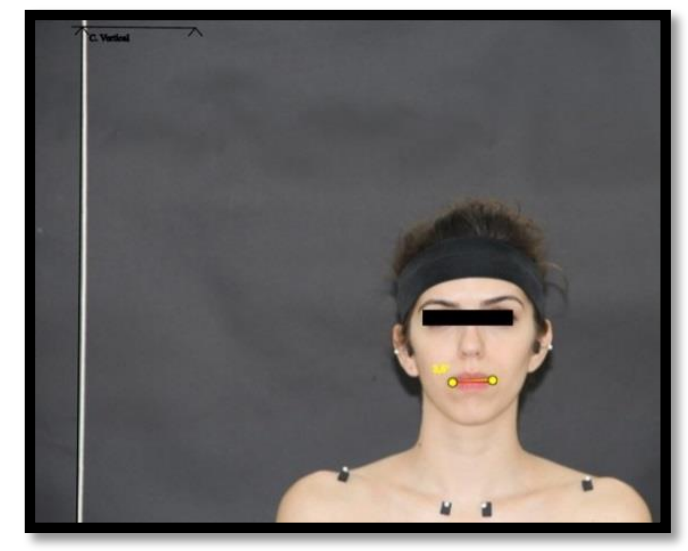

Figura 24 - Ângulo da comissura labial (CL).

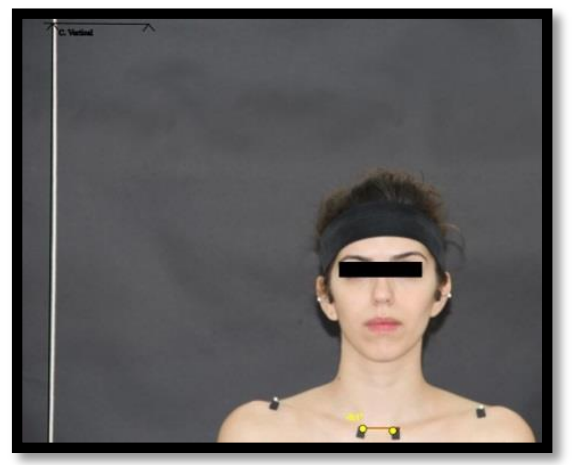

Figura 25 - Ângulo da articulação esternoclavicular (EC). 


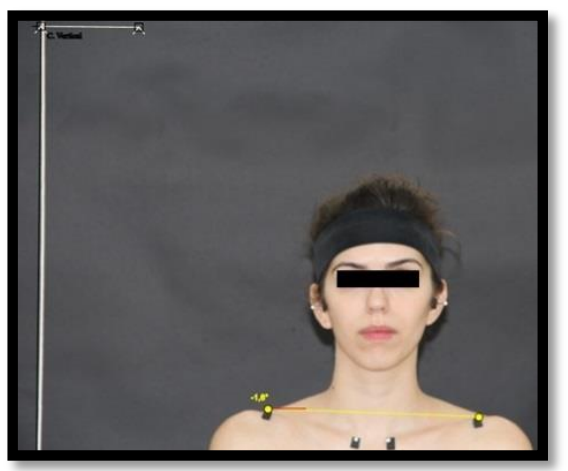

Figura 26 - Ângulo da articulação acromioclavicular (AC).

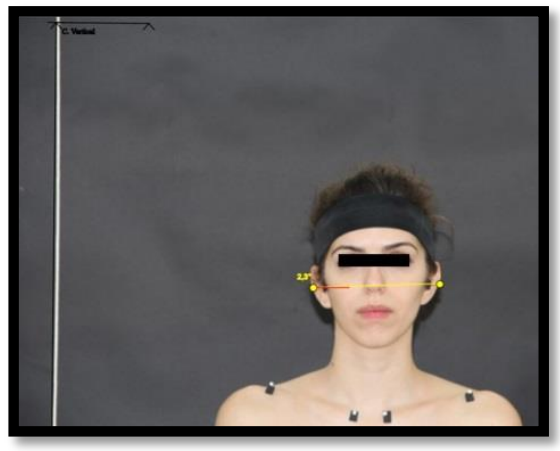

Figura 27 - Ângulo do tragus da orelha (TO).

No plano frontal anterior, os ângulos a serem mensurados estão descritos a seguir e representados através de imagens:

- $\quad$ Ângulo das espinhas ilíacas ântero-superiores (EIAS) - AS: formado a partir da linha que

liga as duas EIAS e uma linha traçada na horizontal paralela ao solo (Figura 28).

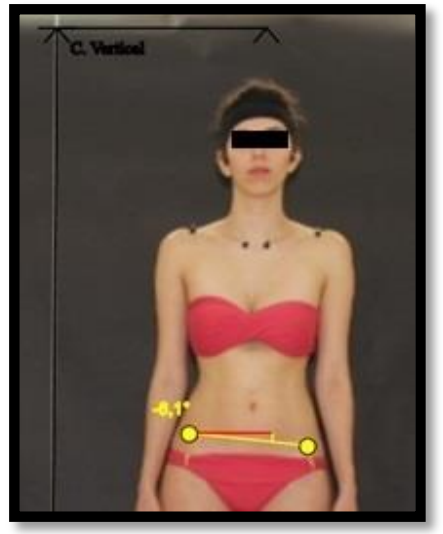

Figura 28 - Ângulo das espinhas ilíacas ântero-superior (AS)

No plano frontal posterior, os ângulos a serem mensurados estão descritos a seguir e representados através de imagens: 
- $\quad$ Ângulo inferior da escápula - IE: formado a partir da linha que liga o ponto referente ao ângulo inferior da escápula direito com o esquerdo e uma linha traçada na horizontal paralela ao solo (Figura 29);

- $\quad$ Ângulo do olécrano da ulna - OU: formado a partir da linha que liga o ponto referente ao centro do olécrano da ulna direita com a esquerda e uma linha traçada na horizontal paralela ao solo (Figura 30);

- $\quad$ Ângulo das espinhas ilíacas póstero-superiores (EIPS) - PS: formado a partir da linha que liga as duas EIPS e uma linha traçada na horizontal paralela ao solo (Figura 31);

- $\quad$ Ângulo das espinhas ilíacas póstero-inferiores (EIPI) - PI: formado a partir da linha que liga as duas EIPI e uma linha traçada na horizontal paralela ao solo (Figura 32);

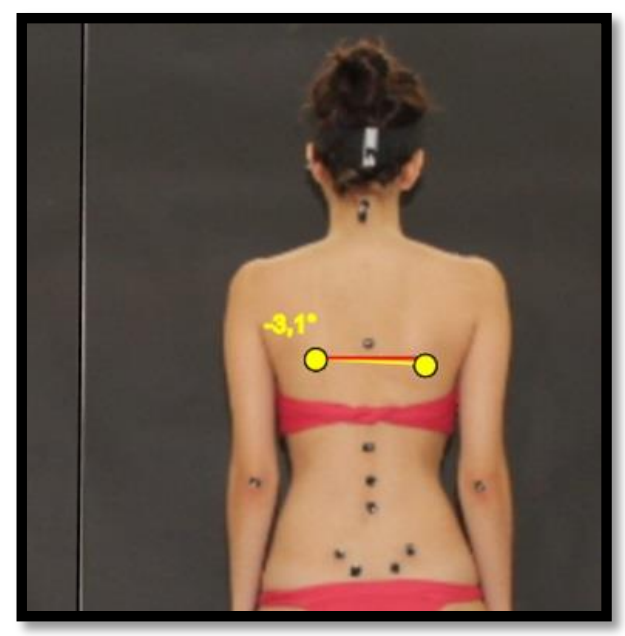

Figura 29 - Ângulo inferior da escápula (IE).

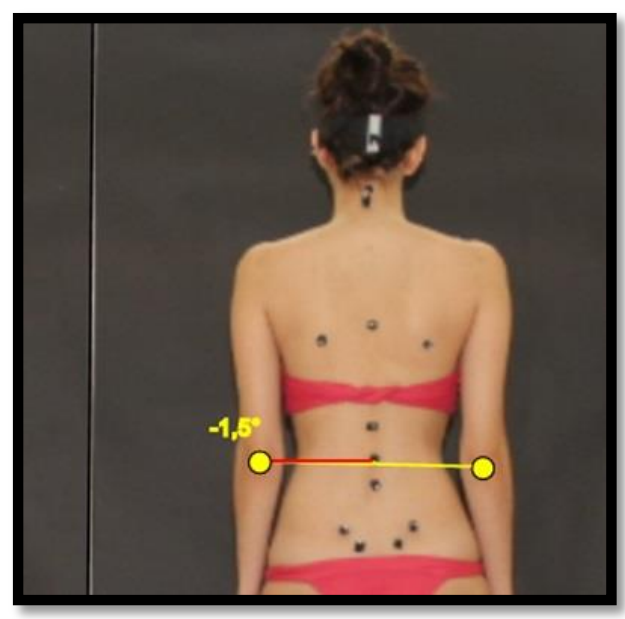

Figura 30 - Ângulo do olecrano da ulna (OU). 


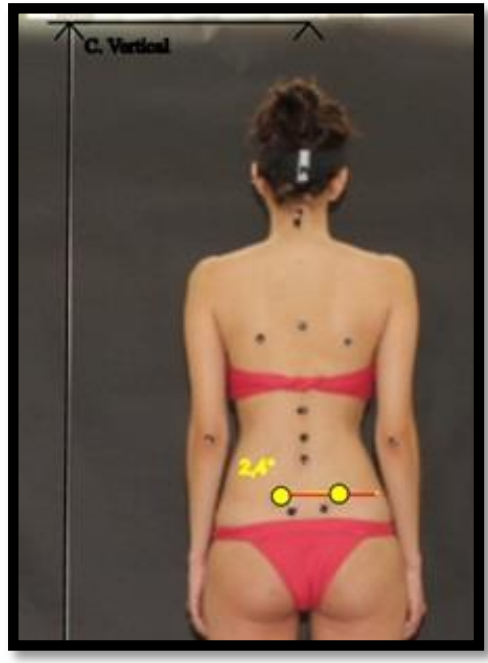

Figura 31 - Ângulo das espinhas ilíacas póstero-superiores (PS).

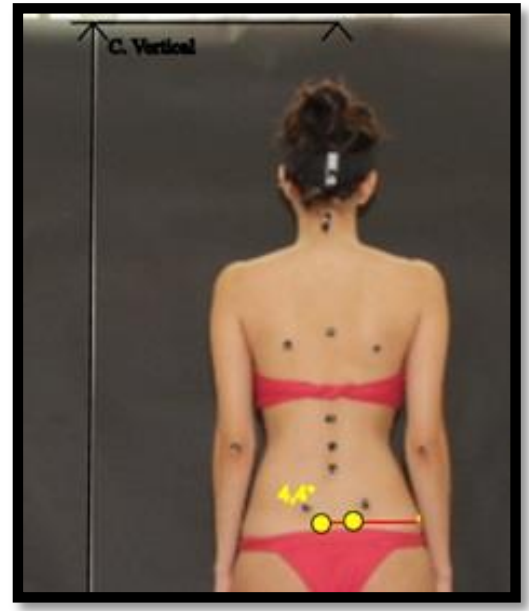

Figura 32 - Ângulo das espinhas ilíacas póstero-inferiores (PI).

No plano sagital, os ângulos a serem mensurados estão descritos a seguir e representados através de imagens:

- $\quad$ Ângulo de protrusão da cabeça - PC: formado pela intersecção entre a reta formada do tragus da orelha até o processo espinhoso de C7 e a reta paralela ao solo (Figura 33);

- $\quad$ Ângulo da báscula pélvica - BP: formado pela intersecção entre a reta formada da EIPI até a EIAS e a reta paralela ao solo (Figura 34);

- $\quad$ Ângulo da lordose cervical - LC: formado pela intersecção entre a reta formada da protuberância occipital até o prolongamento horizontal do processo espinhoso de $\mathrm{C} 4$ até o fio de prumo e a reta formada do processo espinhoso de C7 até o prolongamento horizontal do processo espinhoso de $\mathrm{C} 4$ até o fio de prumo (Figura 35);

- $\quad$ Ângulo da lordose lombar - LL: formado pela intersecção entre a reta formada do processo espinhoso de T12 até o prolongamento horizontal do processo espinhoso de L3 até o fio de prumo e a reta formada do processo espinhoso de L5 até o prolongamento horizontal do processo espinhoso de L3 até o fio de prumo (Figura 36); 
- $\quad$ Ângulo da cifose torácica - CT: formado pela intersecção entre a reta formada do processo espinhoso de $\mathrm{C} 7$ até o prolongamento horizontal do processo espinhoso de T7 até o fio de prumo e a reta formada do processo espinhoso de T12 até o prolongamento horizontal do processo espinhoso de T7 até o fio de prumo (Figura 37).

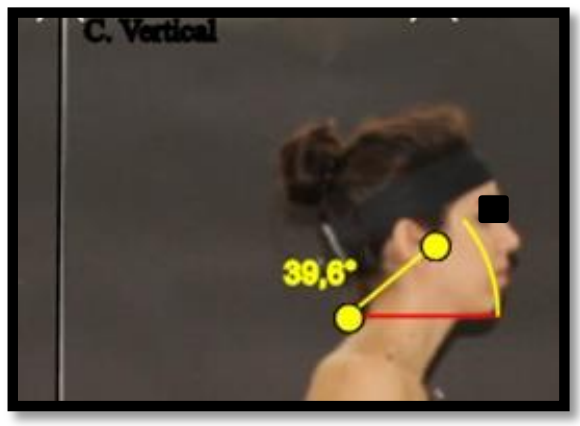

Figura 33 - Ângulo de protusão da cabeça (PC).

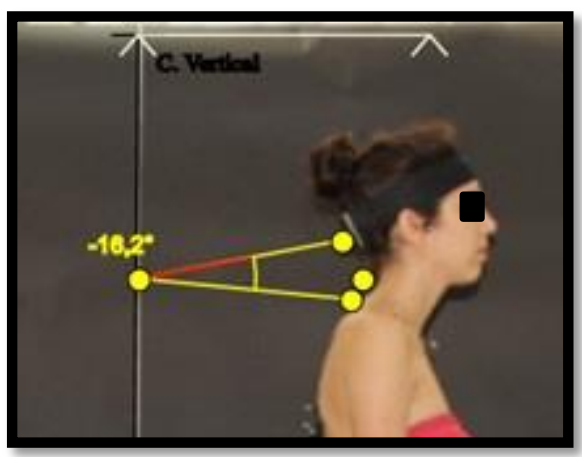

Figura 35 - Ângulo da lordose celvical (LC).

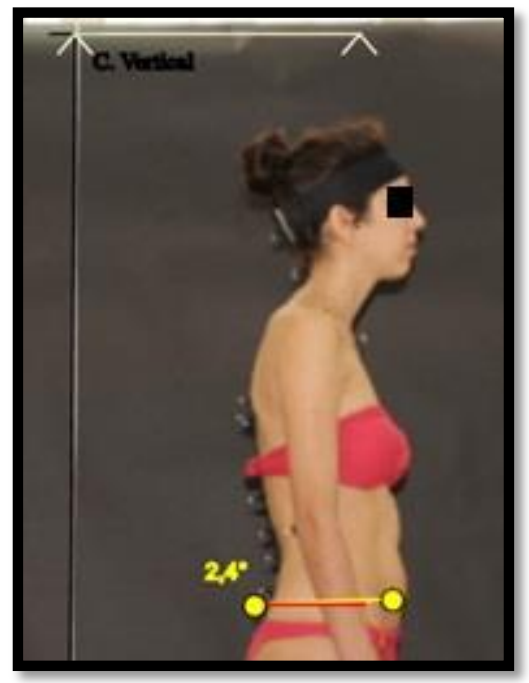

Figura 34 - Ângulo da báscula pélvica (BP).

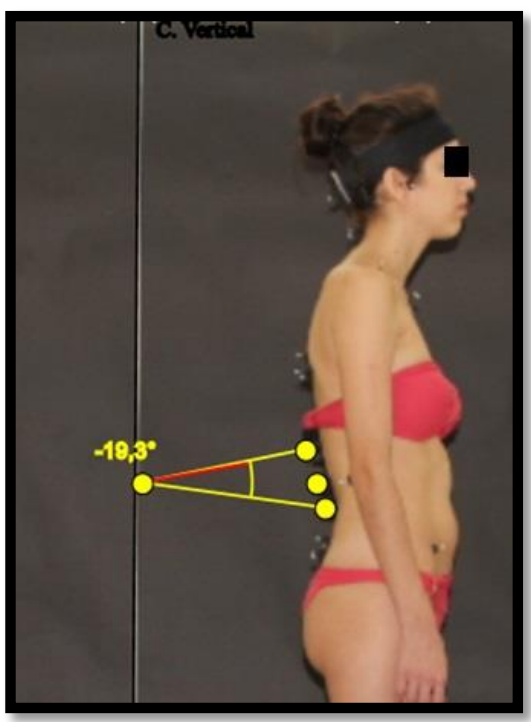

Figura 36 - Ângulo da lordose lombar (LL). 


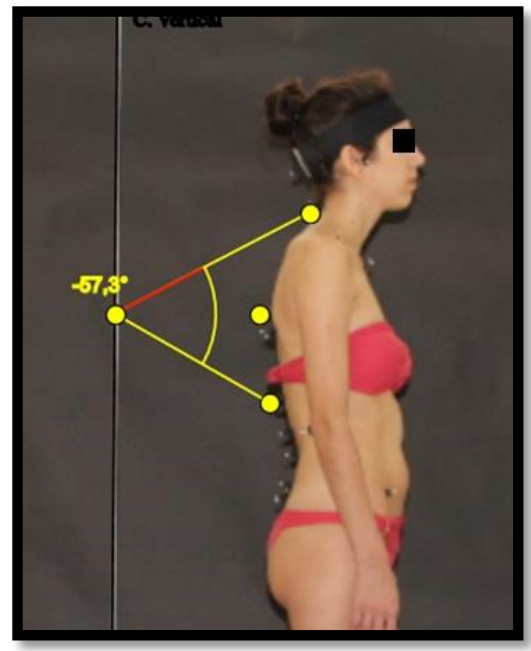

Figura 37 - Ângulo da cifose torácica (CT).

Na tabela 4 estão descritos os ângulos utilizados para quantificação de alterações posturais, bem como os valores de referência observados em publicações prévias (FERREIRA et al., 2014). A presença de alterações posturais será considerada através da diferença nos valores médios angulares entre os grupos com e sem dor cervical. Para os ângulos no plano frontal, quanto mais discrepantes em relação ao valor de $180^{\circ}$ mais acentuada a presença de assimetrias e para os valores no plano sagital serão considerados os valores de referência de publicações prévias (FERREIRA et al., 2014) no qual foram avaliados sujeitos adultos saudáveis, sem queixas de dores musculoesqueléticas. 
Tabela 4 - Descrição dos ângulos, método de obtenção e valores de referência dos ângulos considerados.

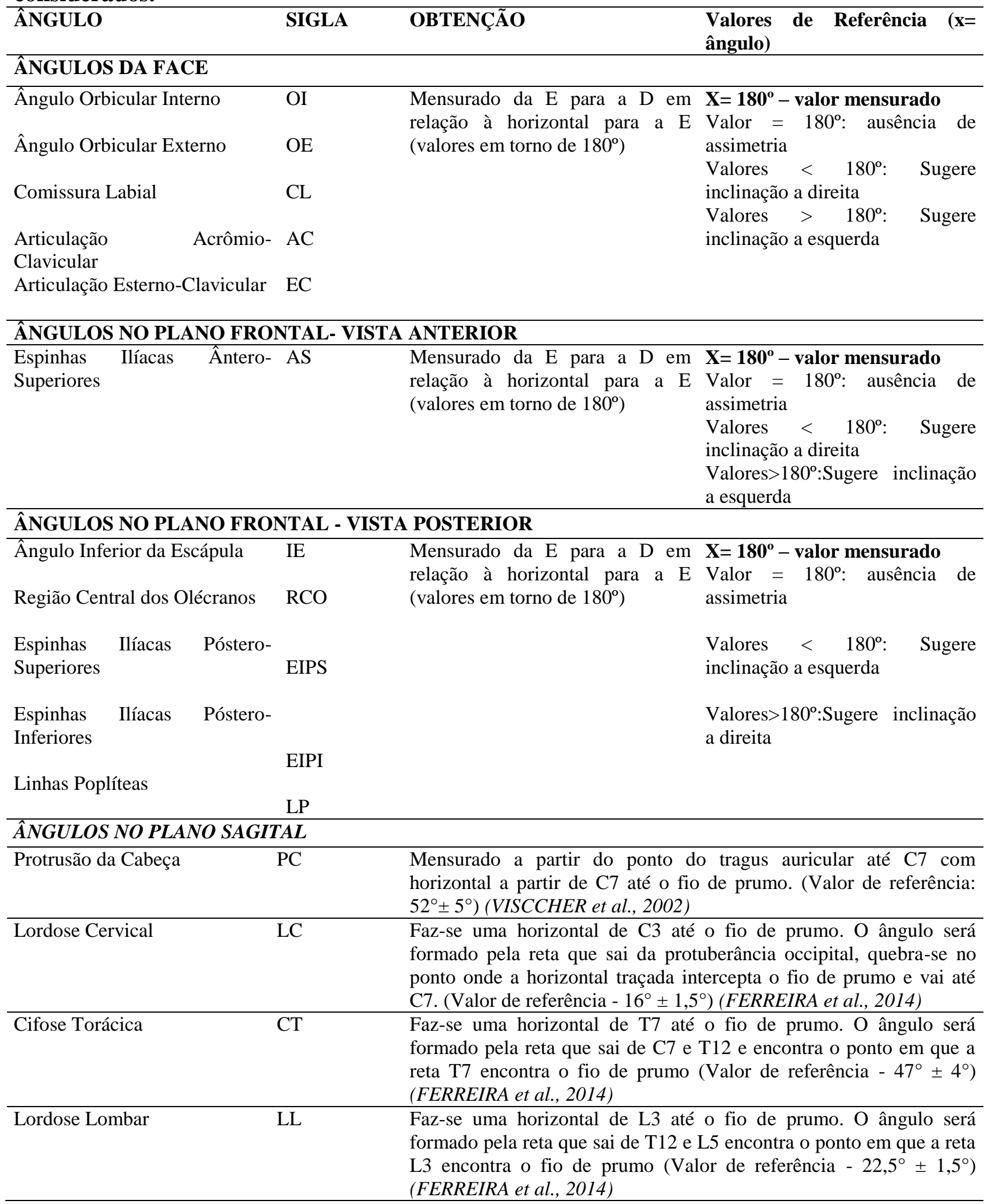




\section{6. Índice de Incapacidade Relacionada à Dor no Pescoço - IIRP (Neck Disability}

\section{Index - ANEXO 3)}

Uma das ferramentas mais utilizadas para avaliação da incapacidade cervical é o Índice de Incapacidade Relacionada à Dor no Pescoço (Neck Disability Index, VERNON et al., 2008) . O IIRP se enquadra nos aspectos de avaliação de funcionalidade e incapacidade recomendados pela Organização Mundial de Saúde (OMS, 2001). Sendo assim, este questionário foi aplicado de forma auto-administrável em todas as voluntárias que relataram dor cervical crônica (Anexo 3).

O IIRP é composto por 10 itens: 1) intensidade dor, 2) Cuidado pessoal, 3) Levantar coisas, 4) Leitura, 5) Dores de Cabeça, 6) Prestar a atenção, 7) Trabalho, 8) Dirigir automóveis, 9) Dormir e 10) Diversão (STERLING e REBBECK, 2005). Foi inicialmente proposto por Vernon e Mior (1991) e a versão adaptada para o português-brasileiro será utilizada (COOK et al., 2006).

As questões do IIRP possuem 6 possíveis repostas com variando entre 0 a 5 . A classificação de incapacidade (alteração mínima detectável é de 5 pontos ou 10\%) é considerada da seguinte maneira:

- $\quad 10-28 \%(5-14$ pontos) - incapacidade leve;

- $\quad 30-48 \%(15-24$ pontos) - incapacidade moderada;

- $\quad 50-68 \%(25-35$ pontos $)$ - incapacidade severa;

- $\quad 72 \%$ ou mais (36 pontos ou mais) - incapacidade completa.

\subsection{Análise estatística}

Os dados demonstraram distribuição normal de acordo com o teste Shapiro Wilks. O teste-t de student para amostras independentes $(\mathrm{p}<0.05)$ foi utilizado para comparar a pontuação máxima 
de cada domínio do MUEQ-Br entre os grupos sem e com dor cervical crônica. Para verificar diferenças entre os valores médios de LDP e palpação muscular entre os grupos de trabalhadores sem dor e com dor cervical crônica e para verificar diferenças entre os ângulos posturais foi utilizado também o teste-t de Student.

Para análise das associações entre as variáveis disfunção temporomandibular, incapacidade relacionada à disfunção cervical, cervicalgia e "aspectos do trabalho" (domínios do MUEQ) foi utilizada a análise de regressão linear múltipla. Foi considerado $\mathrm{p}<0.05$. Para verificação de diferenças entre valores de porcentagem foi utilizado o teste de Qui-quadrado $(\mathrm{p}<0.05)$. Os modelos testados foram: modelo 0 (DTM variável dependente em relação aos preditores "aspectos do trabalho" do MUEQ); modelo 1 (incapacidade variável dependente em relação ao preditores "aspectos do trabalho “ e DTM como independentes); modelo 2 (cervicalgia versus DTM e aspectos do trabalho); modelo 3 (incapacidade como variável dependente em relação à cervicalgia, aspectos do trabalho e DTM) e modelo 4 (DTM variável dependente em relação a incapacidade relacionada à disfunção cervical, cervicalgia e “aspectos do trabalho" (MUEQ)).

O pacote estatístico utilizado foi o SPSS versão 22 (IBM SPSS Statistics for Windows, Version 22.0. Armonk, NY: IBM Corp, 2013). 


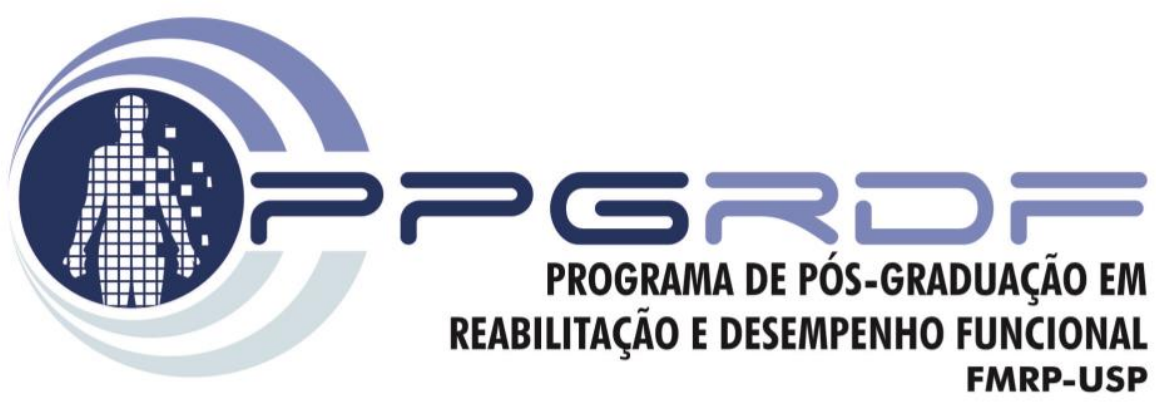

RESULTADOS

"Imaginar é o princípio da criação. Nós imaginamos o que desejamos, queremos o que imaginamos $e$, finalmente, criamos aquilo que queremos".

George Bernard Shaw 


\section{RESULTADOS}

4.1. Avaliação dos aspectos ergonômicos e psicossociais relacionados ao trabalho - MUEQ-Br

Ao comparar a pontuação máxima de cada domínio do MUEQ-Br dos grupos sem e com dor cervical crônica foi verificada pontuação significativamente maior no domínio postura corporal e item queixas no grupo com dor cervical crônica, bem como na pontuação total do questionário (Tabela 5).

Tabela 5- Valores médios e intervalos de confinaça $95 \%$ para a pontuação do MUEQ- Br nos grupos com e sem dor cervical crônica.

Pontuação nos domínios e item Média (IC 95\%)

\begin{tabular}{lccc}
\hline \multicolumn{1}{c}{ Domínios e item } & Pontuação máxima & Sem dor cervical & Com dor cervical crônica \\
\hline Posto de trabalho & 8 pontos & $1.04(0.69-1.39)$ & $1.46(0.93-2.00)$ \\
Postura corporal & 33 pontos & $9.42(8.00-10.84)$ & $12.58(11.21-13.94) *$ \\
Controle do trabalho & 27 pontos & $4.62(3.48-5.75)$ & $4.88(3.64-6.14)$ \\
Demanda do trabalho & 21 pontos & $4.08(2.53-5.63)$ & $4.69(3.18-6.30)$ \\
Pausas & 24 pontos & $5.65(4.28-7.03)$ & $7.77(6.12-9.42)$ \\
Ambiente de trabalho & 27 pontos & $5.31(4.44-6.18)$ & $5.77(4.62-6.92)$ \\
Suporte social & 24 pontos & $3.19(2.42-3.96)$ & $2.92(2.00-3.85)$ \\
Queixas & 55 pontos & $8.58(6.14-11.02)$ & $17.46(14.17-20.75) *$ \\
\hline Total & 219 pontos & $33.31(28.99-37.63)$ & $40.08(35.01-45.15) *$ \\
\hline
\end{tabular}

*test t-student para variáveis contínuas $(\mathrm{p}<0.05)$

IC - Intervalo de Confiança 


\subsection{Classificação quanto aos sinais, sintomas e diagnóstico de DTM}

Foi verificada uma porcentagem maior de trabalhadores com dor cervical crônica que obtiveram algum dos diagnósticos de DTM no RDC/TMD em relação ao grupo sem dor $(42.30 \%$ vs. $23.07 \%)$. Dessa forma, observou-se maior freqüência de DTM no grupo com dor cervical crônica (Tabela 6). Foram observados diagnósticos predominantemente do grupo I (Dor miofascial) em ambos os grupos, entretanto apenas 1 indivíduo obteve diagnóstico do grupo III (artralgia) (tabela 6).

Tabela 6- Classificação diagnóstica dos trabalhadores usuários de computador do grupo sem dor e com dor cervical crônica

\begin{tabular}{lcc}
\hline \multicolumn{1}{c}{ Diagnóstico do RDC } & $\begin{array}{c}\text { Sem dor cervical } \\
(\mathbf{n = 2 6})\end{array}$ & $\begin{array}{c}\text { Com dor cervical } \\
\text { crônica } \\
\text { (n=26) }\end{array}$ \\
\hline Dor miofascial sem limitação na abertura da boca & 2 & 8 \\
$\begin{array}{l}\text { Dor miofascial sem limitação na abertura da boca } \\
\text { /artralgia simples }\end{array}$ & 2 & 2 \\
$\begin{array}{l}\text { Dor miofascial sem limitação na abertura da boca } \\
\text { /artralgia simples / deslocamento do disco com } \\
\text { redução }\end{array}$ & 1 & 0 \\
$\begin{array}{l}\text { Dor miofascial com limitação na abertura da boca/ } \\
\text { osteoartrose da ATM }\end{array}$ & 1 & 0 \\
Artralgia simples & 0 & 1 \\
Total com DTM & $23.07 \%(\mathrm{n}=6)$ & $42.30 \%(\mathrm{n}=11) *$ \\
Total sem DTM & $76.93 \%(\mathrm{n}=20)$ & $57.69(\mathrm{n}=15)$ \\
\hline
\end{tabular}

*Qui- quadrado $(\mathrm{p}<0.05)$

$\mathrm{Na}$ análise dos valores obtidos da intensidade dolorosa através da palpação manual de estruturas do sistema mastigatório, quantificados através da escala numérica de dor $(E N D)$ não foram verificadas diferenças significativas $(p<0.05)$ entre os grupos 
(Tabela 7). O mesmo ocorreu na análise dos valores obtidos através da média das duas medidas do LDP $\left(\mathrm{Kg} / \mathrm{cm}^{2}\right)$ da musculatura da face e região tênar dos grupos sem dor e com dor cervical crônica (Tabela 8).

Tabela 7- Valores médios e intervalo de confiança 95\% (IC 95\%) de intensidade dolorosa à palpação muscular de estruturas orofaciais mensurados através de faces nos grupos sem dor e com dor cervical crônica

\begin{tabular}{|c|c|c|}
\hline Estruturas mastigatórias & $\begin{array}{l}\text { Sem dor (IC 95\%) } \\
(\mathrm{n}=26)\end{array}$ & $\begin{array}{l}\text { Com dor cervical } \\
\text { crônica (IC 95\%) } \\
(\mathrm{n}=\mathbf{2 6})\end{array}$ \\
\hline \multicolumn{3}{|c|}{ Músculo temporal porção anterior } \\
\hline D & $0.62(0.17-1.06)$ & $1.00(0.38-1.62)$ \\
\hline $\mathbf{E}$ & $0.69(0.10-1.29)$ & $1.3(0.66-1.96)$ \\
\hline \multicolumn{3}{|c|}{ Músculo temporal porção media } \\
\hline 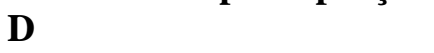 & $0.46(0.02-0.90)$ & $0.58(0.05-1.10)$ \\
\hline $\mathbf{E}$ & $0.42(-0.01-0.86)$ & $0.53(0.13-0.95)$ \\
\hline \multicolumn{3}{|c|}{ Músculo temporal porção posterior } \\
\hline D & $0.35(0-0.69)$ & $0.34(0.04-0.65)$ \\
\hline $\mathbf{E}$ & $0.46(0.05-0.87)$ & $0.5(0.09-0.91)$ \\
\hline \multicolumn{3}{|l|}{ Músculo masseter origem } \\
\hline D & $1.38(0.65-2.11)$ & $1.84(1.23-2.46)$ \\
\hline $\mathbf{E}$ & $1.19(0.58-1.81)$ & $1.46(0.77-2.15)$ \\
\hline \multicolumn{3}{|l|}{ Músculo masseter ventre } \\
\hline D & $1.42(0.77-2.08)$ & $2.19(1.44-2.95)$ \\
\hline $\mathbf{E}$ & $1.92(1.23-2.62)$ & $2.31(1.64-2.98)$ \\
\hline \multicolumn{3}{|l|}{ Músculo masseter inserção } \\
\hline D & $1.31(0.62-1.99)$ & $1.96(1.15-2.77)$ \\
\hline $\mathbf{E}$ & $1.42(0.63-2.22)$ & $1.65(0.98-2.33)$ \\
\hline \multicolumn{3}{|c|}{ Região posterior da mandíbula } \\
\hline D & $0.73(0.26-1.20)$ & $1.03(0.42-1.66)$ \\
\hline $\mathbf{E}$ & $1.38(0.56-2.21)$ & $0.73(0.25-1.21)$ \\
\hline \multicolumn{3}{|c|}{ Região submandibular (Supra-hióideos) } \\
\hline D & $0.19(-0.03-0.41)$ & $0.15(-0.08-0.39)$ \\
\hline $\mathbf{E}$ & $0.31(-0.12-0.74)$ & $0.19(-0.05-0.44)$ \\
\hline \multicolumn{3}{|l|}{ ATM pólo lateral } \\
\hline D & $0.88(0.21-1.56)$ & $0.88(0.33-1.44)$ \\
\hline $\mathbf{E}$ & $0.92(0.22-1.63)$ & $0.61(0.22-1.01)$ \\
\hline \multicolumn{3}{|l|}{ ATM pólo posterior } \\
\hline D & $0.19(-0.18-0.57)$ & $0.07(-0.07-0.23)$ \\
\hline $\mathbf{E}$ & $0.27(-0.26-0.80)$ & $0.11(-0.11-0.34)$ \\
\hline \multicolumn{3}{|l|}{ Músculo pterigóideo lateral } \\
\hline D & $2.23(1.37-3.09)$ & $2.19(1.51-2.87)$ \\
\hline $\mathbf{E}$ & $2.35(1.44-3.26)$ & $2.42(1.70-3.15)$ \\
\hline \multicolumn{3}{|c|}{ Tendão do músculo temporal } \\
\hline D & $1.92(1.23-2.62)$ & $1.50(0.68-2.32)$ \\
\hline $\mathbf{E}$ & $1.81(1.05-2.57)$ & $1.57(0.88-2.27)$ \\
\hline
\end{tabular}


Tabela 8 - Valores médios e intervalo de confiança $95 \%$ dos valores de LDP $\left(\mathrm{kg} / \mathrm{cm}^{2}\right)$ da musculatura orofacial e região tênar dos grupos sem dor e com dor cervical crônica

\begin{tabular}{lll}
\hline \multicolumn{1}{c}{ Estruturas } & Sem dor cervical & Com cervical crônica \\
\hline \multicolumn{1}{c}{ Lado direito } & & \\
\hline Masseter origem & $1.66(1.45-1.87)$ & $1.54(1.37-1.72)$ \\
Masseter ventre & $1.50(1.31-1.68)$ & $1.48(1.30-1.67)$ \\
Masseter inserção & $1.54(1.33-1.74)$ & $1.43(1.25-1.62)$ \\
Temporal anterior & $2.07(1.77-2.37)$ & $1.76(1.52-2.00)$ \\
Temporal médio & $2.31(2.01-2.61)$ & $2.06(1.78-2.34)$ \\
Temporal posterior & $2.40(2.10-2.70)$ & $2.34(2.02-2.66)$ \\
Frontal & $2.33(2.08-2.59)$ & $2.21(1.92-2.50)$ \\
\hline \multicolumn{1}{c}{ Lado esquerdo } & & \\
\hline & & \\
Masseter origem & $1.56(1.40-1.72)$ & $1.44(1.27-1.62)$ \\
Masseter ventre & $1.41(1.25-1.57)$ & $1.39(1.24-1.55)$ \\
Masseter inserção & $1.49(1.32-1.67)$ & $1.41(1.22-1.61)$ \\
Temporal anterior & $2.02(1.76-2.28)$ & $1.83(1.61-2.04)$ \\
Temporal médio & $2.31(2.00-2.61)$ & $1.97(1.76-2.19)$ \\
Temporal posterior & $2.38(1.98-2.78)$ & $2.07(1.79-2.35)$ \\
Frontal & $2.37(2.11-2.63)$ & $2.23(1.89-2.58)$ \\
Região tênar & $4.03(3.33-4.72)$ & $3.58(3.18-3.98)$ \\
& & \\
\hline teste t-student para variáveis contínuas $(\mathrm{p}<0.05)$ & \\
& & \\
\end{tabular}

Não foram verificadas diferenças significativas para os valores de amplitude de movimento mandibular entre os grupos sem e com dor cervical crônica (tabela 9). 
Tabela 9 - Valores médios e intervalo de confiança $95 \%$ de amplitude de movimento mandibular $(\mathrm{mm})$ de ambos os grupos (sem dor e com dor cervical crônica)

\section{Amplitude movimento mandibular (mm)}

Sem dor cervical

$$
(\mathbf{n}=\mathbf{2 6})
$$

\section{Com dor cervical crônica \\ $(\mathbf{n}=\mathbf{2 6})$}

Máxima abertura passiva

$$
\begin{array}{cc}
51.22(49.42-53.01) & 51.30(49.26-53.33) \\
1.31(0.76-1.86) & 1.54(0.99-2.08) \\
& \\
0.15(-0.08-0.39) & 0.19(-0.07-0.46)
\end{array}
$$

Máx. abertura passiva - dor $1.31(0.76-1.86) \quad 1.54(0.99-2.08)$

muscular

Máx. abertura passiva - dor

articular

Máxima abertura ativa

$49.00(47.07-50.94)$

$49.52(47.44-51.59)$

Máx. abertura ativa - dor muscular

$0.50(0.10-0.90)$

$0.12(-0.11-0.34)$

$0.73(0.24-1.22)$

$3.25(2.80-3.70)$

0

Overbite

$3.44(2.99-3.89)$

$3.07(2.61-3.53)$

$8.26(7.26-9.26)$

$3.29(2.80-3.78)$

Desvio lateral direito

$9.01(8.07-9.95)$

$8.70(7.64-9.76)$

Desvio lateral esquerdo

$3.65(3.08-4.22)$

$8.94(7.98-9.90)$

$4.03(3.26-4.81)$

\subsection{Resultados da avaliação dos sintomas de disfunção cervical}

Ao observar à intensidade de dor relativa à palpação manual nas estruturas cervicais, foram observados valores de intensidade de dor significativamente maiores para os músculos, trapézio (ponto médio) lado direito e suboccipitais lado direito e esquerdo no grupo com dor cervical crônica. Porém ao compararmos os valores do LDP, não foram observadas diferenças significativas entre os grupos (tabela 10). 
Tabela 10 - Valores médios e intervalo de confiança $95 \%$ da intensidade de dor obtida através da palpação manual e limiar de dor por pressão na avaliação de músculos cervicais nos grupos sem dor e com dor cervical crônica

\begin{tabular}{|c|c|c|}
\hline $\begin{array}{l}\text { Intensidade de dor* dos } \\
\text { músculos cervicais }\end{array}$ & $\begin{array}{l}\text { Sem dor cervical } \\
(n=26)\end{array}$ & $\begin{array}{c}\text { Com dor cervical } \\
\text { crônica } \\
(\mathbf{n}=\mathbf{2 6})\end{array}$ \\
\hline \multicolumn{3}{|l|}{ Intensidade de dor } \\
\hline \multicolumn{3}{|l|}{ Trapézio (ponto médio) } \\
\hline $\mathrm{D}$ & $1.46(0.69-2.23)$ & $4.03(3.02-5.06) *$ \\
\hline $\mathrm{E}$ & $1.85(0.87-2.82)$ & $2.76(1.74-3.80)$ \\
\hline \multicolumn{3}{|l|}{$\begin{array}{l}\text { Esternocleidomastoideo } \\
\text { (inserção) }\end{array}$} \\
\hline $\mathrm{D}$ & $1.23(0.37-2.10)$ & $1.69(0.78-2.61)$ \\
\hline $\mathrm{E}$ & $0.73(0.13-1.33)$ & $1.23(0.58-1.88)$ \\
\hline \multicolumn{3}{|l|}{ Suboccipitais } \\
\hline $\mathrm{D}$ & $1.00(0.42-1.58)$ & $2.58(1.64-3.51) *$ \\
\hline $\mathrm{E}$ & $1.00(0.46-1.54)$ & $2.15(1.21-3.09) *$ \\
\hline \multicolumn{3}{|l|}{$\begin{array}{c}\text { Limiar de dor por pressão } \\
\left(\mathrm{kg} / \mathrm{cm}^{2}\right)\end{array}$} \\
\hline \multicolumn{3}{|l|}{ Trapézio (ponto médio) } \\
\hline $\mathrm{D}$ & $2.67(2.22-3.11)$ & $2.33(1.95-2.70)$ \\
\hline $\mathrm{E}$ & $2.57(2.21-2.94)$ & $2.47(2.05-2.89)$ \\
\hline \multicolumn{3}{|l|}{$\begin{array}{l}\text { Esternocleidomastoideo } \\
\text { (inserção) }\end{array}$} \\
\hline $\mathrm{D}$ & $1.87(1.62-2.12)$ & $1.92(1.66-2.18)$ \\
\hline $\mathrm{E}$ & $1.80(1.56-2.05)$ & $1.82(1.53-2.12)$ \\
\hline \multicolumn{3}{|l|}{ Suboccipitais } \\
\hline $\mathrm{D}$ & $2.01(1.75-2.27)$ & $1.85(1.58-2.12)$ \\
\hline $\mathrm{E}$ & $1.99(1.71-2.28)$ & $1.93(1.67-2.20)$ \\
\hline
\end{tabular}

\subsection{Avaliação da postura corporal}

Não foram verificadas diferenças significativas $(p<0.05)$ entre os ângulos em todos os planos analisados entre os grupos sem e com dor cervical crônica na análise relativa à avaliação postural (tabela 11$)$. 
Tabela 11 - Valores médios e intervalos de confinaça 95\% dos ângulos (em graus) de avaliação postural obtidos nas fotografias dos planos frontal e sagital dos grupos sem dor e com dor cervical crônica

\begin{tabular}{|c|c|c|}
\hline Ângulos & $\begin{array}{c}\text { Sem dor cervical } \\
(n=26)\end{array}$ & $\begin{array}{l}\text { Com dor cervical crônica } \\
(n=26)\end{array}$ \\
\hline \multicolumn{3}{|l|}{ Ângulos do plano frontal - face] } \\
\hline Ângulo orbicular externo - OE & $\begin{array}{l}178.81(178.06- \\
179.56)\end{array}$ & $179.49(178.79-180.20)$ \\
\hline Comissura labial - CL & $\begin{array}{l}178.62(177.72- \\
179.51)\end{array}$ & $178.82(178.10-179.54)$ \\
\hline Articulação esterno clavicular - EC & $\begin{array}{c}180.04(178.49- \\
181.58)\end{array}$ & $179.02(177.25-180.80)$ \\
\hline $\begin{array}{l}\text { Articulação acrômio clavicular - } \\
\text { AC }\end{array}$ & $\begin{array}{l}179.27(178.42- \\
180.11)\end{array}$ & $178.70(177.90-179.50)$ \\
\hline Ângulo tragus da orelha - TO & $\begin{array}{c}178.60(177.90- \\
179.29)\end{array}$ & $178.77(177.98-179.56)$ \\
\hline
\end{tabular}

\begin{tabular}{lcc}
\hline $\begin{array}{l}\text { Ângulos do plano frontal - } \\
\text { vista anterior }\end{array}$ & & \\
\hline Espinhas ilíacas ântero - superiores & $180.28(179.58-$ & $179.94(178.97-180.90)$ \\
- EIAS & $180.58)$ & \\
& &
\end{tabular}

\begin{tabular}{|c|c|c|}
\hline \multicolumn{3}{|l|}{$\begin{array}{l}\text { Ângulos do plano frontal - } \\
\text { vista posterior }\end{array}$} \\
\hline Ângulos inferiores da escápula - IE & $180(178.55-181.45)$ & $180.39(178.78-182)$ \\
\hline $\begin{array}{l}\text { Angulação do olécrano da ulna - } \\
\text { OU }\end{array}$ & $\begin{array}{c}180.26(179.57- \\
180.96)\end{array}$ & $180.71(180-181.41)$ \\
\hline $\begin{array}{l}\text { Espinhas ilíacas póstero - } \\
\text { superiores - EIPS }\end{array}$ & $\begin{array}{c}179.54(177.68- \\
181.40)\end{array}$ & $180.67(179.64-181.70)$ \\
\hline $\begin{array}{l}\text { Espinhas ilíacas póstero - } \\
\text { inferiores - EIPI }\end{array}$ & $\begin{array}{c}179.94(177.60- \\
182.28)\end{array}$ & $177.33(174.85-179.80)$ \\
\hline \multicolumn{3}{|l|}{ Ângulos do plano sagittal } \\
\hline Protrusão da cabeça - PC & $41.77(40.16-43.37)$ & $42.21(40.61-43.80)$ \\
\hline Lordose cervical - LC & $14.25(12.70-15.81)$ & $14.84(13.58-16.11)$ \\
\hline Cifose torácica - CT & $61.87(60.00-63.74)$ & $60.07(58.02-62.13)$ \\
\hline Lordose lombar - LL & $12.81(11.69-13.92)$ & $11.87(10.74-13.00)$ \\
\hline Báscula pélvica - BP & $\begin{array}{c}185.78(183.23- \\
188.32)\end{array}$ & $186.41(184.55-188.27)$ \\
\hline
\end{tabular}

teste t-student para variáveis contínuas $(\mathrm{p}<0.05)$

Foram verificadas as associações entre a incapacidade cervical, a disfunção temporomandibular, o relato de cervicalgia e os aspectos relacionados ao trabalho (pontuação dos domínios do MUEQ-Br). Foram testados alguns modelos considerando 
a incapacidade cervical como variável dependente, a cervicalgia e a disfunção temporomandibular como independentes. Quando a DTM foi considerada variável dependente em relação aos preditores "aspectos do trabalho" o modelo observado não se mostrou significativo $\left(\mathrm{R}=0.48, \mathrm{R}^{2}=0.24, \mathrm{p}=0.13\right)$, além disso, a variável "controle no trabalho" foi excluída do modelo.

Quando a incapacidade relacionada à cervicalgia foi considerada variável dependente em relação aos preditores "aspectos do trabalho" e DTM (modelo 1) foi observada uma associação significativa entre os fatores com $\mathrm{R}^{2}=0.53(\mathrm{p}<0.001)$. No modelo 1 apenas os preditores postura $(\beta=0.31, \mathrm{p}=0.05)$ e queixas $(\beta=0.50, \mathrm{p}=$ 0.001) mostraram-se significativos individualmente. No entanto, a retirada dos demais preditores levou a redução nos valores do coeficiente de determinação do modelo (Tabela 12).

O modelo 2 (Cervicalgia versus DTM e aspectos do trabalho) também mostrouse significativo, entretanto foi observado $u m R^{2}=0.36$, demonstrando que a capacidade de explicação dos preditores do modelo 2 foram menores do que a capacidade de explicação do modelo 1. Além disso, no modelo 2 apenas o preditor queixas manteve-se significativo individualmente $(\beta=0.43, \mathrm{p}=0.01)$. No entanto, a retirada dos demais preditores levou a redução nos valores do coeficiente de determinação $\left(\mathrm{R}^{2}\right)$ do modelo (Tabela 12). No modelo 3, em que a incapacidade foi considerada variável dependente em relação à cervicalgia, total do MUEQ-Br (aspectos de trabalho) e DTM o $\mathrm{R}^{2}=0.93 \mathrm{e}$ todos os preditores mostraram-se significativos no modelo (Tabela 12). Já no modelo 4, em que a DTM foi considerada variável dependente em relação a incapacidade relacionada à disfunção cervical, cervicalgia e "aspectos do trabalho", novamente o $\mathrm{R}^{2}=$ 0.30. No entanto, este modelo não se mostrou significativo. 
Tabela 12 - Descrição dos dados obtidos na Análise de regressão linear múltipla entre incapacidade cervical, a disfunção temporomandibular (DTM), o relato de cervicalgia e os aspectos relacionados ao trabalho (pontuação dos domínios e item do MUEQ-Br) (n=52).

\begin{tabular}{|c|c|c|c|c|c|}
\hline Preditores Regressão & $\mathrm{R}$ & $\mathrm{R}^{2}$ & $\mathrm{R}^{2}$ ajustado & Erro padrão & $\begin{array}{c}\text { Teste } \mathrm{F} \\
\text { (ANOVA) }\end{array}$ \\
\hline \multicolumn{6}{|c|}{ Modelo 1 - Incapacidade vs. condições do trabalho e DTM } \\
\hline & 0.73 & 0.53 & 0.45 & 12.82 & $\mathrm{P}<0.001$ \\
\hline & $\begin{array}{c}\text { Coeficiente } \\
\beta\end{array}$ & $\begin{array}{l}\text { t-test } \\
\text { (valor } \\
\text { p) }\end{array}$ & $\begin{array}{c}\text { Intervalo de } \\
\text { confiança } 95 \% \\
\text { do coeficiente } \beta\end{array}$ & & \\
\hline Posto & 0.07 & 0.66 & $-5,65-8,86$ & & \\
\hline Postura & 0.31 & 0.05 & $0.01-5.01$ & & \\
\hline Demanda & -0.10 & 0.94 & $-2,77-2.56$ & & \\
\hline Pausa & 0.17 & 0.26 & $-0,98-3,55$ & & \\
\hline Ambiente & -0.51 & 0.73 & $-4,22-3.00$ & & \\
\hline Suporte & 0.12 & 0.94 & $-2,01-5.52$ & & \\
\hline Queixas & 0.50 & 0.001 & $0.81-2.78$ & & \\
\hline DTM & 0.16 & 0.19 & $-5.36-26.19$ & & \\
\hline Preditores Regressão & $\mathrm{R}$ & $\mathrm{R}^{2}$ & $\mathrm{R}^{2}$ ajustado & Erro padrão & $\begin{array}{c}\text { Teste } \mathrm{F} \\
\text { (ANOVA) }\end{array}$ \\
\hline \multicolumn{6}{|c|}{ Modelo 2 - Cervicalgia vs. DTM e condições do trabalho } \\
\hline & 0.61 & 0.36 & 0.25 & 0.63 & 0.01 \\
\hline & $\begin{array}{c}\text { Coeficiente } \\
\beta\end{array}$ & $\begin{array}{l}\text { t-test } \\
\text { (valor } \\
\text { p) }\end{array}$ & $\begin{array}{c}\text { Intervalo de } \\
\text { confiança } 95 \% \\
\text { do coeficiente } \beta\end{array}$ & & \\
\hline Posto & 0.05 & 0.77 & $-0,12-0.15$ & & \\
\hline Postura & 0.35 & 0.06 & $-0,01-0.09$ & & \\
\hline Demanda & -0.01 & 0.97 & $-0.05-0.05$ & & \\
\hline Pausa & 0.07 & 0.66 & $-0.03-0.05$ & & \\
\hline Ambiente & -0.11 & 0.56 & $-0.08-0.05$ & & \\
\hline Suporte & 0.02 & 0.89 & $-0.06-0.07$ & & \\
\hline Queixas & 0.43 & 0.01 & $0.05-0.04$ & & \\
\hline DTM & 0.10 & 0.46 & $-0.19-0.41$ & & \\
\hline Preditores Regressão & $\mathrm{R}$ & $\mathrm{R}^{2}$ & $\mathrm{R}^{2}$ ajustado & Erro padrão & $\begin{array}{c}\text { Teste } \mathrm{F} \\
\text { (ANOVA) }\end{array}$ \\
\hline \multicolumn{6}{|c|}{ Modelo 3 - Incapacidade vs. DTM e cervicalgia e condições de trabalho } \\
\hline & 0.96 & 0.92 & 0.92 & 8.70 & 0.0001 \\
\hline & $\begin{array}{c}\text { Coeficiente } \\
\beta\end{array}$ & $\begin{array}{c}\text { t-test } \\
(\text { valor } \mathrm{p})\end{array}$ & $\begin{array}{l}\text { Intervalo de } \\
\text { confiança } \\
95 \% \text { do } \\
\text { coeficiente } \beta\end{array}$ & & \\
\hline $\begin{array}{l}\text { Pontuação Total do } \\
\text { MUEQ }\end{array}$ & 0.27 & $p<0.0001$ & $0.46-0.87$ & & \\
\hline Dor cervical & 0.83 & $p<0.0001$ & $46.72-57.14$ & & \\
\hline DTM & 0.08 & 0.04 & $0.12-10.95$ & & \\
\hline
\end{tabular}




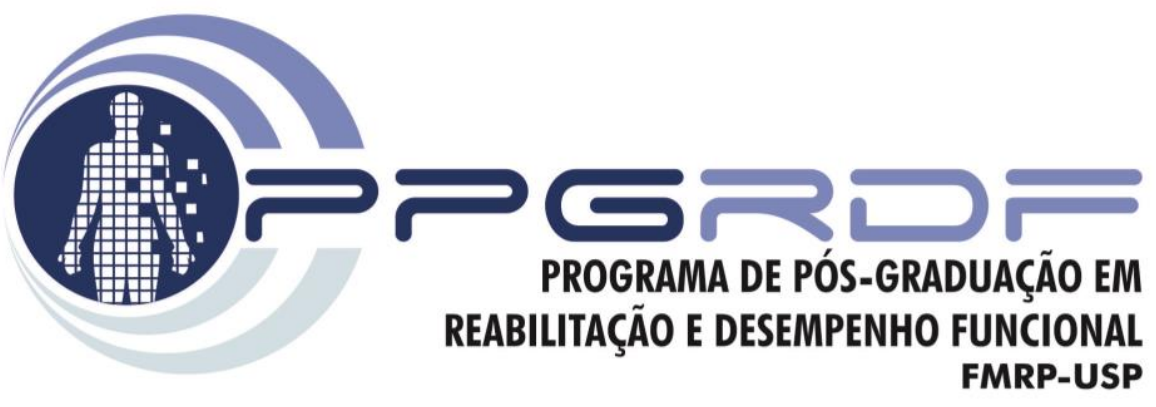

\section{DISCUSSÃO}

"Nenhuma pergunta é tão difícil de se responder quanto aquela cuja resposta é óbvia". 


\section{DISCUSSÃO}

O objetivo central deste estudo foi verificar associações entre dor cervical, disfunção temporomandibular e alterações na postura estática em trabalhadores de escritório usuários de computador com e sem relato de dor cervical crônica.

Os demais objetivos foram: 1) Verificar diferenças nos aspectos físicos e psicossocias relacionados ao trabalho no computador entre trabalhadores com e sem queixa de dor cervical crônica; 2) Verificar a presença de disfunção temporomandibular entre trabalhadores de escritório com e sem queixa de dor cervical crônica; 3) Avaliar a postura corporal estática dos trabalhadores de escritório com e sem queixa de dor cervical crônica; 4) Avaliar o limiar de dor por pressão (LDP) nos músculos mastigatórios e cervicais nos trabalhadores de escritório com e sem queixa de dor cervical crônica; 5) Avaliar associações entre aspectos das condições de trabalho, alteração de postura e dor cervical e DTM.

\subsection{Avaliação de aspectos físicos e psicossocias relacionados ao trabalho}

Ao aplicar o MUEQ-Br para avaliação dos aspectos fisicos e psicossociais relacionados ao trabalho observamos maior pontuação no domínio postura corporal e item queixas, bem como a pontuação total do questionário no grupo com dor cervical crônica, sugerindo que a dor cevical está associada a percepção de má postura pelos trabalhadores, bem como associada a presença geral de queixas musculoesqueléticas.

Ariëns (2001) realizaram um estudo por três anos com mais de 1334 funcionários e observaram que há uma forte relação entre o período sentado no trabalho 
por horas e dor cervical de modo que se o trabalhador está na posição sentado por mais de $95 \%$ de suas horas de trabalho, a probabilidade de sofrer dor no pescoço aumenta.

Resultados mostram também que a duração de tempo de uso do computador pode ter impacto sobre a incidência de dor no pescoço (NEJATI et al., 2014). Além disso, a alta variabilidade motora pode ser um fator de prevenção para cronificação de sintomas. Trabalhadores que realizam tarefas com padrões de movimento mais estereotipados, como os trabalhadores usuários de computador, podem ter mais risco de desenvolver lesões musculoesqueléticas (COTÉ, 2012). Ressalta-se ainda que as mulheres parecem ser mais suceptíveis a estes fatores e essa associação entre variabilidade de postura e cronificação da dor parece ser particularmente relevante para desordens do pescoço e do ombro (COTÉ, 2012).

Paksaichol et al. (2012) relataram que os fatores de risco relacionados ao trabalho, como uso acumulado do computador, ficar sentado por longos períodos ou com a postura da cabeça para a frente, e uma estação de trabalho ruim ergonomicamente, têm sido associados ao aumento do risco de dor no pescoço, além disso os autores relatam que alguns problemas psicossociais, como a alta tensão, alta demanda de trabalho, estresse no trabalho e baixo suporte do colega no trabalho, também tem sido associada com dor no pescoço.

\subsection{Disfunção temporomandibular e dor cervical em trabalhadores usuários de computador}

A maior frequência de diagnósticos de DTM nos trabalhadores com relato de dor cervical crônica (42.30\% em relação a $23.07 \%$ para o grupo sem relato de dor cervical) confirma a hipótese inicial deste estudo de associação entre a presença de DTM e dor 
cervical em trabalhadores usuários de computador. Na literatura há inúmeros estudos demonstrando a associação entre a DTM e as disfunções da coluna cervical (DCC) (STIESCH-SCHOLZ et al., 2003; ARMIJO-OLIVO et al., 2006; BEVILAQUAGROSSI et al., 2007; KRAUS 2007; OLIVO et al., 2010; ARMIJO-OLIVO et al., 2011; ARMIJO-OLIVO; MAGEE, 2013). Entretanto, ainda não é possível através da literatura existente na atualidade estabelecer as relações de causa e efeito entre essas disfunções (LA TOUCHE et al., 2014).

Dentre as possíveis hipóteses que podem explicar tal associação há mecanismos neurofisiológicos, relacionados à convergência de aferências dos neurônios do núcleo caudal do trigêmeo e das raízes nervosas de C2 e C3 na cervical, denominada de “complexo trigêmino-cervical”. Ou seja, a informação nociceptiva resultante da região cervical pode ter sido transmitida por neurônios trigeminais, devido à convergência nociceptiva no complexo trigêmino-cervical entre fibras nervosas cervicais e trigeminais, resultando em dor difusa na região orofacial (BENDTSEN, 2000).

Outro fator que pode justificar nossos resultados, é que as posturas do pescoço também podem levar alterações na postura da mandíbula e alterações na atividade da musculatura mastigatória (GONZALEZ; MANNS, 1996; VISSCHER et al., 2000; ARMIJO-OLIVO, 2006). Este aspecto encontra amparo no fato de que os trabalhadores com dor cervical deste estudo apresentaram maior pontuação no item postura do questionário MUEQ-Br. Rocabado (1983) considera que há um equilíbrio de forças entre a musculatura extensora cervical, a musculatura mastigatória (especificamente os músculos supra-hióideos) e a musculatura flexora anterior para manutenção da postura da cabeça. Além disso, estudos recentes têm demonstrado uma associação entre redução de endurance dos músculos cervicais flexores e extensores e DTM (ARMIJO-OLIVO et al., 2010, ARMIJO-OLIVO et al., 2011), sugerindo possíveis associações entre 
fadigabilidade da musculatura cervical, que pode estar relacionada à sobrecarga dessa musculatura imposta pela manutenção de posturas inadequadas prolongadas nos usuários de computador, e o desenvolvimento de dor na região craniocervical.

Nossas estimativas estão acima das relatadas por Nishiyama et al. (2012b) que observaram uma prevalência de sintomas de DTM de 16.4 em trabalhadores de uma empresa de componentes eletrônicos. Diferenças em nossos achados podem estar atreladas ao fato de que os autores consideraram uma amostra de trabalhadores no geral, e em nosso estudo consideramos apenas usuários de computador no setor administrativo. Além disso, controlamos a presença de dor cervical e o gênero dos participantes deste estudo.

\subsection{Limiar de dor por pressão (LDP) e palpação manual para avaliação de estruturas crânio-cervicais em trabalhadores de escritório usuários de computador}

Em nosso estudo, ao observarmos os resultados referentes à dor relativa à palpação manual e LDP na região nas estrututuras crânio-cervicais, foram verificadas diferenças entre os grupos de trabalhadores com e sem dor cervical apenas para a palpação manual. Ao observar a intensidade de dor relativa à palpação manual nas estruturas cervicais, foram observados valores de intensidade de dor significativamente maiores para os músculos trapézio e suboccipitais no grupo com dor cervical crônica. Porém, ao compararmos os valores do LDP, não foram observadas diferenças significativas entre os grupos.

Alguns achados na literatura não confirmam nossos resultados. Um estudo prévio investigou as alterações no LDP do trapézio superior, elevador da escápula e 
rombóide durante o trabalho no computador, mostrando que o LDP do trapézio superior reduziu significativamente após 15 minutos de atividade envolvendo uso do computador (YOO, 2013). Em outro estudo os autores verificaram redução do LDP do músculo trapézio, também logo após atividade no computador (YOO e YOO, 2013). Entretanto, nenhum trabalho foi verificado em que as estruturas orofaciais tenham sido avaliadas.

Poucos trabalhos adotaram a análise da palpação manual e LDP para avaliação da dor em trabalhadores usuários de computador com queixa inicial musculoesquelética em relação a um grupo sem queixa. Nossos resultados demonstraram que a palpação manual foi mais sensível para detectar diferenças entre os grupos de trabalhadores com e sem dor cervical de forma mais localizada (músculos cervicais), no entanto, os valores de LDP não mostraram diferenças entre os trabalhadores com e sem dor cervical.

Assim, a ausência de diferenças observadas em nosso estudo entre trabalhadores usuários de computador sintomáticos e assintomáticos para dor cervical pode sugerir que ambos os grupos já apresentem alterações relacionadas à percepção de dor local na região do pescoço, uma vez que os valores médios observados para ambos os grupos podem ser considerados, de forma especulativa, baixos já que a literatura relata valores em média de 3 a $3,5 \mathrm{~kg} / \mathrm{cm}^{3}$ sujeitos saudáveis (JOHNSTON et al., 2008) e em nosso estudo verificamos valores em média de $2 \mathrm{~kg}$. Além disso, podemos sugerir que o grupo com dor está mais perceptivel ao sintoma de dor, o que justifica o resultado apenas para a palpação. Tais achados também podem ser explicados pela sensibilização de nociceptores locais nos trabalhadores usuários de computador independentemente do relato de dor cervical (sugerindo sinais de hiperalgesia primária), mas também pode estar relacionada à presença de trigger points nestes locais (JONHSTON et al., 2008; VISSER AND VAN DIEE“N, 2006). Discordando de nossos achados, Levoska (1993) comparou um grupo de mulheres trabalhadoras de escritório com dor cervical em 
relação a um grupo de trabalhadoras sem sintomas cervicais e observaram maior número de tender points no grupo com dor cervical e menores valores de LDP.

Assim, é possível que em relação a um grupo controle sem queixas de dor cervical fosse observada diminuição do LDP das estruturas cervicais e orofaciais de trabalhadores usuários de computador. Assim, é possível que trabalhadores mesmo assintomáticos para a dor cervical já apresentem sinais subclínicos de disfunção cervical, sugerindo que mesmo na ausência de sintomas cervicais ou orofaciais é possível que as alterações que levam ao desenvolvimento destas disfunções já estejam ocorrendo. Especialmente, considerando que ambos os grupos estão expostos aos mesmos contextos que poderiam predispor a queixas de disfunção musculoesquelética. Nossos achados não são confirmados por Jonhston et al. (2008) já que os limiares térmicos, mecânicos e vibratórios mostraram-se significativamente menores no grupo com dores cervicais mais incapacitantes (maior pontuação no Neck Disability Index) em relação aos trabalhadores sem relato de dor cervical e grupo controle, e não foram constatadas diferenças entre os grupos de trabalhadores sem queixa de dor cervical e grupo controle.

\subsection{Avaliação da Postura Corporal}

Nossos resultados não mostraram diferenças significativas entre os ângulos utilizados para avaliação da postura corporal estática em trabalhadores com e sem dor cervical crônica. Nossos achados foram parcialmente confirmados por Nejati et al. (2014). Os autores compararam a postura da cabeça, ombro, cervical e torácica alta em individuos trabalhadores usuários de computador com e sem dor cervical através da análise fotográfica nas posturas sentada em duas circunstâncias: uma com o trabalhador 
olhando para frente em um ponto fixo e outra com o trabalhador realizando suas atividades de trabalho. Foi verificada alteração da postural corporal para os ângulos de protrusão de cabeça e Ângulo de Cifose Torácica entre os grupos apenas para as análises realizadas na postura utilizada no trabalho, mas não nas análises realizadas em postura estática.

Outro estudo realizado por Lau (2010) que também avaliaram indivíduos com e sem dor cervical através da fotogrametria na postura sentada, observaram alterações da postura sagital da coluna torácica e cervical e dor no pescoço nos indivíduos com dor cervical em relação aos assintomáticos. Os participantes com dor cervical apresentaram maior ângulo de Cifose Torácica superior (medido entre a linha horizontal do processo espinhoso de T7 e uma linha ligando o processo espinhoso de T7 e C7) em comparação com as pessoas sem dor cervical. Szeto et al. (2002) também verificaram alterações da postura da cabeça (FHP) de $10 \%$ entre a postura adotada no posto de trabalho e uma postura estática padronizada.

Assim, uma das possíveis explicações para a ausência de diferenças observadas em nosso estudo pode estar relacionada ao fato de termos avaliado os trabalhadores em uma postura ortostática padronizada e não na sua posição de trabalho. Assim, é possível que a postura inadequada utilizada no ambiente de trabalho não seja efetivamente incorporada no esquema corporal dos trabalhadores que utilizam computadores na postura sentada. Outro aspecto ainda é que não consideramos neste estudo um grupo controle de indivíduos que não trabalhem na postura sentada e assintomáticos para dor cervical. É possível que alterações de postura estejam presentes de igual forma entre trabalhadores usuários com e sem dor cervical. Estas hipóteses podem ser especuladas observando-se os dados de Nejati et al. (2014), já que os ângulos de protrusão de cabela (Forward Head Posture - FHP) mostraram-se menores (em média $37^{\circ}$ ) em relação aos 
dados observados na literatura para sujeitos saudáveis $\left(50^{\circ}\right.$ a $\left.57^{\circ}\right)$ (VISSCHER et al., 2002; ARMIJO-OLIVO et al., 2011). Ratificando nossas suposições, Yip et al. (2008) verificaram diferenças na FHP em sujeitos com dor cervical em relação a controles

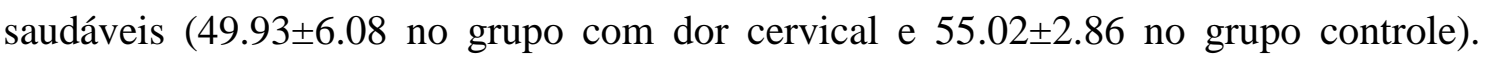
Entretanto os autores não consideraram o tipo de trabalho como critério de inclusão.

Na literatura existem evidências que associam a postura estática prolongada a aumento da sobrecarga musculoesquelética e subsequente aumento do risco de desenvolvimento de sintomas musculoesqueléticos na extremidade superior (SZETO et al., 2002). A FHP é comumente adotada em trabalhadores de escritório usuários de computador e pode envolver uma combinação de flexão cervical inferior e extensão da cervical superior, bem como ombros protrusos (com protrusão e elevação da escápula). Entretanto, a literatura ainda não conseguiu determinar uma clara relação de causa e efeito entre postura e dor cervical. Há evidências sugerindo que a flexão da coluna cervical possa resultar em cargas compressivas sobre a cervical e como consequência provocar respostas de distensão dos tecidos (HARMS-RINGDAHL et al., 1986). Esta sobrecarga nos músculos e articulações da região cervical pode resultar em uma postura em FHP e pode ser um fator contribuinte para o desenvolvimento de distúrbios osteomioarticulares relacionados ao trabalho (DORT) em trabalhadores usuários de computadores (SZETO et al., 2002).

5.5.Associações entre aspectos do trabalho, disfunção temporomandibular e dor no pescoço nos trabalhadores usuários de computador

Ao verificarmos a influência dos preditores disfunção temporomandibular, cervicalgia e os aspectos relacionados ao trabalho (pontuação total do MUEQ-Br) na 
incapacidade cervical dos trabalhadores com e sem queixa de dor cervical, foi observado uma forte associação entre os fatores, especialmente entre cervicalgia e incapacidade cervical. Além disso, todos os preditores mostraram-se significativos no modelo inclusive a DTM. Estes achados confirmam a hipótese inicial de associação entre DTM e cervicalgia, especificamente em relação à influência da presença de DTM na incapacidade relacionada à dor cervical. Alguns autores têm demonstrado que fatores do ambiente de trabalho estão associados ao relato de dor cervical (WAHLSTRÖM et al., 2004), além disso, os fatores psicossociais também parecem exercer influência (HUSH et al., 2009).

Não foram encontrados na literatura estudos que tenham verificado a associação entre cervicalgia, incapacidade cervical, DTM e aspectos do trabalho em trabalhadores usuários de computador. Em um dos poucos estudos encontrados em que foi verificada associação entre DTM e aspectos do trabalho envolvendo computador, Nishiyama et al. (2012a) relataram um odds ratio para sintomas de DTM de 2.23 quando o fator "uso do computador por mais de 2 horas diárias" foi considerado. Em um dos modelos testados o domínio postura do MUEQ-Br e o item queixas demonstraram contribuir para a incapacidade relacionada à dor cervical $\left(\mathrm{R}^{2}=0.53\right)$. Em concordância com nossos achados, Cagnie et al. (2007) relataram associações significativas entre dor cervical e manutenção da postura FHP por tempo prolongado $(\mathrm{OR}=2.01)$ e manter-se na postura sentada por tempo prolongado $(\mathrm{OR}=2.06)$. 


\subsection{Limitações do estudo}

Como limitações deste estudo podemos citar a dificuldade na formação dos grupos $(n=26)$, pois mesmo com uma gama de questionários selecionados, muitas trabalhadoras não aceitaram participar da pesquisa ou aceitaram, porém durante a avaliação foram excluídas por não se adequarem completamente a todos os critérios estabelecidos. Sendo assim, avaliamos 96 voluntárias, mas apenas 52 delas preencheram todos os critérios de inclusão.

O grupo controle não foi inserido no estudo, já que nos dias de hoje com o avanço da tecnologia dificilmente encontraríamos voluntárias que não utilizassem o computador. 


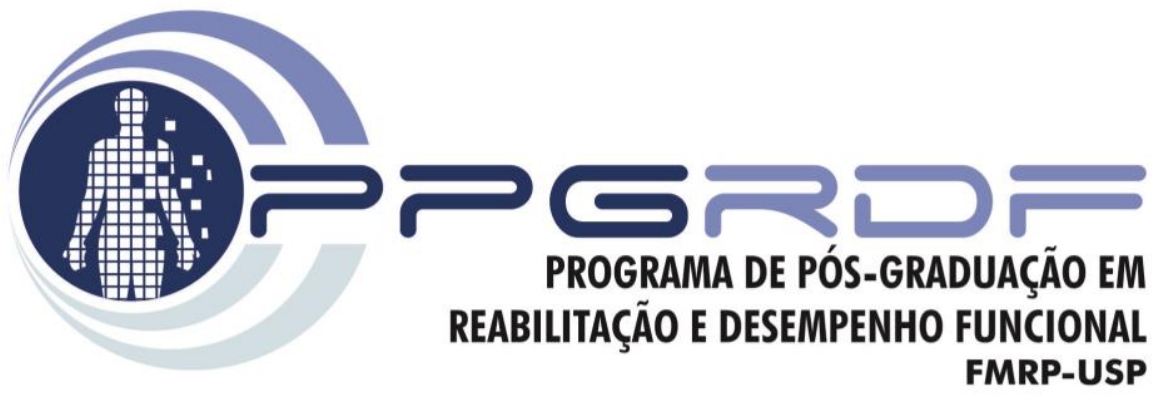

CONCLUSÃo

"Pois ser mestre é isso: ensinar a felicidade". 


\section{CONCLUSÃO}

Nossos resultados demonstram que a incapacidade cervical é influenciada pela disfunção temporomandibular, dor no pescoço e aspectos físicos e psicossociais relacionados ao trabalho com uso do computador.

Os trabalhadores com dor cervical apresentaram maior porcentagem de diagnósticos de DTM quando comparados com o grupo de trabalhadores sem dor, bem como a intensidade da dor à palpação dos músculos cervicais mostrou-se significativamente maior nos trabalhadores usuários de computador com dor cervical. Assim, é possível sugerir uma associação entre relato de dor cervical, incapacidade cervical e DTM no contexto de trabalho envolvendo o computador em mulheres com relato de dor cervical crônica.

Nossos resultados não demonstraram diferenças entre o limiar de dor por pressão de estruturas craniocervicais e postura corporal estática entre trabalhadores usuários de computador com e sem dor cervical crônica. 


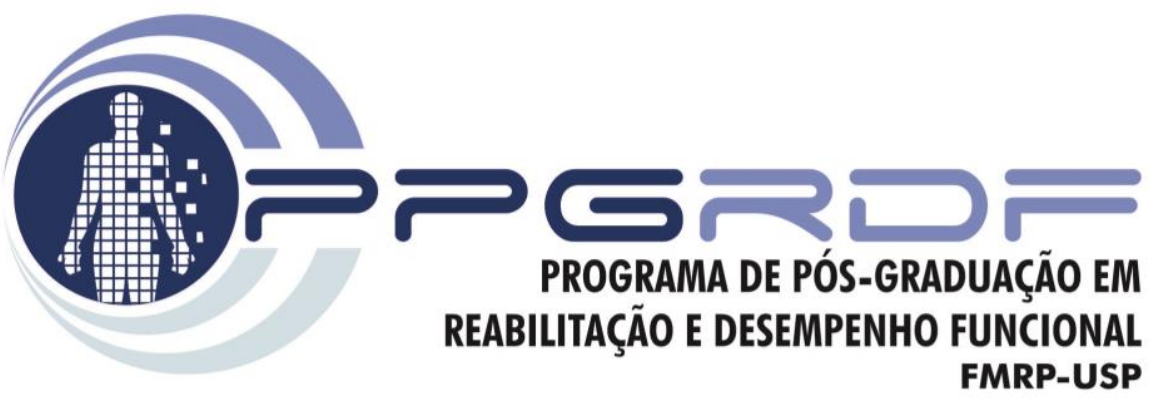




\section{REFERÊNCIAS}

1. AHMAD, M.; HOLLENDER, L.; ANDERSON, Q.; KARTHA, K.; OHRBACH, R. K.; TRUELOVE, E. L.; JOHN, M. T.; SCHIFFMAN, E. L. Research Diagnostic Criteria for Temporomandibular Disorders (RDC/TMD): development of image analysis criteria and examiner reliability for image analysis. Oral Surgery, Oral Medicine, Oral Pathology, Oral Radiology and En dodontology. v.107, n.6, 2009.

2. AMICK, B. C. III; ROBERTSON, M. M.; DERANGO, K.; BAZZANI, L.; MOORE, A.; ROONEY, T.; HARRIST, R. Effect of Office ErgonomicsIntevetion on Reducing Musculoskeletal Symptoms. Spine (Phila Pa 1976). v.28, n.24, p.2706-11, 2003.

3. ARIËNS, G. A. M.; BONGERS, P. M.; DOUWES, M.; MIEDEMA, M. C.; HOOGENDOORN, W. E.; VAN DER WAL, G; BOUTER, L.; VAN MECHELEN, W.; Are neck flexion, neck rotation and sitting at work risk factors for neck pain? Results of a prospective cohort study. Occup Environ Med. v.58, p.200-207, 2001.

4. ARMIJO-OLIVO, S.; MAGEE, D. J.; PARFITT, M.; MOJOR, P.; THIE, N. M. The association between the cervical spine, the stomatognathic system and craniofacial pain: a critical review. J. Orofac. Pain. v.20, n. 4, p.271-87, 2006.

5. ARMIJO-OLIVO, S.; FUENTES, J. P.; DA COSTA, B. R.; MAJOR, P. W.; WARREN, S.; THIE, N. M.; MAGEE, D. J. Reduced endurance of the cervical flexor muscles in patients with concurrent temporomandibular disorders and neck disability. Man Ther. v.15, n.6, p.586-92, 2010.

6. ARMIJO-OLIVO, S.; SILVESTRE, R. A.; FUENTES, J. P.; DA COSTA, B. R.; MAJOR, P. W.; WARREN, S.; THIE, N. M.; MAGEE, D. J. Patients With 
Temporomandibular Disorders Have Increased Fatigability of the Cervical Extensor Muscles. Clin J Pain. v.14, 2011.

7. ARMIJO-OLIVO, S.; RAPPOPORT, K.; FUENTES, J; GADOTTI, I. C.; MAJOR, P. W.; WARREN, S.; THIE, N. M.; MAGEE, D. J. Head and cervical posture in patients with temporomandibular disorders. J Orofac Pain. v.25, n.3, p.199-209, 2011.

8. BARBIERI, D. F.; NOGUEIRA, H. C.;BERGAMIN, L. I.;OLIVEIRA, A. B. Physical and psychosocial indicators among office workers from public sector with and without musculoskeletal symptoms. Work. Reading. v. 41, p. 24612466, 2012.

9. BARROS, E. N. C.; ALEXANDRE, N. M. C. Cross-cultural adaptation of the nordic musculoskeletal questionnaire. International Nursing Review. London, v. 50, n. 2, p. 101-108, 2003.

10. BENDTSEN L. Central sensitization in tension-type headache e possible pathophysiological mechanisms. Cephalalgia Int J Headache. v.20, n.5, p.486508, 2000.

8. BELli, J. F. C.; CHAVES, T. C.; OLIVEIRA, A. S.; BEVILAQUA-GROSSI, D. Analysis of body posture in children with mild to moderate asthma. European Journal of Pediatrics. v.168, n.10, p.1207-16, 2009.

9. BEVILAQUA-GROSSI, D.; CHAVES, T. C.; OLIVEIRA, A. S. Cervical spine signs and symptoms: perpetuating rather than predisposing factors for temporomandibular disorders in women. J. Appl. Oral Sci. [online]. v.15, n.4, pp. 259-264, 2007. 
10. BEVILAQUA, D. G.; LIPTON, R. B.; NAPCHAN, U.; ASHINA, S.; BIGAL, M. E. Temporomandibular disordens and cutaneous allodynia are associated in individuals with migrane. Cephalgia. p.1-8, 2009.

11. BIASOTTO-GONZALEZ, D. A.Abordagem interdisciplinar das disfunções temporomandibulares. Manole, 2005.

12. BLATTER, B. M.; BONGERS, P. M. Duration of computer use and mouse use in relation to musculoskeletal disorders of the neck or upper limb. Int. J. Ind. Ergon. v.30, p.295-306,2002.

13. BOGDUK, N. Neck pain: an update. Aust Fam Physician. v.17, p.75-80, 1998.

14. BONGERS, P. M.; IJMKER, S.; VAN DEN HEUVEL, S.; BLATTER, B. M.. Epidemiology of work related neck and upper limb problems: psychosocial and personal risk factors (part I) and effective interventions from a bio behavioural perspective (part II). J Occup Rehabil. v.16, p.279-302, 2006.

15. BRANDT, M.; SUNDSTRUP, E.; JAKOBSEN, M. D.; JAY, M. D.; COLADO, J. C.; WANG, Y.; ZEBIS, M. K.; ANDERSEN, L. L.. Associantion between neck/shoulder pain and trapezius muscle tenderness in office workers. Pain Research and treatment. 2014.

16. BURGESS, K. E.; GRAHAM-SMITH, P.; PEARSON, S. J. Effect of acute tensile loading on gender-specific tendon structural and mechanical properties. Journal of Orthopaedic Research. New York. v. 27, n. 4, p.510-516, 2009.

17. CATHCART, S.; PRITCHARD D. Reliability of pain threshold measurement in young adults. J. Headache Pain. v.7, n.1, p.21-6, 2006

18. CAGNIE, B.; DANNEELS, L.; VAN TIGGELEN, D.; DE LOOSE, V.; CAMBIER, D. Individual and work related risk factors for neck pain among office workers: a cross sectional study. Eur Spine J. v.16, n.5, p.679-86, 2007. 
19. CHAN, V. H. Biostatistics 104: correlational analysis. Singapore Med. J., Singapore, v. 44, n. 12, p. 614-9, 2003.

20. CHAVES, T. C. Confiabilidade intra e interexaminadores do Limiar de Dor por Pressão (LDP) e sua correlação com a Palpação Manual (PM) de estruturas do sistema mastigatório de crianças com e sem relato de dor orofacial relacionada à disfunção temporomandibular (DTM). Dissertação (Mestrado). 2006. $151 \mathrm{f}$. Dissertação (Mestrado) - Faculdade de Medicina de Ribeirão Preto, Universidade de São Paulo, Ribeirão Preto, 2006.

21. CHAVES, T. C; NAGAMINE, H. M.; SOUZA, L. M.; OLIVEIRA, A.S.; GROSSI, D.B. Intra- and Interrater Agreement of Pressure Pain Threshold for Masticatory Structures Chidren Reporting orofacial Pain Related to Temporomandibular Disorders and Symptomfree Children. Journal of orofacial Pain, v.21, n.2, p.133-142, 2007.

22. CHAVES, T.C.; OLIVEIRA, A. S.; GROSSI, D. B. Principais instrumentos para avaliação da disfunção temporomandibular, parte I: índices e questionários; uma contribuição para a prática clínica e de pesquisa. Fisioterapia e pesquisa. v.15, n.1, p.92-100, 2008.

23. CHAVES, T. C.; OLIVEIRA, A. S.; BEVILAQUA-GROSSI, D. Principais instrumentos para avaliação da disfunção temporomandibular, parte II: critérios diagnósticos, uma contribuição para a prática clínica e de pesquisa. Fisioterapia e Pesquisa. v.15, n.1, p.101-6, 2008.

24. CHO, C. Y; HWANG, Y. S.; CHERNG, R. J. Musculoskeletal symptom factors among office workload computer use. J Manipulative Physiol Ther. Lombard. v. 7, n. 35, p. 534-540, 2012. 
25. CHUNG, S. C.; KIM, J. H; KIM, H. S. Reliability and validity of the pressure pain thresholds (PTT) in the TMJ capsules by electronic algometer. Cranio. v.11, n.3, p. 171-6, 1993.

26. CLAMAN, L.; PATTON, D.; RASHID, R. Standardized portrait photography for dental patients. Am J Orthod Dentofac Orthop. v.98, p.197-205, 1990.

27. COOK, C.; RICHARDSON, J. K.; BRAGA, L.; MENEZES, A.; SOLER, X.; KUME, P.; ZANINELli, M.; SOCOLOWS, F.; PIETROBON, R. Crosscultural adaptation and validation of the Brazilian Portuguese version of the Neck Disability Index and Neck Pain and Disability Scale. Spine (Phila Pa 1976). v.31, n.14, p.1621-27, 2006.

28. COTÉ, P.; VANDERVELDE, G.; CASSIDY, J. D. et al.. The burden and determinants of neck pain in workers. Results of the bone and joint decade 20002010 task force on neck pain and its associated disorders. J Manipulative Physiol Ther. v.32, p.570-86, 2009.

29. COTÉ, J. N. A critical review on physical factors and functional characteristics that may explain a sex/gender difference in work-related neck/shoulder disorders. Ergonomics. London. v. 55, n. 2, p. 173-182, 2012.

30. CUNHA, J.B.; BLANK V.L.; BOING A.F. Time trends of sick leave in razilian civil servants (1995-2005). Rev. Bras. Epidemiol. v.12, n. 2, p. 226-236, 2009.

31. CUCCIA, A.; CARADONNA, C. The relationship between the stomatognathic system and body posture. Clinics (Sao Paulo). v.64, n.1, p.61-6, 2009. Review.

32. CUNHA, C. A. Determinação do limiar de dor à pressão (LDP) da articulação temporomandibular (ATM) ideal para determinação diagnóstica de artralgial: um estudo baseado em algometria e ressonância magnética. 2011. Dissertação 
(Mestrado) - Faculdade de Odontologia de Bauru, Universidade de São Paulo, Bauru, 2011.

33. DE BRUIJN, I.; ENGELS, J. A.; VAN DER GULDEN, J. W. J. A simple method to evaluate the reliability of OWAS observations. Appl Ergon. London. v. 29, n. 4, p. 281-283, 1998.

34. DE LEEUW, R. Dor orofacial: guia de avaliação, diagnostico e tratamento. $4^{\circ}$ ed. São Paulo: Quintessence, 2010.

35. DE WIJER, A. et al.. Symptons of the stomatognathic system in temporomandibular and cervical dysfunction. J. Oral Rehabil., Oxford, v. 23, p. 733-41, 1996.

36. DUARTE, M. A.; GOULART, E. M. A.; PENNA, F. J. Limiar de dor e idade na infância e adolescência. J. Pediatr. (Rio J.), Rio de Janeiro, v. 75, n. 4, p. 244-8, 1999.

37. DWORKIN, S. F.; LERESCHE, L. Research Diagnostic Criteria for temporomandibular disorders: review, criteria, examinations and specifications, critique. Journal Temporomandibular disorders: Facial and Oral pain. v.6, n.4, p.300-55, 1992.

38. DWORKIN, S. F. The Oppera study act one. J. Pain. v.12, n.11, nov.,2011.

39. ELTAYEB, S.; STAAL, J. B.; KENNES, J.; LAMBERTS, P. H.; DE BIE, R. A. Prevalence of complaints of arm, neck and shoulder among computer office workers and psychometric evaluation of a risk factor questionnaire. BMC Musculoskelet Disord. v.14, p. 8-68, 2007.

40. ETÖZ, O. A.; ATAOĞLU, H. Evaluation of pain perception in patients with temporomandibular disorders. J Oral Maxillofac Surg. v. 65, n.12, p.2475-8, 2007. 
41. FALLA, D. Unravelling the complexity of muscle impairment in chronic neck pain. Man Ther. v.9, n.3, p. 125-33, 2004.

42. FERNÁNDEZ-DE-LAS-PEÑAS，C.; GALÁN-DEL-RÍO， F.; FERNÁNDEZCARNERO, J.; PESQUERA, J.; ARENDT-NIELSEN, L.; SVENSSON, P. Bilateral widespread mechanical pain sensitivity in women with myofascial temporomandibular disorder: evidence of impairment in central nociceptive processing. J Pain. v. 10, n.11, p.1170-8, 2009.

43. FERREIRA, M. C.; BEVILAQUA-GROSSI, D.; SPECIALI, J.G. et al.. Body posture changes in women with migraine with and without temporomandibular disorder. Brazilian J. Phys Ther. v.18, p.19-29, 2014.

44. FINK, M.; TSCHERNITSCHEK, H.; STIESCH-SCHOLZ, M. Asymptomatic cervical spine dysfunction (CSD) in patients with internal derangement of the temporomandibular joint. Cranio.v.20, p. 192-197, 2002.

45. FRICTON, J. R., SCHIFFMAN, E. L. Reliability of a craniomandibular index. J. Dent Res. v.65, n.11, p.1359-64, 1986.

46. GERR, F.; MARCUS, M.; ENSOR, C.; KLEINBAUM, D.; COHEN, S.; EDWARDS, A.; GENTRY, E.; ORTIZ, D. J.; MONTEILH, C. A prospective study of computer users: I. Study design and incidence of musculoskeletal symptoms and disorders. Am. J. Ind. Med. v.41, p.221-235, 2002.

47. GOMES, M. B.; GUIMARAES, J. P.; NEVES, A. C. Palpation and pressure pain threshold: reability and validity in patients with temporomandibular disorders. Cranio. v.26, n.3, p.201-10, 2008.

48. GONÇALVES, D. A.; SPECIALI, J. G.; JALES, L. C.; CAMPARES, C. M; BIGAL, M. E. Temporomandibular symptoms, migraine and chronic daily headaches in the population. Neurology. v.73, n.8, p. 645-6, 2009. 
49. GONZALEZ, H. E.; MANNS, A. Forward head posture: its structural and functional influence on the stomatognathic system, a conceptual study. Cranio, Baltimore, v. 14, p. 71-80, 1996.

50. GOULET, J. P. et al.. The reproducibility of muscle and joint tenderness detection methods and maximum mandibular movement measurement for the temporomandibular system. J. Orofac. Pain, Carol Stream, v. 12, n. 1, p. 17-26, 1998.

51. HÄGG, G. M.; ASTRÖM, A. Load pattern and pressure pain threshold in the upper trapezius muscle and psychosocial factors in medical secretaries with and without shoulder/neck disorders. Int Arch Occup Environ Health. v. 69, n.6, p.423-32, 1997.

52. HALEY, D.P.; SCHIFFMAN, E. L.; LINDGREN, B. R.; ANDERSON, Q.; ANDREASEN, K. The relationship between clinical and MRI findings in patients with unilateral temporomandibular joint pain. J. Am. Dent. Assoc. v.132, n.4, p.476-81, 2001.

53. HARMS-RINGDAHL, K.; EKHOLM, J.; SCHULDT, K.; NEMETH, G.; ARBORELIUS, U. P. Load moments and myoelectric activity when the cervical spine is held in full flexion and extension. Ergonomics. v.29, n.12, p. 1539$1552,1986$.

54. HARRISON, D. D. et al.. Sitting biomechanics part 1: review of the literature. J. Manipulative. Physiol. Ther. Lombard. v. 22, n. 9, p. 594-609, 1999.

55. HIGNETT, S.; MCATAMNEY, L. Rapid entire body assessment (REBA). Appl Ergon. London. v. 31, n. 2, p. 201-205, 2000. 
56. HOROWITZ, L.; SARKIN, J. M. Video display terminal operation: a potential risk in the etiology and maintenance of temporomandibular disorders. Cranio.v.10, n.1, p. 43-50, 1992.

57. HOY, D. G.; PROTANI, M.; DE R, BUCHBINDER R. The epidemiology of neck pain. Best Pract Res Clin Rheumatol. v.24, n.6, p.783-92, 2010.

58. HUSH, J. M.; MICHALEFF, Z.; MAHER, C. G.; REFSHAUGE, K. Individual, physical and psychological risk factors for neck pain in Australian office workers: a 1-year longitudinal study. Eur Spine J. v.18, p.1532-40, 2009

59. INGAWALE, S.; GOSWAMI, T. Temporomandibular joint: disorders, treatments, and biomechanics. Ann. Biomed Eng. v.37, p.976-996, 2009.

60. ISSELÈE, H. et al.. Short-term reproducibility of pressure pain thresholds in masseter and temporalis muscles of symptom-free subjects. Eur. J. Oral Sci.,Copenhagem, v. 105, p. 583-7, 1997.

61. IUNES, D. H.; CASTRO, F.A.; SALGADO, H. S; MOURA, I. C.; OLIVEIRA, A. S.; BEVILAQUA-GROSSI, D. Confiabilidade inter e intra-examinadores e repetibilidade da avaliação postural pela fotogrametria. Rev. Bras. Fisioter. v.9, n.3, p.327-34, 2005.

62. JANWANTANAKUL， P.; PENSRI， P.; JIAMJARASRANGSRI， V. et al.. Prevalence of self-reported musculoskeletal symptons among office workers. Occup Med (lond). v.58, p.436-8, 2008.

63. JENSEN, K. et al.. Pressure-pain threshold in human temporal region. Evaluation of a new pressure algometer. Pain, Amsterdam, v. 25, n. 3, p. 31323, 1986 
64. JENSEN, C.; FINSEN, L.; SØGAARD, K.; CHRISTENSEN, H.; Musculoskeletal symptoms and duration of computer and mouse use. Int. J. Ind. Ergon. v.30, p.265-275, 2002.

65. JOHNSTON, V.; JIMMIESON, N. L.; SOUVLIS, T.; JULL, G. Interaction of psychosocial risk factors explain increased neck problems among female office workers. Pain. v.129, n.3, p. 311-20, 2007.

66. JOHNSTON, V.; JIMMIESON, N. L.; JULL, G.; SOU VLIS, T. Quantitative sensory measures distinguish office workers with varying levels of neck pain and disability. Pain. v.137, n.2, p.257-65, 2008.

67. JOHNSTON, V.; JIMMIESON, N. L.; JULL, G.; SOUVLIS, T. Contribution of individual, workplace, psychosocial and physiological factors to neck pain in female office workers. Eur J Pain. v. 13, n.9, p.985-91, 2009.

68. JOHNSTON, V.; JULL, G; SOUVLIS, T.; JIMMIESON, N. L. Interactive effects from self-reported physical and psychosocial factors in the workplace on neck pain and disability in female office workers. Ergonomics. v.53, n.4, p.502$13,2010$.

69. KITSOULIS, P.; MARINI, A.; ILIOU, GALANI V.; ZIMPIS, A.; KANAVAROS, P. et al.. Signs and symptoms of temporomandibular joint disorders related to the degree of mouth openind and hearing loss. BMC Ear Nose Throat Disord. 11:5, 2011.

70. KORHONEN, T.; KETOLA, R.; TOIVONEN, R.; LUUKKONEN, R.; HÄKKÄNEN, M.; VIIKARI- JUNTURA, E. Work related and individual predictors for incident neck pain among office employees working with video display units. Occup. Environ. Med.v.60, p.475-482, 2003. 
71. KORPIEN, L.; PÄÄKKÖÖNEN, R.; GOBBA, F. Self-reported neck symptoms and and use of personal computers, laptops and cell phones among Finns aged 18-65. Ergonomics. v.56, n.7, p.1134-1146, 2013.

72. KRAUS S.Temporomandibular disorders, head and orofacial pain: cervical spine considerations. Dent Clin North Am. v.51,n.1, p.161-93, 2007.

73. KUORINKA, I.; JONSSON, B.; KILBOM, A.; VINTERBERG, H.; BIERINGSORENSEN, F.; ANDERSSON, G.; JORGENSEN, K. Standardised Nordic questionnaires for the analysis of musculoskeletal symptoms. Appl Ergon. London.v. 18, p. 233-237, 1987.

74. LAU, K. T.; CHEUNG, K. Y.; CHAN, K. B.; CHAN, M. H.; LO K. Y.; CHIU, T. T. Relationships between sagittal postures of thoracic and cervical spine, presence of neck pain, neck pain severity and disability. Man Ther. v.15, n.5, p.457-62, 2010.

75. LIST, T.; HELKIMO, M.; FALK, G. Reliability and validity of a pressure threshold meter in recording tenderness in the masseter muscle and the anterior temporalis muscle. Cranio, Baltimore, v. 7, n. 3, p. 223-9, 1989.

76. LUEDER, R.; ALLIE, P. Ergonomics Review: Armrest Design and Use. An Ergonomics Review of the Literature for Steelcase Furniture. Acess: 28. 10.14. Disponível em: $\underline{\text { www.humanics-es.com/armrest-ergonomics.htm }}$

77. LUND, J.P.; WIDMER, C. G.; FEINE, J. S. Validity of diagnostic and monitoring tests used for temporomandibular disorders. J Dent Res. v.74, n.4, p.1133-43, 1995.

78. MADELINE, P.; VANGSGAARD, S.; HVIID ANDERSEN, J.; GE, H. Y.; ARENDT-NIELSEN, L. Computer work and self-reported variables on 
anthropometrics, computer usage, work ability, productivity, pain, and physical activity. BCM Musculoskeletal Disorders. 2013.

79. MAKOFSKY, H. The effect of head posture on muscleocontract position: the sliding cranium theory. Cranio, Chattonooga. v. 7, n. 4, p. 286-296, 1989.

80. MARQUES, N. R.; HALLAL, C. Z.; GONÇALVES, M. Características biomecânicas, ergonômicas e clínicas da postura sentada: uma revisão. Fisioterapia e Pesquisa. São Paulo. v. 17, n. 3, p. 270-276, 2010.

81. MCAVINEY, J.; SCHULZ, D.; BOCK, R.; HARRISON, D. E.; HOLLAND, B. Determining the relationship between cervical lordosis and neck complaints. Journal of Manipulative and Physiological Therapeutics. v.28, n 3. mar./abr. 2005.

82. MCATAMNEY, L.; CORLETT, E. N. RULA: a survey method for the investigation of work-related upper limb disorders. Applied Ergonomics, London. v. 24, n.2 p. 91-99, 1993.

83. NAYLER, J. R. Clinical Photography: A guide for the clinician.J. Postgrad Med. v.49,n.3, p. 256-62, 2003.

84. NEJATI, P.; LOTFIAN, S.; MOEZY, A.; MOEZY, A.; NEJATI, M. The relationship of forward head posture and rounded shoulders with neck pain in Iranian office workers. Medical journal of the Islamic Rupublic of Iran. v.28, n.26, 2014.

85. NISHIYAMA, A.; KINO, K.; SUGISAKI, M.; TSUKAGOSHI, K.A survey of influence of work environment on temporomandibular disorders-related symptoms in Japan. Head \& face medicine.2012.

86. NISHIYAMA, A.; Kino, K.; Sugisaki, M.; Tsukagoshi, K. Influence of phychosocial factors and habitual behavior in temporomandibular disorder - 
Related symptoms in a working population in Japan. Open Dent J. p.240-247, 2012.

87. NORDANDER, C.; OHLSSON, K.; BALOGH, I.; HANSSON, G. A.; AXMON, A.; PERSSON, R.; SKERFVING, S. Gender differences in workers with identical repetitive industrial tasks: exposure and musculoskeletal disorders. Int Arch Occup Environ Health. Berlin. v. 81, n. 8, p. 939-947, 2008.

88. OHA, K.; ANIMÄGI， L.; PÄÄSUKE，M.; COGGON，D.; MERISALU， E. Individual and work-related risk factors for musculoskeletal pain: cross-sectional study among Estonian computer users. BCM Musculoskeletal Disorders. v.15, 2014.

89. OliVO, S. A.; FUENTES, J.; MAJOR, P. W.; WARREN, S.; THIE, N. M.; MAGEE, D. J. The association between neck disability and jaw disability. J Oral Rehabil. v.37, n.9, p.670-9, 2010.

90. PAKSAICHOL, A.; JANWANTANAKUL, P.; PUREPONG, N.; PENSRI, P.; BEEK, A. J. Office workers risk factors for the development of non-specific neck pain: a systematic review of prospective cohort studies. Eviron Med. v.69, p.610-618, 2012.

91. PAKSAICHOL, A.; JANWANTANAKUL, P ; LAWSIRIRAT, C. Development of a neck pain risk score for predicting nonspecific neck pain with disability in office workers: A i-year prospective cohort study. Journal of Manipulative and Phsysiological therapeutics. Month, 2014

92. PYNT, J.; HIGGS, J.; MACKEY, M. Seeking the optimal posture of the seated lumbar spine. Physiotherapy Theory and Practice. London. v. 17 n. 1, p. 5-21, 2001. 
93. RAINE, S.; TWOMEY, L. T. Head and shoulder posture variations in 160 asymptomatic women and men. Arch Phys Med Rehabil.v.78, p.1215-23, 1997.

94. RANASINGHE, P.; PERERA, Y. S.; LAMABADUSURIYA, D. A.; KULATUNGA, S.; JAYAWARDANA, N.; RAJAPAKSE, S.; KATULANDA P. Work related complaints of neck, shoulder and arm among computer office workers: a cross-sectional evaluation of prevalence and risk factors in a developing country. Environ Health. v.4, p.10-70, 2011 b.

95. ROCABADO, M. Biomechanical relationship of the craneal cervical and hyoid regions. Cranio, Baltimore, v. 1, n. 3, p. 61-6, 1983.

96. ROCHA, C. P; CROCI, C. S.; CARIA, H. F. Is there relationship between temporomandibular disorders and head and cervical posture? A systematic review. Journal of Oral Rehabilitation. v.40, p.875-881, 2013.

97. ROY, J. S.; MACDERMID, J. C.; BOYD, K. U.; FABER, K. J.; DROSDOWECH, D.; ATHWAL, G. S. Rotational strength, range of motion, and function in people with unaffected shoulders from various stages of life. Sports Med Arthrosc Rehabil Ther Technol. London. v. 2, n. 1, p. 4, 2009

98. SAITO, E. T.; AKASHI, P. M.; SACCO IDE, C. Global body posture evaluation in patients with temporomandibular joint disorder. Clinics (Sao Paulo). v.64, n.1, p.35-9, 2009.

99. SCHIFFMAN, E. L.; TRUELOVE, E. L.; OHRBACH, R.; ANDERSON, G. C.; JOHN, M. T.; LIST, T.; LOOK, J. O. The Research Diagnostic Criteria for Temporomandibular Disorders. I: overview and methodology for assessment of validity. J Orofac Pain.v.24,n.1, p.7-24, 2010. 
100. SCHOMACHER, J.; BOUDREAU, S. A.; PETZKE, F.; FALLA, D. Localized pressure pain sensitivity is associated with lower activation of the semispinalis cervicis muscle in patients with chronic neck pain. Clin J Pain. v.29, n.10, p.898-906, 2013

101. SILLANPÄ̈̈, J.; HUIKKO, S.; NYBERG, M.; KIVI, P.; LAIPPALA, P.; UITTI, J. Effect of work with visual display units on musculo-skeletal disorders in the office environment. Occupacional Medicine. v.53, n.7, p.443-451, 2003.

102. SILVEIRA, A.; ARMIJO-OLIVO, S.; GADOTTI, I.C.; MAGEE, D. Masticatory and cervical muscle tenderness and pain sensitivity in a remote area in subjects with a temporomandibular disorder and neck disability. J Oral Facial Pain Headache. v.28, n.2, p.138-46, 2014

103. SIM, J.; LACEY, R. J.; LEWIS, M. The impact of workplace risk factors on the occurrence of neck and upper limb pain: a general population study. BMC Public Health. v.6, p.234-244, 2006.

104. SIMA, F. T. Estudo de validação e confiabilidade de um novo algômetro digital de pressão extra e intra-oral para detecção de sensibilidade dolorosa miofascial e da ATM [doutorado]. São Paulo: Universidade de São Paulo; 2007.

105. SONNE, M.; VILLALTA, D. L.; ANDREWS, D. M. Development and evaluation of an office ergonomic risk checklist: ROSA--rapid office strain assessment. Appl Ergon. v.43, n.1, p. 98-108, 2012.

106. SLADE, G. D.; SANDERS, A. E.; OHRBACH, R.; FILLINGIM, R. B.; DUBNER, R.; GRACELY, R. H.; BAIR, E.; MAIXNER, W.; GREENSPAN, J. D. Pressure pain thresholds fluctuate with, but do not usefully predict, the clinical course of painful temporomandibular disorder. Pain. v.155, p.2134-43, 2014. 
107. STERLING, M.; REBBECK, T. The Neck Disability Index (NDI). Aust J. Physiother. v.51,n.4, p.271, 2005.

108. STIESCH-SCHOLZ, M.; FINK, M.; TSCHERNITSCHEK, H. Comorbidity of internal derangement of the temporomandibular joint and silent dysfunction of the cervical spine. Journal of Oral Rehabilitation. v.30, p. 386-391, 2003.

109. SUVINEN, T. I.; READE, P.C; KEMPPAINEN, P.; KONONEN, M.; DWORKIN, S. F. Review of aetiological concepts of temporomandibular pain disorders: towards a biopsychosocial model for integration of physical disorder factors with psychological and psychosocial illness impact factors. Eur J Pain. v.9, p.613-33, 2005.

110. SVENSSON, P.; WANG, K.; SESSIE, B. J.; ARENDT-NIELSEN, L. Association between pain and neuromuscular activity in the human jaw and neck muscles. Pain. v. 109,p. 225-232, 2004

111. SZETO, G. P.; STRAKER, L.; RAINE, S. A field comparison of neck and shoulder postures in symptomatic and asymptomatic office workers. Appl Ergon. v.33,n.1, p.75-84, 2002.

112. TINGEY, E. M.; BUSCHANG, P. H; THROCKMORTON, G. S. Mandibular rest position: a reliable position influenced by head support and body posture. Am J Orthod Dentofacial Orthop. v.120, n.6, p. 614-22, 2001.

113. TOMMASELlI, A. M. G.; SILVA, J. F. C.; HASEGAWA, J. K.; GALO, M.; DAL POZ, A. P. Fotogrametria: aplicações à curta distância. FTC 40 anos, Perfil Científico-Educacional. p.147-59, 1999.

114. TAKALA, E. P. et al.. Systematic evaluation of observational methods assessing biomechanical exposures at work. Scandinavian Journal of Work, Environment \& Health. Helsinki. v. 36, n. 1. p. 3-24, Jan. 2010. 
115. TICHAUER, E. R.; GAGE, H. The Biomechanical Basis of Ergonomics. John Wiley \& Sons. New York, p. 99, 1978.

116. TURCI, A. M.; BEVILAQUA-GROSSI, D.; PINHEIRO, C. F.; BRAGATTO, M. M.; CHAVES, T. C. The Brazilian Portuguese version of the revised Maastricht Upper Extremity Questionnaire (MUEQ-Br revised): translation, cross-cultural adaptation, reliability, and structural validation. BMC Musculoskeletal Disorders (on line), v. 16, p. 41, 2015.

117. VARATHARAJAN, S. et al.. Are work disability prevention interventions effective for the management of neck pain or upper extremity disorders? A systematic Review by the Ontario Protocol for Traffic Injury Management (OPTIMA) Collaboration. J. Occup. Rehabil., 2014

118. VERNON, H.; MIOR, S. The neck disability index: a study of reliability and validity. J Manipulative Physiol Ther. v.14, n.7, p.409-15, 1991.

119. VERNON, H. The neck Disability Index: State-of-the-Art, 1991-2008. J Manipulative Physiol Ther. v. 31, p.491-502, 2008.

120. VISSCHER, C. M.; LOBBEZOO, F.; DE BOER, W.; VAN DER ZAAG, J.; VERHEIJ, J. G.; NAEIJE, M. Clinical test in distinguishing between persons with or without craniomandibular or cervical spinal pain complains. Eur. J. Oral Sci. v.108, n.6, p.475-83, 2000.

121. VISSCHER, C. M.; LOBBEZOO, F.; DE BOER, W.; VAN DER ZAAG, J.; NAEIJE, M. Prevalence of cervical spinal in craniomandibular pain patients. Eur J Oral Sci v.109, p.76-80, 2001.

122. VISSCHER, C. M.; DE BOER, W.; LOBBEZOO, F.; HABETS, L. L.; NAEIJE, M., Is there a relationship between head posture and craniomandibular pain? Journal of Oral Rehabilitation, v.29, n.11, p.1030-1036, 2002. 
123. VISSCHER, C. M.; LOBBEZOO, F.; NAEIJE, M. Comparison of algometry and palpation in the recognition of temporomandibular disorder pain complaints. J. Orofac. Pain. v.18, n.3, p.214-9, 2004.

124. VISSER, B.; VAN DIEËN, J. Pathophysiology of upper extremity muscle disorders. J Electromyogr Kinesiol. v.16, p.1-16, 2006.

125. WAHLSTRÖM, J. Ergonomics, musculoskeletal disorders and computer work. Occup. Med. (Chic. Ill.) v.55, p.168-176, 2005.

126. World Health Organization. International Classification of functioning, disability and health: ICF. World Health Organization; 2001.

127. YIP, CH.; CHIU, T. T.; POON, A. T. The relationship between head posture and severity and disability of patients with neck pain. Man Ther.v.13, n.2, p.148-54, 2008.

128. YOO, W.G. Changes in pressure pain threshold of the upper trapezius, levator spacular and rhomboid muscles during continuous computer work. J Phys Ther Sci. v.25, 2013.

129. YOO, I. G.; YOO WG. Changes in the cervical FRR, shoulder muscle pain and position after continuous detailed assembly work. Work 2013.

130. ZIEFLE, M. Sitting posture, postural discomfort, and visual performance: a critical view on the interdependence of cognitive and anthropometric factors in the VDU workplace. International Journal of Occupational Safety and Ergonomics. Norwood. v. 9, n. 4, p. 503-514, 2003. 


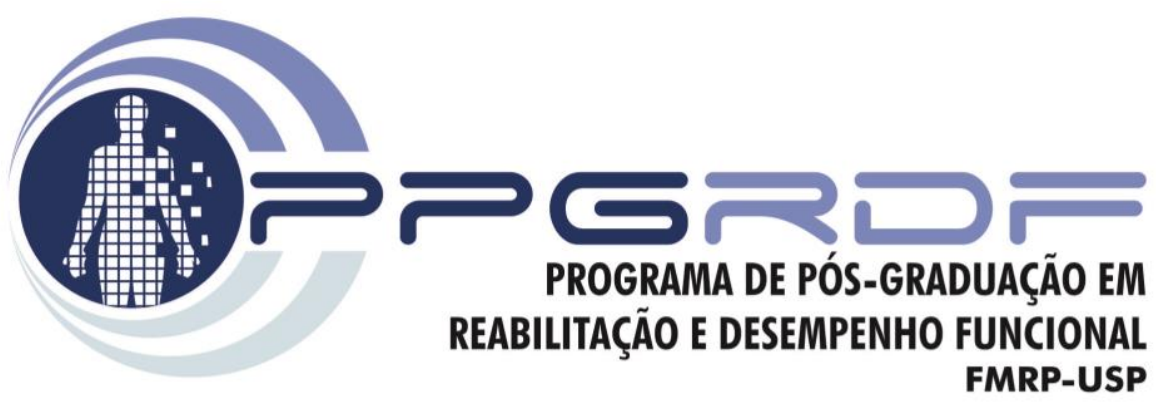

\section{ANEXOS}

“Há escolas que são gaiolas e há escolas que são

asas.

Escolas que são gaiolas existem para que os pássaros desaprendam a arte do vôo. Pássaros engaiolados são pássaros sob controle. Engaiolados, o seu dono pode levá-los para onde quiser. Pássaros engaiolados sempre têm um dono. Deixaram de ser pássaros.

Porque a essência dos pássaros é o vôo.

Escolas que são asas não amam pássaros engaiolados. $O$ que elas amam são pássaros em vôo. Existem para dar aos pássaros coragem para voar. Ensinar o vôo, isso elas não podem fazer, porque o vôo já nasce dentro dos pássaros. $O$ vôo não pode ser ensinado. Só pode ser encorajado"

Rubem Alves 


\section{ANEXO 1 - Documento de aprovação do projeto pelo Comitê de Ética em}

\section{Pesquisa.}

\section{HOSPITAL DAS CLINICAS DA FACULDADE DE MEDICINA} DE RIBEIRÄO PRETO DA UNIVERSIDADE DE SÃO PAULO

Ribeirão Preto, 21 de março de 2013

Oficio $\mathrm{n}^{\circ} 909 / 2013$

$\mathrm{CEP} / \mathrm{MGV}$

PROCESSO HCRP $\mathrm{n}^{\circ} 17111 / 2012$

Prezadas Pesquisadoras,

O trabalho intitulado "DOR CERVICAL CRÔNICA E POSTURA EM TRABALHADORES DE ESCRITÓRIO USUÁRIOS DE COMPUTADOR ${ }^{n}$, foi analisado pelo Comitê de Ética em Pesquisa, em sua $362^{\circ}$ Reunião Ordinária realizada em 18/03/2013, e enquadrado na categoria: APROVADO, bem como o Termo de Consentimento Livre e Esclarecido Versão 2.

Este Comite segue integralmente a Conferencia Internacional de Harmonização de Boas Práticas Clínicas (IGH-GCP), bem como a Resoluçao n० 196/96 CNS/MS.

Lembramos que devem ser apresentados a este CEP, o Relatório Parcial e o Relatório Final da pesquisa. De acordo com Carta Circular $n^{\circ}$ $003 / 2011 / C O N E P / C N S$, datada de 21/03/2011, o sujeito de pesquisa ou seu representante, quando for o caso, deverá rubricar todas as folhas do Termo de Consentimento Livre e Esclarecido - TCLE - apondo sua assinatura na última do referido Termo; o pesquisador responsável deverá da mesma forma, rubricar todas as folhas do Termo de Consentimento Livre e Esclarecido - TCLE - apondo sua assinatura na última página do referido Termo.

Atenciosamente.

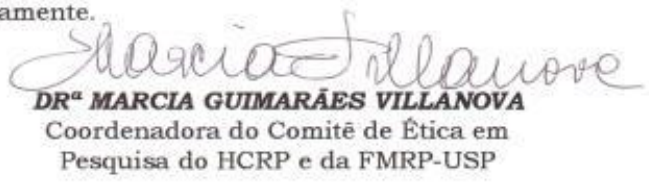

Ilustrissimas Senhoras

PROF $^{a}$ DR $^{\text {a }}$ THAIS CRISTINA CHAVES

MARCELA MENDES BRAGATTO (Aluna)

Depto. de Neurociências e Ciências do Comportamento 


\section{ANEXO 2 - Questionário Maastrich Upper Extremity Questionnaire - Br (MUEQ-Br)}

\section{Informações Gerais}

\section{Maastricht Upper Extremity Questionnaire - Br}

1. Gênero

$\square$ Masculino $\quad \square$ Feminino

2. Sobrenome

3. Data de nascimento

4. Onde você trabalha?

5. Qual seu cargo atual?

Cidade/Estado/País

6.a) Há quanto tempo você trabalha nesse cargo?

Ano(s)

6.b) Há quanto tempo você trabalha utilizando computador? (considere empregos anteriores)

7. Quantos dias você trabalha por semana (Não incluindo hora extra)

Dia(s)

8. Quantas horas você trabalha por dia? (Não incluindo intervalos e hora extra)

9. Quantas horas por dia de trabalho você trabalha usando um computador? Ano(s)

\section{Posto de trabalho}

10. Minha mesa de trabalho tem altura adequada.

11. Eu posso ajustar a altura da minha cadeira.

12. Quando eu uso o mouse, meu braço fica apoiado sobre a mesa.

13. A cadeira que eu uso durante o trabalho dá suporte à minha coluna.

$\square$ Coluna Baixa

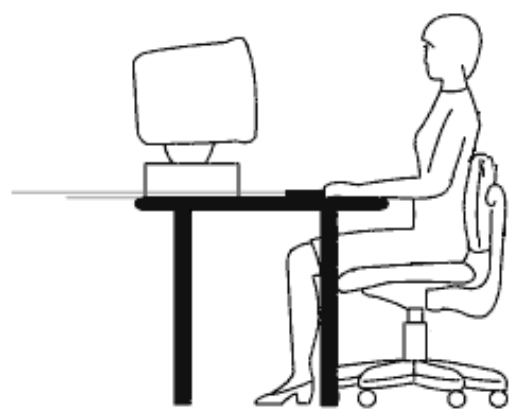

$\checkmark$ Coluna Média

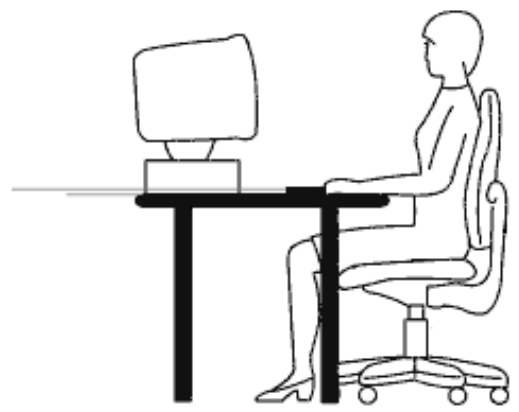

14. O teclado do meu computador fica diretamente em minha frente.

15. A tela do meu computador fica diretamente em minha frente.

16. Eu tenho espaço suficiente para trabalhar em meu escritório.

\section{Postura Corporal}

17. Durante meu trabalho eu mantenho uma boa postura de trabalho.

18. No trabalho eu fico sentado por muitas horas na mesma posição.

19. Por mais de duas horas por dia eu sento com meus ombros elevados.

20. Durante meu trabalho eu sento com uma postura desajeitada.

21. No meu trabalho eu realizo repetidas tarefas.

22. Eu acho meu trabalho fisicamente desgastante.

23. Quando eu digito minha mão fica posicionada em linha reta com meu antebraço.

24. Quando eu trabalho minha cabeça fica inclinada.

25. Minha cabeça fica virada para a esquerda ou direita durante $o$ trabalho.

26. Meu tronco fica virado para a esquerda ou direita durante o trabalho.

$\begin{array}{ccccc}\text { Sempre } & \text { Frequentemente } & \text { Às vezes } & \text { Raramente } & \text { Nunca } \\ \square & \square & \square & \square & \square \\ \square & \square & \square & \square & \square \\ \square & \square & \square & \square & \square \\ \square & \square & \square & \square & \square \\ \square & \square & \square & \square & \square \\ \square & \square & \square & \square & \square \\ \square & \square & \square & \square & \square \\ \square & \square & \square & \square & \square \\ \square & \square & \square & \square & \square \\ \square & \square & \square & \square & \square\end{array}$


Anexos 116

27. Meu tronco fica em uma posição desalinhada.

\section{Controle do Trabalho}

28. Eu decido como realizar minhas tarefas de trabalho.

29. Eu participo com os outros na tomada de decisões.

30. Eu decido minha rotina de tarefas.

31. Eu determino o tempo e a velocidade das tarefas.

32. Eu resolvo problemas de trabalho sozinho.

33. Meu trabalho aprimora minhas habilidades.

34. No trabalho eu aprendo coisas novas.

35. Eu tenho que ser criativo em meu trabalho.

36. Eu realizo tarefas variadas em meu trabalho.

\section{Demanda de Trabalho}

37. Eu trabalho sob extrema pressão.

38. Eu encontro dificuldade em terminar minhas tarefas a tempo.

39. Eu faço hora extra para terminar minhas tarefas.

40. Eu não tenho tempo suficiente para terminar minha tarefa de trabalho.

41. No trabalho eu corro para terminar minhas tarefas no prazo.

42. Eu encontro em meu trabalho tarefas difíceis.

43. Eu tenho tarefas de trabalho demais

\section{Pausas}

44. Eu posso planejar minhas pausas do trabalho.

45. Eu posso dividir meu tempo de trabalho.

46. Eu posso decidir quando realizar uma pausa.

47. Eu alterno minha postura corporal.

48. Eu alterno minhas tarefas de trabalho.

49. Eu realizo tarefas de trabalho sem computador.

50. A cada duas horas eu faço uma pausa de dez minutos.

51. Eu acho minhas pausas de trabalho suficientes.

\section{Ambiente de Trabalho}

52. Eu acho meu ambiente de trabalho bom.

53. $O$ ar dentro da sala é seco demais.

54. $O$ ar dentro da sala é frio demais.

55. No escritório existe ar indesejado (mau cheiro, cheiros fortes, odores que incomodam).

56. Tem ar fresco disponível em meu trabalho.

57. Meu ambiente de trabalho é barulhento.

58. Meu local de trabalho tem claridade demais.

59. Eu olho fixamente para a tela do computador.

60. A tela do computador reflete as luzes da sala.

\section{Suporte Social}

61. O trabalho flui tranquilamente.

$\begin{array}{ccccc}\text { Sempre } & \text { Frequentemente } & \text { Às vezes } & \text { Raramente } & \text { Nunca } \\ \square & \square & \square & \square & \square \\ \square & \square & \square & \square & \square \\ \square & \square & \square & \square & \square \\ \square & \square & \square & \square & \square \\ \square & \square & \square & \square & \square \\ \square & \square & \square & \square & \square \\ \square & \square & \square & \square & \square \\ \square & \square & \square & \square & \square \\ \square & \square & \square & \square & \square\end{array}$

$\begin{array}{ccccc}\text { Sempre } & \text { Frequentemente } & \text { Às vezes } & \text { Raramente } & \text { Nunca } \\ \square & \square & \square & \square & \square \\ \square & \square & \square & \square & \square \\ \square & \square & \square & \square & \square \\ \square & \square & \square & \square \\ \square & \square & \square & \square & \square \\ \square & \square & \square & \square & \square \\ \square & \square & \square & \square & \square\end{array}$

$\begin{array}{ccccc}\text { Sempre } & \text { Frequentemente } & \text { Às vezes } & \text { Raramente } & \text { Nunca } \\ \square & \square & \square & \square & \square \\ \square & \square & \square & \square & \square \\ \square & \square & \square & \square & \square \\ \square & \square & \square & \square & \square \\ \square & \square & \square & \square & \square \\ \square & \square & \square & \square & \square \\ \square & \square & \square & \square & \square \\ \square & \square & \square & \square & \square\end{array}$

$\begin{array}{ccccc}\text { Sempre } & \text { Frequentemente } & \text { Às vezes } & \text { Raramente } & \text { Nunca } \\ \square & \square & \square & \square & \square \\ \square & \square & \square & \square & \square \\ \square & \square & \square & \square & \square \\ \square & \square & \square & \square & \square \\ \square & \square & \square & \square & \square \\ \square & \square & \square & \square & \square \\ \square & \square & \square & \square & \square \\ \square & \square & \square & \square & \square \\ \square & \square & \square & \square & \square\end{array}$


\begin{tabular}{l|l} 
Anexos & 117
\end{tabular}

62. Eu posso perguntar e questionar em meu trabalho.

63. Minhas tarefas de trabalho dependem de outros colegas.

64. Meu ambiente de trabalho é confortável.

65 . Se eu cometer algum erro nas tarefas de trabalho eu tenho suporte dos meus colegas.

66. Se eu cometer algum erro nas tarefas de trabalho eu tenho suporte dos meus supervisores.

67. Meus colegas são amigáveis.

68. Meus supervisores são amigáveis.

\section{Queixas}

(I) Durante os últimos três meses eu tive dor ou queixas, por pelo menos uma semana, em uma ou mais das seguintes regiões corporais:

69. Pescoço

$\square$ Não $\quad \square \operatorname{Sim}$

70. Ombro(s)

$\square$ Não $\quad \square \operatorname{Sim}$

71. Braço(s)

$\square$ Não

$\square \operatorname{Sim}$

$\rightarrow$ Se sim,

$\square$ Esquerda

$\square$ Direita

$\square$ Ambos

72. Cotovelo(s)

$\square$ Não

$\square \operatorname{Sim}$

$\rightarrow$ Se sim,

$\square$ Esquerda

$\square$ Direita

$\square$ Ambos

73. Antebraço(s)

$\square$ Não

$\square \mathrm{Sim}$

-> Se sim,

$\square$ Esquerda

$\square$ Direita

$\square$ Ambos

74. Punho(s)

$\square$ Não

$\square \mathrm{Sim}$

$\square$ Esquerda

$\square$ Direita

$\square$ Ambos

75. Mão(s)

$\square$ Não

$\square \mathrm{Sim}$

$\rightarrow$ Se sim,

$\square$ Esquerda

$\square$ Direita

$\square$ Ambos

(II) Qual dessas dores/queixas é a pior que você sente?

Classifique esta dor: Nenhuma dor

$\rightarrow$ Se sim,

$\square$ Esquerda

$\square$ Ambos

(III) Você sente alguma delas por mais de três meses?

$\square$ Não $\square$ Sim -> Se sim, cite qual é esta dor.

(IV)

A partir daqui extremidade superior será usada para representar pescoço, ombro, mão, punho, braço, antebraço e cotovelo.

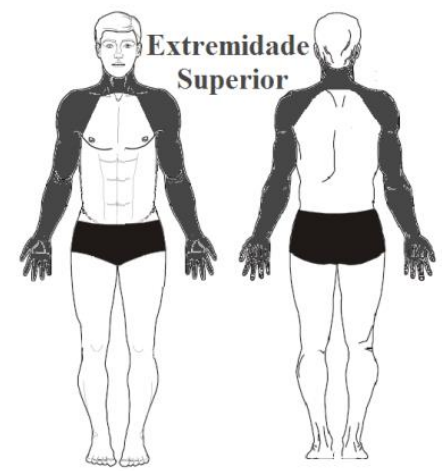

\section{A pior dor possível}

10

76. Durante os últimos três meses eu tive dor/queixa/incapacidade em minha extremidade superior

$\square$ Não $\quad \square \operatorname{Sim}$

77. O período mais longo de queixa (os últimos três meses) em que eu não pude desenvolver minhas atividades diárias foi: $\square$ Nenhum dia 口 $\operatorname{Dia}(\mathrm{s})$ Semana(s)

78. Durante os últimos três meses eu consultei um médico por causa da dor em minha extremidade superior.
$\square$ Não
$\square \operatorname{Sim}$
-> Se sim, qual foi o diagnóstico médico?

79. Que tipo de tratamento você recebeu (os últimos três meses)?
$\square$ Nenhum
$\square$ Fisioterapia
$\square$ Medicação
$\square$ Cirurgia
$\square$ Outro

80. Por causa da dor em minha extremidade superior eu já perdi algum emprego. 

$\square$ Não
$\square \operatorname{Sim}$

81. Por causa da queixa em minha extremidade superior (nos últimos três meses) eu faltei no trabalho.

$\square$ Não $\quad \square$ Sim

82. Durante os últimos três meses, as minhas atividades foram prejudicadas por causa das minhas queixas na extremidade superior.
$\square$ Não
$\square \operatorname{Sim}$
$\square$ Em meu trabalho
$\square$ Em meu tempo de lazer

83. Minhas queixas são devido a um acidente prévio.

$\square$ Não

$\square \operatorname{Sim}$

(V) As próximas questões estão relacionadas às queixas de dor na extremidade superior nos últimos três meses.

84. Eu sinto dor em meu membro superior logo que termino o trabalho.
$\square$ Não
$\square \operatorname{Sim}$
-> Esta dor desaparece após um curto período de descanso?
$\square$ Não $\quad \square \operatorname{Sim}$

85. Eu sinto fadiga e exaustão em minha extremidade superior.

$\square$ Não $\quad \square$ Sim $\quad$-> Esta queixa desaparece após um curto período de descanso? $\quad \square$ Não $\quad \square$ Sim

86. Eu sinto rigidez em meus dedos.

$\square$ Não $\quad \square \operatorname{Sim} \quad->$ Esta rigidez desaparece após um curto período de descanso? $\quad \square$ Não $\quad \square$ Sim

87. Eu sinto dormência em meus dedos.

$\square$ Não $\quad \square \operatorname{Sim} \quad->$ Esta dormência desaparece após um curto período de descanso? $\quad \square$ Não $\quad \square$ Sim

88. Eu sinto formigamento em meus dedos.
$\square$ Não
$\square \operatorname{Sim}$
-> Este formigamento continua após o trabalho?
$\square$ Não $\quad \square \operatorname{Sim}$

89. Eu sinto fraqueza em minha extremidade superior.

$\square$ Não $\quad \square \operatorname{Sim}$

90. Minhas mãos incham

$\square$ Não $\quad \square \operatorname{Sim} \quad->$ Este inchaço continua após o trabalho? $\quad \square$ Não $\quad \square$ Sim

91. Eu sinto inchaço/rigidez em minha extremidade superior.

$\square$ Não $\quad \square$ Sim

92. Eu sinto uma dor contínua em minha extremidade superior.
$\square$ Não
$\square \operatorname{Sim}$

93. Eu percebo mudança de cor, temperatura e transpiração em minha extremidade superior.

$\square$ Não

$\square \operatorname{Sim}$

94. Dentre os seguintes itens, quais você utiliza para reduzir sua dor relacionada ao trabalho?
$\square$ Nenhum
$\square$ Munhequeira
$\square$ Cinta
$\square$ Colar Cervical
$\square$ Outro

95. Dentre os seguintes itens, quais você utiliza para reduzir sua dor relacionada ao trabalho?
$\square$ Nenhum
$\square$ Suporte para mouse
$\square$ Apoio para pés
$\square$ Suporte para textos
$\square$ Outro 


\title{
ANEXO 3 - Índice de Incapacidade Relacionada à Dor no Pescoço - IIRP (Neck Disability Index)
}

\author{
Índice de Incapacidade relacionado ao Pescoço (IIRP)
}

Este questionário foi criado para dar informações ao seu doutor sobre como a sua dor no pescoço tem afetado a sua habilidade para fazer atividades diárias. Por favor,

responda a cada uma das perguntas e marque em cada seção apenas uma alternativa que melhor se aplique a você.

\section{Seção 1 - Intensidade da dor}

$\square$ Eu não tenho dor nesse momento.

$\square$ A dor é muito leve nesse momento.

$\square \quad$ A dor é moderada nesse momento.

$\square$ A dor é razoavelmente grande nesse momento.

$\square \quad$ A dor é muito grande nesse momento.

$\square$ A dor é a pior que se possa imaginar nesse momento.

\section{Seção 2 - Cuidado pessoal (se lavar, se vestir, etc)}

$\square$ Eu posso cuidar de mim mesmo(a) sem aumentar a dor.

$\square$ Eu posso cuidar de mim mesmo(a) normalmente, mas isso faz aumentar a dor.

$\square$ É doloroso ter que cuidar de mim mesmo e eu faço isso lentamente e com cuidado.

$\square$ Eu preciso de ajuda, mas consigo fazer a maior parte do meu cuidado pessoal.

$\square$ Eu preciso de ajuda na maioria dos aspectos relacionados a cuidar de mim mesmo(a)

$\square \quad$ Eu não me visto, me lavo com dificuldade e fico na cama.

\section{Seção 3 - Levantar coisas}

$\square \quad$ Eu posso levantar objetos pesados sem aumentar a dor.

$\square$ Eu posso levantar objetos pesados, mas isso faz aumentar a dor.

$\square$ A dor me impede de levantar objetos pesados do chão, mas eu consigo se eles estiverem colocados em uma boa posição, por exemplo, em uma mesa.

$\square \quad$ A dor me impede de levantar objetos pesados, mas eu consigo levantar objetos com peso entre leve e médio se eles estiverem colocados em uma boa posição.

\section{Seção 6 - Prestar Atenção}

Eu consigo prestar atenção quando eu quero sem dificuldade.

$\square \quad$ Eu consigo prestar atenção quando eu quero com uma dificuldade leve.

$\square \quad$ Eu tenho uma dificuldade moderada em prestar atenção quando eu quero.

$\square \quad$ Eu tenho muita dificuldade em prestar atenção quando eu quero.

$\square \quad$ Eu tenho muitíssima dificuldade em prestar atenção quando eu quero.

$\square$ Eu não consigo prestar atenção.

\section{Seção 7 - Trabalho}

$\square \quad$ Eu posso trabalhar tanto quanto eu quiser.

$\square \quad$ Eu só consigo fazer o trabalho que estou acostumado(a) a fazer, mas nada além disso.

$\square \quad$ Eu consigo fazer a maior parte do trabalho que estou acostumado(a) a fazer, mas nada além disso.

$\square \quad$ Eu não consigo fazer o trabalho que estou acostumado(a) a fazer.

$\square \quad$ Eu mal consigo fazer qualquer tipo de trabalho.

$\square \quad$ Eu não consigo fazer nenhum tipo de trabalho.

\section{Seção 8 - Dirigir automóveis}

$\square \quad$ Eu posso dirigir meu carro sem nenhuma dor no pescoço.

$\square \quad$ Eu posso dirigir meu carro tanto quanto eu queira com uma dor leve no meu pescoço.

$\square \quad$ Eu posso dirigir meu carro tanto quanto eu queira com uma dor moderada no meu

pescoço.

$\square \quad$ Eu não posso dirigir o meu carro tanto quanto eu queira por causa de uma dor moderada no meu pescoço. 
$\square \quad$ Eu posso levantar objetos muito leves.

$\square$ Eu não posso levantar nem carregar absolutamente nada.

\section{Seção 4 - Leitura}

$\square$ Eu posso ler tanto quanto eu queira sem dor no meu pescoço

$\square \quad$ Eu posso ler tanto quanto eu queira com uma dor leve no meu pescoço.

$\square$ Eu posso ler tanto quanto eu queira com uma dor moderada no meu pescoço.

$\square$ Eu não posso ler tanto quanto eu queira por causa de uma dor moderada no meu pescoço.

$\square$ Eu mal posso ler por causa de uma grande dor no meu pescoço.

$\square$ Eu não posso ler nada

$\square$ Pergunta não se aplica por não saber ou não poder ler.

\section{Seção 5- Dores de cabeça}

$\square$ Eu não tenho nenhuma dor de cabeça.

$\square$ Eu tenho pequenas dores de cabeça com pouca freqüência.

$\square$ Eu tenho dores de cabeça moderadas com pouca freqüência.

$\square$ Eu tenho dores de cabeça moderadas muito freqüentemente.

$\square \quad$ Eu tenho dores de cabeça fortes freqüentemente.

$\square$ Eu tenho dores de cabeça quase o tempo inteiro.

\section{CLASSIFICAÇÃO:} pontos

$\square$ 10-28\% (5-14 pontos) - incapacidade leve

$\square 30-48 \%$ (15- 24 pontos) - incapacidade moderada

$\square 50-68 \%$ ( 25 - 35 pontos) - incapacidade severa

$\square 72 \%$ ou mais (36 pontos ou mais) - incapacidade completa $\square \quad$ Eu mal posso dirigir por causa de uma dor forte no meu pescoço.

$\square \quad$ Eu não posso dirigir meu carro de maneira nenhuma.

$\square$ Pergunta não se aplica por não saber dirigir ou não dirigir muitas vezes.

\section{Seção 9 - Dormir}

$\square \quad$ Eu não tenho problemas para dormir

Meu sono é um pouco perturbado (menos de uma hora sem conseguir dormir).

$\square \quad$ Meu sono é levemente perturbado (1-2 horas sem conseguir dormir).

$\square$ Meu sono é moderadamente perturbado (2-3 horas sem conseguir dormir).

$\square$ Meu sono é muito perturbado (3-5 horas sem conseguir dormir).

$\square$ Meu sono é completamente perturbado (1-2 horas sem sono)

\section{Seção 10 - Diversão}

$\square$ Eu consigo fazer todas as minhas atividades de diversão sem nenhuma dor no pescoço.

$\square$ Eu consigo fazer todas as minhas atividades de diversão com alguma dor no pescoço.

$\square$ Eu consigo fazer a maioria, das minhas atividades de diversão por causa da dor no meu pescoço.

$\square \quad$ Eu consigo fazer poucas das minhas atividades de diversão por causa da dor no meu pescoço.

$\square$ Eu mal consigo fazer qualquer atividade de diversão por causa da dor no meu pescoço

$\square$ Eu não consigo fazer nenhuma atividade de diversão. 


\title{
APÊNDICE 1 - Termo de Consentimento Livre e Esclarecido
}

\author{
TERMO DE CONSENTIMENTO LIVRE ESCLARECIDO PARA OS PARTICIPANTES DE PESQUISA
}

Pesquisadores responsáveis: Profa. Dra. Thaís Cristina Chaves (chavestc@fmrp.usp.br) Fone: (016)

36024694 e_Marcela Mendes Bragatto (marcelabragatto@hotmail.com) Fone: (016) 81170115

“DOR CERVICAL CRÔNICA E POSTURA EM TRABALHADORES DE ESCRITÓRIO USUÁRIOS DE

\section{COMPUTADOR"}

Esclarecimento geral: Você está convidado (a) a participar de uma pesquisa que busca identificar a associação entre dores no pescoço, na face e alterações da postura do corpo em trabalhadores de escritório usuários de computador, por isso gostaríamos de contar com a sua colaboração. É possível que trabalhadores usuários de computador desenvolvam dor no pescoço e associada a esta, dores na face e alterações da postura.

Procedimento - Caso você aceite participar, serão feitos registros fotográficos de corpo inteiro na postura em pé e em trajes de banho. Você também responderá a um questionário de perguntas relacionadas à dor no pescoço e será avaliada à dor no pescoço e regiões da face através de um aparelho chamado algômetro. O equipamento será utilizado por um profissional habilitado que aplicará pressão sobre sua pele nas áreas mencionadas. Você terá em mãos um equipamento que finalizará o teste (botão on/off), assim que o você começar a sentir dor ao invés da pressão. Você não deverá sentir dor e por isso será convidado a apertar o botão no momento exato em que começar a sentir dor. Todas as avaliações serão realizadas no Laboratório de Pesquisa Interdisciplinar na Disfunção Musculoesquelética (LAPIDIM) localizado no prédio da Fisioterapia e Terapia Ocupacional dentro do campus da USP de Ribeirão Preto. A avaliação durará em torno de sessenta minutos e você poderá participar do projeto em horários alternativos fora do horário de expediente de trabalho.

Benefícios e Risco - Apesar do desconforto de ser fotografado em trajes de banho, fato este necessário para realização das análises posturais, garantiremos que a identidade você será mantida em sigilo. Sua identificação pessoal não ficará relacionada à sua imagem e apenas um examinador do estudo terá acesso às imagens de sua face, após a obtenção das fotos seu rosto será encoberto para realização das demais etapas do estudo. Caso você aceite participar, é importante destacar que não existem benefícios diretamente destinados a você durante a participação nesta pesquisa. No entanto, os dados obtidos nessa pesquisa auxiliarão no entendimento das associações entre alterações da postura, dores cervical e na face e a sobrecarga causada no corpo devido ao trabalho relacionado à postura sentada e na posição para o uso do computador. Assim, estratégias de prevenção podem ser adotadas caso os resultados desse estudo demonstrem essa associação.

Você poderá sentir desconforto durante o exame de avaliação da dor por pressão, porém, nada que possa gerar risco a sua saúde. É importante que você entenda que não existe nenhum tipo de seguro de saúde ou de vida que possa trazer benefícios em função da sua participação neste estudo.

Liberdade de Participação - A sua participação neste estudo depende plenamente da sua vontade e autorização, estando livre para desistir em qualquer momento. Além disso, você não terá nenhum gasto financeiro adicional devido à participação nesse projeto.

Sigilo de Identidade - Caso aceite participar, é importante que fique claro que as informações obtidas nesta pesquisa não serão de maneira alguma associadas à sua identidade e não poderão ser consultadas por outras pessoas além das pesquisadoras desse estudo e nem utilizadas para outros fins que o da presente pesquisa sem a sua autorização oficial. Estas informações poderão ser utilizadas para fins científicos, ficando resguardados a sua privacidade e anonimato. Além disso, os registros fotográficos serão visualizados apenas por um examinador envolvido no projeto e os responsáveis pela pesquisa e as imagens registradas serão devidamente arquivadas no computador do laboratório e protegidas através de senha, com o acesso restrito somente aos pesquisadores.

O Sr(a) tem todo direito de procurar o pesquisador responsável para solucionar dúvidas e obter informações, antes, durante ou mesmo após o curso da pesquisa. Eventuais dúvidas sobre os aspectos éticos relacionados a essa pesquisa podem ser esclarecidas junto ao Comitê de Ética em Pesquisa do Hospital das Clínicas da Faculdade de Medicina de Ribeirão Preto (F: 36022228). 
Apêndices 122

\begin{tabular}{|l|}
\hline Assinatura do voluntário: \\
\hline Nome do voluntário: \\
\hline RG: \\
\hline Data de nascimento: \\
\hline Data da coleta de dados: \\
\hline
\end{tabular}

Assinatura do pesquisador responsável: Nome do pesquisador:

RG:

Data da coleta:

Ribeirão Preto, de de 20 


\section{APÊNDICE 2 - Ficha Avaliação}

\section{FICHA AVALIACCÃO}

Nome:

Data de nascimento: idade: anos Altura: Peso:

Telefone: E-mail:

Data avaliação

Toma medicamento para dor? Qual?

Ultima vez que tomou medicamento para dor?

Patologia?

Outros medicamentos?

\section{Período Menstrual}

Faz uso de anticoncepcionais? quanto tempo?

Qual nome do medicamento?

Quando será a sua próxima menstruação?

\section{Questionário Geral}

Você tem história de trauma no pescoço ou na face? ( ) Sim ( ) Não Onde?

Há quanto tempo?

Você costuma ter dor no pescoço? ( ) Sim ( ) Não

No último mês você teve essa dor? ( ) Sim ( ) Não

Se você teve dor no pescoço, responda: com que freqüência?

( ) todos os dias do mês

( ) mais de 15 dias por mês

( ) entre 1 a 7 dias por mês

( ) entre 8 e 15 dias por mês

( ) menos de 4 crises no ano

Há quanto tempo você tem dor no pescoço?

( ) menos de 3 meses ( ) menos de 2 anos ( ) 2 a 5 anos ( ) 6 a 10 anos ( ) mais de 10 anos 


\section{Questionário DTM}

1. Você costuma ter dor na face, nos maxilares, têmporas, na frente do ouvido, nos músculos da mastigação? ( ) Sim ( ) Não

\section{Se o paciente respondeu NÃO pular para item 9}

2. No último mês você teve alguma dessas dores? ( ) Sim

( ) Não

3. Se você teve dor na face/músculos da mastigação, responda: com que freqüência?

( ) todos os dias do mês

( ) mais de 15 dias por mês

( ) entre 1 a 7 dias por mês

( ) entre 8 e 15 dias por mês

( ) entre 4 e 11 crises por ano

( ) menos de 4 crises no ano

4. Há quanto tempo você tem dor na face/músculos mastigatórios?

( ) menos de 3 meses ( ) menos de 2 anos ( ) 2 a 5 anos ( ) 6 a 10 anos ( ) mais de 10 anos

5. Descreva sua dor na face/músculos mastigatórios:

( ) latejante, pulsátil

( ) em pontadas agulhadas

( ) em queimação, ardente

( ) como um peso por cima da cabeça

( ) como um choque

( ) em pressão

6. Qual horário do dia em que aparece a sua dor?

( ) logo pela manhã ( ) final do dia ( ) o dia todo ( )depois das refeições

( ) à noite

7. Você está sentindo essa dor na face/músculos mastigatórios agora?

Nenhuma dor

A pior dor possível

\begin{tabular}{lllllllllll|}
\hline & 1 & 2 & 3 & 4 & 5 & 6 & 7 & 8 & 9 & 10
\end{tabular}


8. Localize os locais onde você sente dor na FACE:
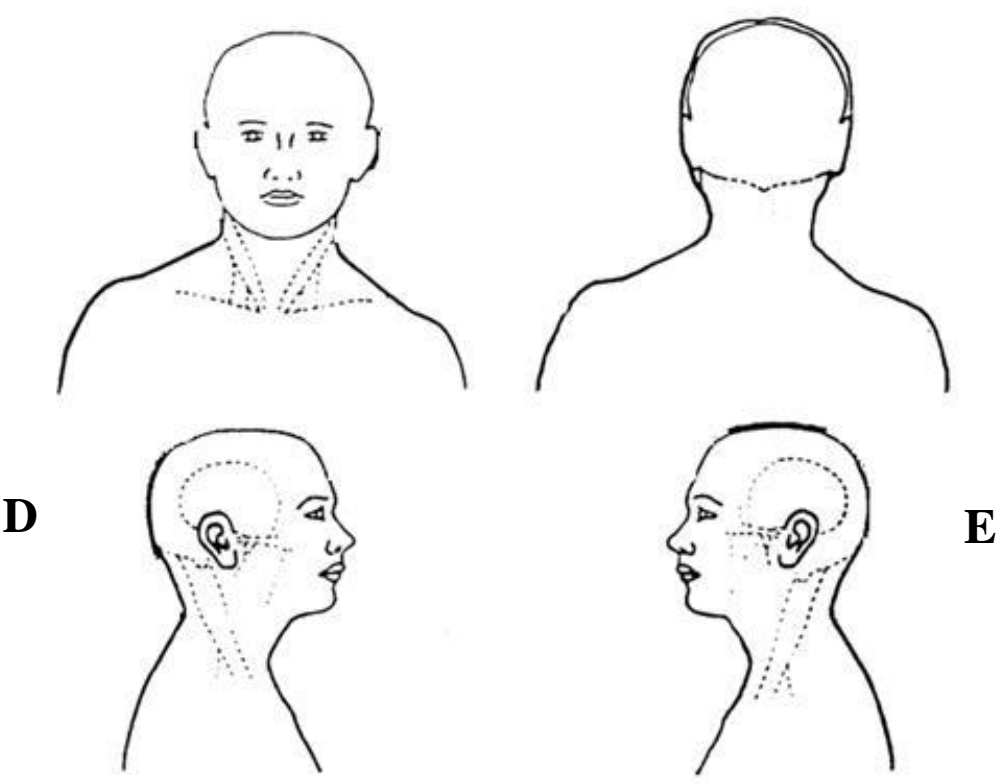

9. Você alguma vez teve travamento articular de forma que não foi possível abrir a boca totalmente?

$$
\text { ( ) } \operatorname{sim}(\text { ) Não }
$$

10.Se SIM: Esta limitação de abertura mandibular foi severa a ponto de interferir com a mastigação?

( ) Sim ( ) Não

11.Você já apresentou (alguma vez na vida) ou apresenta inchaço ou dor em qualquer das articulações que não sejam as articulações perto de seus ouvidos (ATMs)? （） Sim ( ) Não

12.Você tem algum desses sintomas?

Estalo

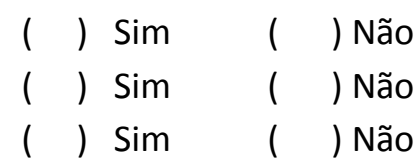

Ranger de dentes/bruxismo

Apertamento dental

Com que freqüência?

( ) todos os dias do mês

( ) entre 8 e 15 dias por mês

( ) entre 1 a 7 dias por mês

( ) mais de 15 dias por mês

Há quanto tempo?

( ) menos de 3 meses ( ) menos de 2 anos ( ) 2 a 5 anos ( ) 6 a 10 anos ( ) mais de 10 anos

Mordida desconfortável

( ) Sim

( ) Não

Rigidez matinal

( ) $\operatorname{sim}($ ) Não

Barulho no ouvido

( ) $\operatorname{Sim}($ ) Não 


\section{Formulário de exame (RDC/TMD):}

1. Você tem dor no lado direito da sua face, lado esquerdo ou ambos os lados?

Em nenhum dos lados $0 \quad$ No lado direito $1 \quad$ No lado esquerdo $2 \quad$ Em ambos os $\operatorname{lados} 3$

2. Você poderia apontar as áreas onde você sente dor?

Direito

Articulação

Músculos

Ambos

3
Esquerdo

Articulação

1

Músculos 2

Ambos

3

3. Padrão de abertura

Sem desvio

0

Desvio lateral direito (não corrigido) 1

Desvio lateral direito corrigido (“S”) 2

Desvio lateral esquerdo (não corrigido) 3

Desvio lateral esquerdo corrigido ("S") 4

Outro

Tipo:

(especifique)

4. Amplitude de movimento de abertura da boca

Você tem dor durante abertura da boca?

( ) Sim ( ) Não

a. Abertura ativa sem dor: $\mathrm{mm} /$ $\mathrm{mm}$ 
b. Abertura máxima passiva: $\mathrm{mm} /$ $\mathrm{mm}$

c. Abertura máxima ativa: $\mathrm{mm} /$ $\mathrm{mm}$

d.Overbite: $\mathrm{mm} /$ Overjet: $\mathrm{mm}$

Para os itens "b" e "c" somente

\begin{tabular}{lcccccccc}
\hline \multicolumn{1}{c}{ Dor Muscular } \\
\hline Itens & nenhuma & direito & esquerdo & ambos & nenhuma & direito & esquerdo & ambos \\
B & 0 & 1 & 2 & 3 & 0 & 1 & 2 & 3 \\
C & 0 & 1 & 2 & 3 & 0 & 1 & 2 & 3 \\
\hline
\end{tabular}

5. Ruídos articulares:

\begin{tabular}{lcccc}
\hline & \multicolumn{2}{c}{ Abertura } & \multicolumn{2}{c}{ Fechamento } \\
\hline & Direito & Esquerdo & Direito & Esquerdo \\
Nenhum & 0 & 0 & 0 & 0 \\
Estalido & 1 & 1 & 1 & 1 \\
Crepitação Grosseira & 2 & 2 & 2 & 2 \\
Crepitação fina & 3 & 3 & 3 & 3 \\
\hline
\end{tabular}

Medida do estalido na abertura

$\_$m

Medida do estalido no fechamento $\mathrm{mm} /$ mm

Estalido recíproco eliminado durante abertura protrusiva (NA: não apresenta)
( ) Sim ( ) Não
( ) Direito ( ) Esquerdo

6. Excursões 
Você tem dor durante os desvios laterais?

a. Desvio lateral direito

$\mathrm{mm} /$ $\mathrm{mm}$

b. Desvio lateral esquerdo $\mathrm{mm} /$ $\mathrm{mm}$

c. Protrusão $\mathrm{mm} /$ $\mathrm{mm}$

\begin{tabular}{lcccccccc}
\hline \multicolumn{1}{c}{ Dor Muscular } \\
\hline Itens & nenhuma & direito & esquerdo & ambos & nenhuma & Direito & esquerdo & ambos \\
A & 0 & 1 & 2 & 3 & 0 & 1 & 2 & 3 \\
B & 0 & 1 & 2 & 3 & 0 & 1 & 2 & 3 \\
C & 0 & 1 & 2 & 3 & 0 & 1 & 2 & 3 \\
\hline
\end{tabular}

Desvio da linha média em repouso: - mm direito esquerdo

7. Ruídos articulares

\begin{tabular}{lcccc}
\hline Ruídos do lado direito & Nenhum & Estalido & $\begin{array}{c}\text { Crepitação } \\
\text { grosseira }\end{array}$ & $\begin{array}{c}\text { Crepitação } \\
\text { leve }\end{array}$ \\
\hline Excursão direita & 0 & 1 & 2 & 3 \\
Excursão esquerda & 0 & 1 & 2 & 3 \\
Protrusão & 0 & 1 & 2 & 3 \\
\hline
\end{tabular}

\begin{tabular}{lcccc}
\hline Ruídos do lado esquerdo & Nenhum & Estalido & $\begin{array}{c}\text { Crepitação } \\
\text { grosseira }\end{array}$ & $\begin{array}{c}\text { Crepitação } \\
\text { leve }\end{array}$ \\
\hline Excursão direita & 0 & 1 & 2 & 3 \\
Excursão esquerda & 0 & 1 & 2 & 3
\end{tabular}




\section{Palpação Muscular}

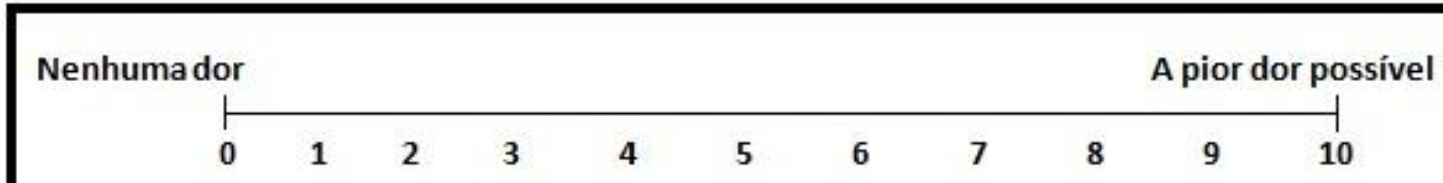

\begin{tabular}{|c|c|c|c|c|c|c|}
\hline \multirow[t]{2}{*}{ Músculos/áreas } & \multirow[t]{2}{*}{ Direito } & \multirow[t]{2}{*}{ Esquerdo } & \multicolumn{2}{|c|}{$\begin{array}{c}\text { Provoca dor } \\
\text { na face }\end{array}$} & \multicolumn{2}{|c|}{$\begin{array}{l}\text { Presença de } \\
\text { trigger point }\end{array}$} \\
\hline & & & $\mathbf{D}$ & $\mathbf{E}$ & $\mathbf{D}$ & $\mathbf{E}$ \\
\hline Temporal anterior & & & & & & \\
\hline Temporal médio & & & & & & \\
\hline Temporal posterior & & & & & & \\
\hline Masseter origem & & & & & & \\
\hline Masseter ventre & & & & & & \\
\hline Masseter inserção & & & & & & \\
\hline Região submandibul & & & & & & \\
\hline $\begin{array}{l}\text { Região posterior da } \\
\text { mandíbula }\end{array}$ & & & & & & \\
\hline ECM (inserção) & & & & & & \\
\hline Trapézio - ponto mé & & & & & & \\
\hline Suboccipitais & & & & & & \\
\hline Pterigóideo lateral & & & & & & \\
\hline Tendão do temporal & & & & & & \\
\hline ATM pólo posterior & & & & & & \\
\hline
\end{tabular}




\begin{tabular}{|l|l|l|l|l|l|l|}
\hline ATM pólo lateral & & & & & & \\
\hline
\end{tabular}

(*DOR FAMILIAR)

Algometria

\begin{tabular}{|l|l|l|l|l|}
\hline \multicolumn{1}{|c|}{ Músculos } & \multicolumn{2}{c|}{ Direito } & \multicolumn{2}{c|}{ Esquerdo } \\
\hline & 1 & 2 & 1 & 2 \\
\hline Hipotenar & & & & \\
\hline Frontal & & & & \\
\hline Temporal anterior & & & & \\
\hline Temporal médio & & & & \\
\hline Temporal posterior & & & & \\
\hline Masseter origem & & & & \\
\hline Masseter ventre & & & & \\
\hline Masseter inserção & & & & \\
\hline ECM - inserção & & & & \\
\hline Trapézio Médio & & & & \\
\hline Suboccipitais & & & & \\
\hline
\end{tabular}

